\title{
A COMPARATIVE STUDY OF THE EFFECTS OF PROCESSING INSTRUCTION AND OUTPUT-BASED INSTRUCTION ON THE ACQUISITION OF ITALIAN FUTURE TENSE
}

\section{ALESSANDRO GIOVANNI BENATI}

A thesis submitted in partial fulfilment of the requirements of the University of Greenwich for the Degree of Doctor of Philosophy 


\begin{abstract}
The present study was carried out to investigate the possible effects of two types of form-focused instruction (henceforth FFI) on the acquisition of a specific feature of the Italian verbal morphology system: namely the future tense, which has hitherto never been researched within this framework. Processing instruction was compared to a more traditional type of grammar instruction output-based. The impact of these two types of FFI was investigated on a well documented strategy (Musumeci 1989) used by second language (henceforth L2) learners when interpreting tenses. This strategy consists in giving precedence to lexical items (in this case temporal adverbs, i.e. oggi, domani) over morphological markers during learner's interpretation of tenses.
\end{abstract}

In order to carry out this investigation, first year students (39 subjects) in their second semester, learning Italian at the University of Greenwich were randomly assigned to three groups. One group received processing instruction, which involved grammar explanation and comprehension practice directed at altering the way second language learners process input and make correct meaning-form connections; the other group received output-based type of instruction which consisted in an explanation of grammar rules followed by written and oral practice (part of which was meaning-oriented) which was directed at altering the way L2 learners produce the target language; the third group was used as a control group and received no instruction. The groups were exposed to two consecutive days of instructional treatment and pre-tests and post-tests were carried out. The tests consisted of an aural interpretation task, a written completion text and an oral limited response production task. A delayed post-test was also administered to assess the possible effects of instruction after three weeks. Based on previous research carried out in a feature of Spanish (Cadierno 1993) verbal morphology, it was hypothesised that processing instruction would have positive effects on the accuracy with which subjects interpreted sentences in Italian (future tense vs present tense) in which temporal reference is only expressed by verb morphology. It was also hypothesized that the effects of processing instruction would be visible on the production of both the written and the oral task. A further hypothesis was that the effects of instruction would hold over a post-test session three weeks later. Overall the statistical analyses carried out on the data supported the three hypotheses of this study. The results obtained in this research provide some evidence that processing instruction has positive effects on the acquisition of Italian verbal morphology, these effects being greater on the developing system of beginners L2 learners, than output-based instruction. However the output-based group performed better than the control group in the interpretation task. This is an interesting finding as it was not hypothesised, but is likely to have significant implications for further research within this framework.

The present study also showed that processing instruction was successful in altering the way in which learners processed the input and its effects had also an impact on the way learners produced future tense at sentence level in both a written and an oral production task. Finally, these effects were proved durable over a three week period. The results obtained in the present study have implications at two levels. At the theoretical level this study provides further support for the role that input processing plays in SLA. At the pedagogical level it demonstrates the effectiveness of processing instruction not only on an interpretation task but also on a written and oral production task. This is further evidence of the suitability of this pedagogical approach (processing instruction) to encourage linguistic competence among L2 learners. 
To Grace and Francesco 


\section{Acknowledgements}

This study has been made possible by The University of Greenwich which funded my research. Therefore I express my gratitude to the Buisness School \& the School of Humanities.

I would like to thank my supervisors at the University of Greenwich: Dr. Paul Taylor and Professor Fiorella Liverani Bertinelli at the University of Perugia, for their valuable and attentive supervision.

A special thanks to Professor Nina Spada at the University of McGill, Montreal, Professor Bill Van Patten at the University of Illinois, Professor Rennols and Swatee Patel at the University of Greenwich for their priceless assistance.

I also would like to thank all the students on the Italian courses at the University of Greenwich and Queen Mary for their forbearance and assistance during the data collection and the course arrangements.

Last, but not least I thank all my family for all their patience during the time I carried out my work. 


\section{CONTENTS}

\section{INTRODUCTION}

page

Background to the research 1

Aims of the present study 3

Corpus of the research 4

CHAPTER ONE: THE ROLE OF FORMAL INSTRUCTION IN SLA:

THE CURRENT THEORETICAL FRAMEWORKS 6

Introduction 6

1.1 The non-interface position 6

1.2 The facilitative position: several versions 12

$\begin{array}{ll}\text { 1.2.1 The interface position } & 12\end{array}$

1.2.2 The variability position 19

1.2.3 The teachability hypothesis $\quad 22$

1.2.4 The selective attention hypothesis $\quad 24$

1.3 Implications for this study 25

\section{CHAPTER TWO:THE CONTRIBUTION OF DIFFERENT TYPES}

OF FORMAL INSTRUCTION TO SLA: AN EVOLUTION IN

$\begin{array}{ll}\text { CL ASSROOM RESEARCH } & 27\end{array}$

$\begin{array}{ll}\text { Introduction } & 27\end{array}$

2.1 Defining FFI in classroom SLA 27

2.2 Review of some studies on the effects of instruction 29

2.3 Review of studies on the effects of particular types of FFI 32

2.3.1 Studies on the effects of an explicit type of instruction and 32 corrective feedback

2.3.2 Studies on different types of input enhancement 36

2.3.3 Studies on the effects of consciousness-raising tasks 38

2.4 Implications for this study $\quad 39$ 
CHAPTER THREE: THE INPUT PROCESSING MODEL 41

Introduction $\quad 41$

3.1 From the bindinglaccess framework to a model of input processing 41

3.2 The input processing theory $\quad 50$

3.3 Evidence for the primacy of lexical items over grammatical markers $\quad 55$ during input processing

$\begin{array}{lr}3.4 \text { Implications for this study } & 58\end{array}$

\section{CHAPTER FOUR:REVIEW OF STUDIES ON THE EFFECTS}

$\begin{array}{ll}\text { OF PROCESSING INSTRUCTION } & 60\end{array}$

$\begin{array}{ll}\text { Introduction } & 60\end{array}$

4.1 Processing instruction: a comprehension type of grammar instruction 60

4.2 Empirical studies on the effects of processing instruction 65

4.3 Summary of results from previous research and contribution to 75 the present study

4.4 Research questions and hypotheses of this study 76

CHAPTER FIVE - RESEARCH DESIGN AND METHODOLOGY 78

$\begin{array}{ll}\text { Introduction } & 78\end{array}$

$\begin{array}{ll}5.1 \text { The plan } & 78\end{array}$

5.2 The target linguistic feature $\quad 80$

5.3 The groups \& The programme : subjects \& comparability $\quad 81$

$\begin{array}{ll}5.4 \text { Teaching procedures \& Materials } & 84\end{array}$

5.4.1 Input-based treatment with pedagogical rules $\quad 85$

$\begin{array}{ll}\text { 5.4.2 Output-based treatment } & 89\end{array}$

5.5 Tests \& Scoring procedures 95

5.5.1 Interpretation task 95

5.5.2 Written completion task 96

$\begin{array}{ll}\text { 5.5.3 Oral limited response task } & 97\end{array}$ 
$\begin{array}{lr}5.6 \text { Pilot studies } & 98\end{array}$

5.6.1 Pilot study $1 \quad 98$

$\begin{array}{ll}5.6 .2 \text { Pilot study } 2 & 101\end{array}$

$\begin{array}{ll}\text { 5.6.3 Pilot study } 3 & 103\end{array}$

5.7 Instructional \& data collection procedures $\quad 105$

5.8 Statistical analysis:quantitative and qualitative level 106

CHAPTER SIX - RESULTS 107

$\begin{array}{ll}\text { Introduction } & 107\end{array}$

$\begin{array}{ll}6.1 \text { Interpretation data } & 107\end{array}$

$\begin{array}{ll}\text { 6.2 Production data(written and oral) } & 115\end{array}$

$\begin{array}{ll}\text { 6.2.1 Written data } & 115\end{array}$

6.2.2 Oral data 122

$\begin{array}{ll}\text { 6.2.3 Qualitative analysis for the production data } & 128\end{array}$

6.3 Summary of results 130

CHAPTER SEVEN: DISCUSSION-LIMITATIONS AND

IMPLICATIONS 134

$\begin{array}{ll}\text { Introduction } & 134\end{array}$

7.1 Discussion of the findings 134

$\begin{array}{ll}7.2 \text { Implications for theory } & 139\end{array}$

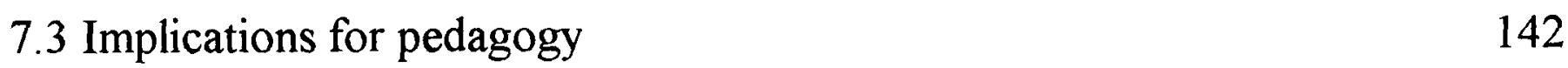

$\begin{array}{ll}7.4 \text { Limitations of the present study } & 144\end{array}$

$\begin{array}{ll}\text { 7.5 Suggestions for future research } & 145\end{array}$

$\begin{array}{lr}\text { REFERENCES } & 147\end{array}$ 
page

\section{APPENDICES}

APPENDIX A: Instructional material for processing instruction $\quad 160$

APPENDIX B: Instructional material for output-based instruction 192

APPENDIX C: Consent form $\quad 212$

$\begin{array}{ll}\text { APPENDIX D: Questionnaire } & 213\end{array}$

$\begin{array}{ll}\text { APPENDIX E: Pre-tests } & 214\end{array}$

$\begin{array}{ll}\text { Interpretation task } & 215\end{array}$

$\begin{array}{ll}\text { Written production task } & 216\end{array}$

$\begin{array}{ll}\text { Oral production task } & 217\end{array}$

$\begin{array}{ll}\text { Interpretation task sentences } & 219\end{array}$

$\begin{array}{ll}\text { APPENDIX F: Post-tests } 1 & 220\end{array}$

$\begin{array}{ll}\text { Interpretation task } & 221\end{array}$

$\begin{array}{ll}\text { Written production task } & 222\end{array}$

$\begin{array}{ll}\text { Oral production task } & 223\end{array}$

$\begin{array}{ll}\text { Interpretation task sentences } & 225\end{array}$

$\begin{array}{ll}\text { APPENDIX G: Post-tests } 2 & 226\end{array}$

$\begin{array}{ll}\text { Interpretation task } & 227\end{array}$

$\begin{array}{ll}\text { Written production task } & 228\end{array}$

$\begin{array}{ll}\text { Oral production task } & 229\end{array}$

$\begin{array}{ll}\text { Interpretation task sentences } & 231\end{array}$

APPENDIX H: List of regular verbs used in the study 232

APPENDIX I : Individual scores of tests 233 


\section{LIST OF FIGURES}

3.1 Van Patten's model of acquisition $\quad 47$

3.2 Gass five stage model $\quad 48$

4.1 Output-based instruction that focuses on ou tput 62

4.2 Processing instruction that focuses on input 63

6.4 Interaction Plot for instruction and time for the Interpretation task $\quad 110$

$\begin{array}{ll}\text { 6.8 Performance in the Interpretation task } & 114\end{array}$

6.12 Interaction Plot for instruction and time for the Written task 117

$\begin{array}{ll}\text { 6.16 Performance in the Written task } & 121\end{array}$

6.20 Interaction Plot for instruction and time for the Oral task 124

$\begin{array}{ll}6.24 \text { Performance in the Oral task } & 127\end{array}$

\section{LIST OF TABLES}

4.3 Studies investigating the effects of processing instruction on SLA 74

$\begin{array}{ll}5.1 \text { Overview of the experiment } & 79\end{array}$

5.2 Sample of activities for the processing instruction group $\quad 87-88$

5.3 Number and types of activities for the processing instruction group $\quad 88$

5.4 Paradigmatic presentation of future tense 90

5.5 Non-paradigmatic presentation of future tense 91

5.6 Sample of activities for output-based type of instruction group 92-93

5.7 Number and types of activities for the output-based group 94

5.8 Main differences between processing instruction and the output-based 94 type of instruction

6.1 One-way Anova summary table for Interpretation task (pre-test) 108

6.2 Means and Standard Deviations for the Interpretation task (pre-test) 108

6.3 Two-way Anova (Repeated Measures) summary table for Interpretation task (pre-test,post-test 1,post-test 2) 
6.6 Two-way Anova (Repeated Measures) summary table for Interpretation task (post-test 1,post-test 2)

6.7 Means and Standard Deviations for the Interpretation task

6.9 One-way Anova summary table for Written task (pre-test)

6.10 Means and Standard Deviations for the Written task (pre-test)

6.11 Two-way Anova (Repeated Measures) summary table for Written task(pre-test,post-test 1,post-test 2)

6.13 Summary table for Post-hoc analysis on the written task (post-test 1)

6.14 Two-way Anova (Repeated Measures) summary table for Written task(post-test 1,post-test 2)

6.15 Means and Standard Deviations for the Written task

6.17 One-way Anova summary table for Oral task (pre-test)

6.18 Means and Standard Deviations for the Oral task (pre-test)

6.19 Two-way Anova (Repeated Measures) summary table for Oral task(pre-test,post-test 1,post-test 2)

6.21 Summary table for Post-hoc analysis on the oral task (post-test1)

6.22 Two-way Anova (Repeated Measures) summary table for Oral task (post-test 1,post-test 2)

6.23 Means and Standard Deviations for the Oral task 126

6.25 Two-way Anova (Repeated Measures) summary table for qualitative $\quad 128$ differences in the Written task (post-test 1 )

6.26 Two-way Anova (Repeated Measures) summary table for qualitative differences in the Oral task (post-test 1 ) 


\section{ABBREVIATIONS}

CLT (Communicative Language Teaching)

FFI (Form-focused instruction)

EC (Error Correction)

- ESL (English as a second language)

L2 (Second Language)

L1 (First Language)

MI (Metalinguistic information)

SLA (Second Language Acquisition) 


\section{DEFINITIONS OF MAIN TERMS USED IN THIS STUDY}

Acquisition (SLA) - Acquisition is defined in this study as the process of internalization of rules which comprise the $\mathrm{L} 2$.

Consciousness Raising - This term has been defined by Rutherford \& Sharwood Smith (1988:107) as ' any deliberate attempt to draw the learner's attention specifically to the formal properties of the target language'.

Form-focused instruction (FFI) - This term is used in this thesis to refer to a focus on the formal properties of the L2, within an overall meaning-based approach, provided through either spontaneous or predetermined ways. The term FFI is also adopted in contrast to the distinction used by Long (1991) between 'focus on form' vs 'focus on forms' (see pages $27-28$ in the text).

Formal instruction - This involves any attempts to inductively or deductively focus language learner's attention on specific properties of a $\mathrm{L} 2$

Input - Input is defined as the language to which the L2 learner is exposed and provides the data to extract the rules of the $\mathrm{L} 2$.

Input Enhancement - This term is defined as any external attempts carried out by the instructor to make some features of the input more salient.

Input Processing - Input processing is the set process by which L2 learners acquire the target language. It involves, through the input data, building up mental representations of the target L2 grammar. 
Intake - Intake is the portion of the input that is noticed by the L2 learner and taken into temporary memory.

Processing instruction - Processing instruction is a type of grammar instruction whose main aim is to affect the way in which $\mathrm{L} 2$ learners attend to input data (see also paragraph 4.1 in the text). Sometime the term input-based approach is used to refer to processing instruction. 


\section{INTRODUCTION}

\section{Background to the research}

Classroom research on the effects of formal instruction on SLA has principally focused on one main issue: whether grammar instruction per se makes a positive impact on SLA (Long 1983). The question as to how we should teach grammar and particularly whether there is one type of grammar instruction which is more effective than others has been somewhat neglected. However, in the last ten years we have witnessed an evolution in classroom research investigating the effects of instruction in SLA (Spada 1997). This is partly because more studies have been carried out (Doughty \& Williams 1998) to systematically describe how instruction is operationalised in the classroom and partly because these studies have directly addressed the question as to whether particular types of FFI are more beneficial than others. Within this research framework another relevant question regarding the role of FFI is whether it would be more effective when provided via one modality versus another (i.e. comprehension vs production).

Van Patten has argued that a type of instruction, which he called 'processing instruction', which helps learners to process information via comprehension practice, might be more effective than that which requires learners to produce language too prematurely. This type of explicit grammar instruction was created by Van Patten (1990) and is thought to be more effective as it provides a more direct route for the learner to convert input to intake.

Van Patten and his colleagues at the University of Urbana-Champaign in Illinois, conducted some empirical studies on the effects of processing instruction on the acquisition of various features of the Spanish linguistic system. The general findings of these studies, which will be reviewed in chapter three of the present study, show that learners receiving this type of grammar approach, seem to benefit in their ability to process input (interpretation tasks) as well as being able to access the target feature when performing production tasks. 
At the theoretical level the main reason for carrying out this type of research is that, as mentioned earlier, research designed to investigate the possible contribution of instruction in SLA has mainly addressed the question whether or not instruction 'per se' makes a difference, particularly in affecting the rate, route and ultimate success of language acquisition. However, it is still not clear how instruction would make a difference. There have been several attempts through theoretical views to answer this question as discussed in chapter one for example, the non-interface position (Krashen 1982), the interface position (McLaughlin 1978, Seliger 1979, Sharwood-Smith 1981), the variability position (Bialystok 1982, Tarone 1983) and the teachability hypothesis (Pienemann 1984). However none of these views has been able to account successfully for the results of the empirical research.

One possible avenue of research for explaining how formal instruction affects the language acquisition process has been put forward by Terrell (1991) who indicates that in order to explain the effects of instruction on SLA it is necessary to investigate the relationship that might exist between types of instruction to which learners are exposed and how learners process the linguistic data .

Similarly, Gass (1988) and Van Patten (1991) have advocated an approach that emphasises the explicit role of instruction in altering processes and strategies used by L2 learners in processing input (this will be discussed in chapter three). This is in contrast to the type of instruction used in previous research which tended to view instruction as the explicit explanation of grammar and subsequent practice by asking learners to produce a given structure or form.

The present study considers three levels of empirical and theoretical research in SLA: (a) studies carried out to investigate the role of formal instruction and the effects of different types of FFI on language acquisition and (b) input processing theory which has sought to obtain a better understanding of why and how instruction makes a difference in SLA, and finally (c) empirical studies on the effects of processing instruction. 


\section{Aims of the present study}

Based on the findings of theoretical research on the effect of processing instruction and on theoretical issues on input processing theory this study seeks to broaden the debate around the role and effects of processing instruction. This study extends previous research (Van Patten \& Cadierno 1993 and Sanz 1995 on direct object pronouns, Cadierno 1993 on past tense verb morphology) which suggested that learners' strategy for processing input could be altered through processing instruction that eventually enhances the acquisition of the target grammar feature, by comparing the relative effects of two types of instruction (comprehension-based vs productionbased) on the acquisition of Italian future tense verb morphology. Despite the positive outcomes of the previous studies on the effects of processing instruction on various features of Spanish, it was not known whether processing instruction would have an equal or different effect on another romance language and more specifically on a different linguistic feature of verbal morphology. In addition to this, the effects of processing instruction on students' developing system, in the case of the verbal morphology study (Cadierno 1993), were measured on only one production written task. In the light of the findings of previous studies and with the intention of adding some value to this particular field, the specific aim of the present study is threefold:

1. to find some empirical evidence to support the hypothesis that processing instruction has a positive effect on the acquisition of linguistic features of verbal morphology (by beginner learners): in the case of the present study the 'future tense' ;

2. more specifically to determine the effects (immediate \& delayed) of processing instruction on L2 learners' developing system on another language: namely Italian; 3. to measure the possible effects of processing instruction on verbal morphology on an interpretation task and particularly on two different production tasks: oral and written. To this end, this study also seeks to provide further evidence, as to whether one way of influencing SLA may be by altering the means by which L2 learners process input. More specifically this study will investigate the possible impact of processing instruction in altering a well documented strategy used by L2 learners which consists of the precedence given by L2 learners to lexical items (temporal adverbs such as oggi, domani, fra un mese) over morphological markers for processing semantic information contained in the input.

This strategy is supported by empirical studies concerning learners of Spanish (Lee et al 1997) and Italian (Musumeci 1989). 


\section{Corpus of the research}

The thesis follows a logical progression and is organised as follows:

In chapter one the main studies carried out to investigate to what extent formal instruction aids SLA will be reviewed in order to evaluate the current theoretical frameworks. A critical analysis and some considerations of the current theoretical frameworks on the role of formal instruction in SLA and the studies carried out to account for these frameworks will provide support for a new approach to the investigation of the role of formal instruction which should address the questions of why and how formal instruction makes a difference.

In chapter two, studies conducted to investigate the question as to whether different types of FFI (three main lines of research will be identified) affects SLA in different ways will be presented and discussed. This partly pedagogical issue is the result of an evolution in classroom research to determine what type of formal instruction is more effective and beneficial to SLA. This chapter will create the basis for another question relevant to role of FFI. The question is: 'whether FFI is more effective when provided through comprehension practice or production practice'.

Chapter three discusses input processing theory. Empirical support for one specific strategy used by L2 learners to process input will be provided. At the end of this section the theoretical implications for instruction in a processing framework will be addressed.

In Chapter four the main characteristics of this new approach to the teaching of grammar called 'processing instruction' will be presented and five major empirical studies on the effects of this new approach on the acquisition of several Spanish linguistic features will be reviewed and some of their limitations outlined. Some pedagogical implications for this study will be identified.

At the end of this chapter the major research questions and the specific hypotheses being tested in this study will be presented and the contributions of the present study to the ongoing debate will be discussed. 
In chapter five the research design of this study and the procedures used for data collection and analysis will be presented.

In chapter six the results of the statistical analysis are provided and summarised.

Finally in chapter seven the findings of this experimentation will be interpreted and discussed in relation to previous research. This last chapter includes a discussion of the implications and addresses some limitations of this study. Furthermore some suggestions for further research will be provided.

The Appendices contain the two packs of teaching materials, tests, forms and the questionnaire used for the experiment. 


\section{CHAPTER ONE: THE ROLE OF FORMAL INSTRUCTION IN SLA: THE CURRENT THEORETICAL FRAMEWORKS}

\section{Introduction}

I will begin this section by regrouping some theoretical positions around the role of formal intruction in SLA into two main theoretical views, and review some of the studies which have found support for these two main positions. These are the noninterface position which has been challenged by many scholars and the facilitative position which consists of several different versions and generally accounts for a more positive role of formal instruction in SLA. These two theoretical views have been drawn from a large number of studies carried out to examine whether or not instruction affects SLA. In the conclusion some implications for the present study will be outlined.

\subsection{The non-interface position}

One of the most prominent and at the same time most criticized theories in SLA research has been Krashen's Monitor Theory (Krashen 1982) which is based on five hypotheses:

1. The Acquisition-Learning Hypothesis

2. The Natural Order Hypothesis

3. The Monitor Hypothesis

4. The Input Hypothesis

5. The Affective Filter Hypothesis

However in relation to the non-interface position in this paragraph we will be discussing only the first hypothesis as it is relevant to the discussion in this section. In the hypothesis called the 'Acquisition-Learning Hypothesis', Krashen claims that learners possess two different systems to develop competence: an 'acquired' system and a 'learned' system

The 'learned' system is activated when learners are involved in the process of paying attention to the L2 in order to understand the rules. Therefore, in this case L2 learning is a conscious construction of rules in the pedagogical context. 
The 'acquired' system instead, is, according to Krashen, a subconscious and intuitive process which arises when learners are involved in using language in actual communication. In Krashen's view L2 acquisition and learning are two autonomous means of internalizing the L2 rules, and learning cannot turn into acquisition as the two types of knowledge are completely separated and unrelated. The key aspect of second language acquisition, in Krashen's theory, is therefore an unconscious process which results from the experience of using the language. This process does not benefit from any conscious learning, for example the learning of grammatical rules, no matter how much the learner practises. Despite the fact that Krashen accepts that formal instruction contributes to the learning of explicit knowledge however, he sees this as a 'fragile and peripheral' role as he has claimed again in a recent paper (Krashen 1993:22). In other words, according to Krashen, formal instruction has a very limited role in SLA, since the 'learned' knowledge that results from grammatical instruction does not help the learner in the 'acquisition' of the language.

As a result of this view he has hypothesised that if learners are exposed to comprehensible input and provided with opportunities to focus on meaning and messages rather than grammatical forms and accuracy, they are able to acquire the L2 in the same way as L1. In practical terms, L2 teaching should focus on providing a rich variety of comprehensible input and opportunities for the learners to use language spontaneously and meaningfully. This will be even more beneficial on the one hand for beginners and foreign language learners who cannot use the informal naturalistic environment for input, while on the other hand less beneficial for those learners who have other sources of comprehensible input and who are linguistically advanced enough to take advantage of it.

Krashen's position, known as the non-interface position, finds some support in a number of studies which could be grouped into two main areas:

a) the first area of research includes studies carried out to compare acquisition in both the classroom and the naturalistic environment and specifically investigating L2 errors, the sequence of development of syntactic structures and the sequence of acquisition of grammatical morphemes; 
b) the second area is related to research whose aim is to investigate the possible effects of formal instruction on the route of acquisition and formal accuracy in language use through classroom experiments.

a) The first group of studies have shown no effects of formal instruction on the route of acquisition. This finding comes from studies carried out to investigate L2 errors (among others see: Felix 1981, Lightbown 1983).

In the case of Felix's study (1981), which involved thirty-four German high school students learning English as a L2 under classroom conditions, he compared formal classroom learners' behaviour and naturalistic learners' behaviour ${ }^{1}$ in respect to errors relating to various features (negation, interrogation and pronouns).

His general findings showed that both naturalistic and classroom learners follow the same developmental trends. Felix concludes that formal instruction has no power to prevent developmental errors in L2 learners and we can draw a number of structural parallels between utterances of naturalistic L1 learners and instructed learners. As Felix claims (1981:108) "this observation suggests that at least some of the principles that govern naturalistic language acquisition also determine the processes by which students learn a foreign language under classroom conditions".

Lightbown's study (1983) carried out among seventy-six learners of English in school showed also a detrimental effect of instruction which not only does not prevent 'natural errors' but seems to interfere with the natural process of language learning in making learners over-learn some structures which would cause a delay in the acquisition of certain grammatical features when compared to naturalistic SLA.

There are also some studies where the acquisition of syntactic features (Ellis 1984, Pavesi 1986, Weinert 1987) and grammatical morphemes (Makino 1980, Pica 1983, Van Patten 1990) have been investigated by comparing naturalistic and tutored acquisition.

\footnotetext{
${ }^{1}$ This refers to language learners who acquire a L2 in natural settings. It contrasts with the instructed language classroom setting.
} 
The general findings of these studies show again that the sequence of acquisition through which learners pass in learning given linguistic features is not affected by formal instruction, as the sequence of acquisition of the two types of learners is similar. In the case of Weinert's study (1987), which studied the acquisition of German negation by forty-two Scottish secondary school children, he indicates that learners produce similar structures to that found in naturalistic acquisition.

As in the case of Lightbown (1983) Weinert emphasizes a possible 'detrimental' effect of instruction given that classroom activities that require immediate production from the learners result in a heavy reliance on routines and patterns that would interfere in their interlanguage ${ }^{2}$ development.

Among the studies which have compared the acquisition of grammatical morphemes in classroom and naturalistic learners is that of Van Patten (1990) where he has investigated the use of certain pronouns in both naturalistic and classroom learners of Spanish. The results of this study also showed the limited role of instruction which in this case is not able to circumvent certain natural processes of acquisition .

The overall findings of the comparative studies carried out on L2 morphology and syntax seem to show that the sequence of acquisition is the same in classroom and natural settings and instruction does not alter the route of acquisition of classroom learners.

Krashen's position would easily explain these findings which showed that formal instruction does not affect the developmental route of acquisition and therefore has a very limited role.

Furthermore Krashen's view about the existence of two separate and independent linguistic knowledges seems to be justified in the light of these studies since the 'learned' knowledge which results from grammatical instruction does not help the L2 learners in the 'acquisition' of the language.

b) Among studies belonging to the second group involving classroom experiments, one study ( Kaplan 1987) also seems to show limited effects or no effects for formal instruction on the route of acquisition and therefore supporting Krashen's noninterface position.

\footnotetext{
${ }^{2}$ Selinker (1972) coined this term to refer to systematic knowledge of a L2 which is independent from both the learner's $\mathrm{L} 1$ and the target language.
} 
The two main aims of Kaplan's study (1987) were to investigate the pattern of French past tense (present perfect and imperfect) in the early stages of acquisition (sixteen beginners and intermediate students of French as a foreign language at university level) and to establish the possible effects of instruction in students' route of development. One of the findings of this study was that learners' acquisition of the past tense system did not match the instructional sequence used by the language instructors. As in the other studies formal instruction does not seem to be the major factor in the acquisition of grammatical forms or structures.

Finally, a group of experimental studies (Lightbown, Spada \& Wallace 1980, Ellis 1984, Terrell, Baycroft \& Perrone 1987, Kadia 1988) known by many scholars as 'accuracy studies', have investigated the effects of instruction on formal accuracy.

The result seems to be unanimous in indicating that instruction does not have any effects on normal spontaneous communication, but that it might however, improve accuracy in more carefully monitored speech. Nevertheless, this improvement seems to diminish over time, as demonstrated by Lightbown, Spada \& Wallace (1980) whose study will be reviewed here in more details. Lightbown, Spada \& Wallace investigated the possible effects of instruction on the accuracy with which three different stuctures were produced by one hundred and seventy-five French speaking children studying English in school. The three structures under investigation were:

1. five functions of the ' $s$ ' inflection (plural, possessive, third person singular, copula, auxiliary);

2. 'be' form used in referring to age;

3. locative prepositions indicating motion towards a goal.

Two instruments designed for this study were used to collect the data. One was a grammatical judgement task which required the students to identify and correct incorrect uses of the structure under investigation and was administered immediately before and after instruction, and also after a period of five months to look for delayed effects. 
The second test was a communicative game requiring students to describe some pictures. The instruction period consisted of two days of review of the target structures using a list of 25 correct and incorrect sentences.

The results of the first test reported here suggested that instruction had a positive effect on the learners' accuracy in production, however the delayed post-test showed that those effects were not long-lasting.

Terrell, Baycroft \& Perrone (1987) conducted a study using a group of seventy English University students taking Spanish at beginners level. The aim of this study was to investigate the effects of formal instruction on the forms and uses of the Spanish subjunctive mood. The data were collected through six hours of recorded oral examination in which the students were involved in spontaneous conversation on various topics. The examiners looked at all cases where the subjunctive was used correctly, incorrectly and not used even if required. As pointed out by the experimenters the results of this study indicated that formal instruction had no effect on learners' ability to use the subjunctive correctly in free conversation. Furthermore, Terrell, Baycroft \& Perrone concluded (1987:27) that 'students do not seem to be able to monitor their conversational output by using learned rules in order to increase accurate use of the subjunctive'. In summary, the studies we have reviewed (in section a and section b) seem to support Krashen's non-interface view in showing that the sequence of acquisition through which L2 learners pass in learning a specific linguistic feature is not effected by instructional sequence. In addition to that, the experimental studies reveal that instruction has no effect on spontaneous communication even if it does have a short-lasting effect on monitored and careful speech. However, studies which have shown positive effects of formal instruction on the route of acquisition (see next section 'strong interface position') undermines Krashen's position. 


\subsection{The facilitative position: several versions}

The facilitative position claims that formal instruction seems to be able to help 'learning' by in particular speeding up the process of natural acquisition.

As Long (1994: 654) has indicated there are several versions of this view:

The interface position

The variability position

The teachability hypothesis

The selective attention hypothesis

\subsubsection{The interface position}

The interface position questions Krashen's claim that 'acquisition' and' learning' are not related, and while admitting that learners have two types of L2 knowledge, posits that these two phenomena are not entirely separated and unrelated. The interface position can be divided into two main positions:
a) weak interface
b) strong interface

a) The weak position was put forward by Seliger (1979) who claimed that although conscious knowledge of a rule does not have a great importance in spontaneous communication, it does have a purpose, and this purpose is that it acts as 'facilitator' for the acquisition to take place. This is achieved by speeding up the process of 'natural acquisition'. Seliger acknowledges that the process of internalization of rules is different than the process involved in learning pedagogical rules and 'learned knowledge' cannot be converted into 'acquired knowledge', however, he claims that the knowledge of pedagogical rules does affect language learning in two ways:

- by making internalization easier when the learner is ready;

- by facilitating the set of features, which although acquired are rarely used by the learner. 
The weak interface position supports the claim that formal instruction has no positive effects on the route of SLA. Seliger maintains that pedagogical rules will not alter the sequence in which L2 are naturally acquired; this claim is empirically supported by several studies which, as mentioned previously, have shown no effects of formal instruction on the route of acquisition (Felix 1981, Makino 1980, Ellis 1984, Pavesi 1986, Weinert 1987, Kaplan 1987 and Van Patten 1990) and on spontaneous communication (Lightbown, Spada and Wallace 1980, Ellis 1984, Terrell, Baycroft \& Perrone 1987 and Kadia 1988).

On the other hand, the weak position can also account for the positive effects of formal instruction on the rate and ultimate success of SLA since pedagogical rules will be able to enhance the speed of development. This claim is also supported in particular by a number of studies, (Long 1983, Weslander \& Stephany 1983, Spada 1987, Ellis \& Rathbone 1987) which have shown positive effects for formal instruction on these aspects of SLA. Long (1983) considered eleven studies that had investigated whether learners receiving formal instruction achieve a higher level of proficiency than those who do not. According to Long there is enough evidence to sustain the view that second language instruction makes a difference in terms of being beneficial for adults as well as for children, intermediate and advanced students, despite the way it is measured (by means of integrative or discrete-point tests) and in acquisition-rich and acquisition-poor environments (that is, in settings where learners have little opportunity to hear the language outside their language class).

In his review he compared the achievement of learners after a considerable period of classroom instruction, natural exposure and a combination of the two.

Weslander \& Stephany (1983) examined the effects of instruction on five hundred and seventy-seven children with limited English proficiency in a public school in Iowa.

Weslander \& Stephany reported in their study that it was the beginners that benefitted from formal instruction.

Krashen (1985) has argued that formal instruction would also be expected to show positive effects for beginners who could not obtain the comprehensible input outside the classroom. However the role of grammar instruction changed only superficial aspects of L2 learners' performance. 
Ellis \& Rathbone (1987) investigated the posible effects of class attendance on the levels of learning achieved by thirty-nine adults learners of L2 German. They found a positive effect for instruction which was very formal and consisted of controlled practice of grammatical items. The attendance of the students in an overall period of six months correlated with a number of measures of grammatical learning.

Nina Spada (1987), investigating the possible relation between type of contact and type of instruction in an adult intensive ESL programme at University level involving forty-eight students, found out that informal contact with the L2 is a less powerful predictor of differences in learners' L2 abilities than instruction.

Although the later three studies examined sought a positive effect of formal instruction in the rate and ultimate success of SLA, their results seems also to partially provide empirical support for Krashen's non-interface position, since he argued that the classroom can speed up the acquisition processes, particularly in the case of adult beginners who have difficulty in obtaining comprehensible input in natural settings.

b) The strong interface position has been developed by a number of scholars. They have developed different models of SLA in the belief that 'learned' or 'explicit' knowledge can become 'acquired' or 'implicit' knowledge provided that the learners have the opportunity and motivation to automatize new rules through practice.

Stevick (1980) proposed a model called the 'Levertov Machine' which allows for 'learnt' knowledge to become 'acquired'. He suggests that 'learning' may relate to secondary memory which is able to hold material for longer than two minutes, but from which materials are usually lost very quickly unless it is used occasionally.

On the other hand acquisition can relate to tertiary memory which contains material that is never lost.

Stevick sees, like Krashen, acquisition as the product of communicative experience; however, he believes that learning can become acquisition, when material in secondary memory is transferred into tertiary memory. McLaughlin (1978) offers an alternative distinction from Krashen's Monitor model. This is the distinction between controlled and automatic processing. 
Controlled process requires active attention, so only a limited number of features can be controlled at a time. On the other hand, automatic processing takes place without active control or attention.

According to McLaughlin automatic processing follows the earlier use of controlled process and therefore SLA entails going from the controlled to the automatic mode of operation.

Bialystok (1981) has also developed a model of SLA based on two types of knowledge which can interact. The 'explicit' knowledge and the 'implicit' knowledge. He claims that through practice, 'explicit' turns into 'implicit'.

Sharwood-Smith (1981) building on the work of Bialystok and McLaughlin (1978), has proposed a full interface model to account for the role of formal instruction. According to his model, a learner can produce L2 output in three different ways:

- by using implicit knowledge

- by using explicit knowledge

- by using both

This means that explicit knowledge lacking in automacity can provide feedback into implicit knowledge, and if there is enough practice the explicit knowledge can become automated as part of implicit knowledge.

This is also the view of Anderson (1983) who distinguishes two types of knowledge: declarative knowledge and procedural knowledge. Anderson indicates that learning begins with declarative knowledge (this knowledge is acquired very suddently by being told) and slowly becomes proceduralized (procedural knowledge is acquired by performing a skill) through practice.

Ellis (1994) claims that the implication to be drawn from Sharwood-Smith is that the adult learner who receives grammar teaching on specific linguistic features can practise these in and out of the classroom until he can use them in a subconscious way in fluent communicative speech. 
Sharwood-Smith (1981) takes the argument further, emphasizing that grammar teaching or as he calls it 'consciousness-raising' can take many different forms along two main dimensions: elaborateness and explicitness. In the case of elaborateness he is concerned with whether the teaching offers a brief description or highly structured explanations. As far as explicitness is concerned the issue is whether the teaching offers indirect clues or standard pedagogical rules. Therefore the important issue for Sharwood-Smith is not whether grammar should be taught, but in what way it should be taught.

The strong interface position can offer an explanation of why instruction seems to have a facilitative effect on the rate and ultimate success of acquisition. This is, according to Ellis (1994) because classroom learners have two main advantages compared to their naturalistic counterparts:

- they can increase their acquired or implicit knowledge by means of the intake environment' supplied by classroom;

- they can automatize explicit knowledge through practice.

Studies reviewed by Long 1983 , as well as the studies conducted by Weslander \& Stephany 1983, Spada 1987 and Ellis \& Rathbone 1987 that have investigated the effects of formal instruction on the rate and ultimate success of SLA seem to support this view. These studies have suggested that formal instruction is of value in promoting rapid and higher levels of acquisition.

The strong interface position can also provide explanation for the positive effects of instruction on the route of acquisition. This is due to the possibility of explicit knowledge turning into implicit through automatization as maintained by McLaughlin. Positive effects of formal instruction have been reported in studies carried out through comparison between naturalistic and classroom SLA.

Lightbown (1987) conducted one study on the acquisition of certain functions of grammatical morphemes and the possessive marker -ing-. She suggests that instruction can affect the order of acquisition of certain grammatical morphemes. 
However Lightbown found that the effects were only temporary since natural processing took over once the structures were no longer the subject of instruction.

Pica (1983) carried out an investigation with eighteen beginner students of English which she divided into three groups: one group receiving only instruction, the second group only natural exposure and the third a mix of instruction and opportunities for informal contact. Her findings also supported the hypothesis that instruction has a direct effect on the route of acquisition, but this effect is selective, this is to say that it is related to the complexity of the linguistic feature of the language.

In this study Pica showed that instruction can improve the learners' production of simple morphemes such as the plural and third person $-s$ - in English, but has no positive effect on more complex structures

In summary, it can be affirmed that the strong interface, which allows for an interaction between 'learning' and 'acquisition', has empirical support in those studies which have shown positive effects of instruction on the rate and success of SLA, and on the route of L2 development. However, this position cannot account for studies which have shown no effects of instruction on the route of acquisition (see noninterface position).

The 'projection hypothesis' can also offer an explanation of the possible effects of instruction on the process or route of acquisition. Positive effects on the route of acquisition have also been reported in the so-called 'projection studies' (Zobl 1983, 1985, Pavesi 1986, Eckman, Bell \& Nelson 1988, White 1996) which have indicated that the relationship between instruction and acquisition is more complex than what we have assumed. According to these studies instruction leads to the acquisition not only of the features that have been taught, but also of others features that are implicationally associated with them. This is made possible by the existence of a 'projection device' in learners which enables them to acquire one rule and that would trigger the acquisition of other rules which are clustered with it.

Furthermore Zobl (1983) has proposed that instruction can give learners examples of marked features which will trigger the acquisition of unmarked ones. 
Eckman, Bell \& Nelson's study (1988) is based on the 'Accessibility Hierarchy' theory (Keenan \& Comrie 1977) which has been used to predict the acquisitional order of relative clauses in a L2. The population of this study consisted of thirty-six students studying English as a second language at University level.

The purpose of this study was to ascertain whether students generalize instruction to other related structures where they are taught a particular one. More specifically the study was carried out to investigate whether students instructed on how to form relative clauses where the subject is relativized, would be able to project this learning to structures where an object (which is more marked) or an object of a preposition was relativized.

The results of this study seem to support the hypothesis that maximal generalisation of learning takes place from exposure to structures which are typologically more marked. Therefore, instruction seems to be effective when it targets stages which are several steps beyond the L2 learner's current level of development.

White (1998) has carried out a classroom study on the acquisition of possessive determiners among eighty-six francophone school children learning English which suggests that when learners are exposed to more advanced features they benefit more from instruction (this study will be presented in more detail in the next chapter). 


\subsubsection{The variability position}

According to Ellis (1994:654) the variability hypothesis differs from the interface hypothesis in the claim that teaching learners new structures would affect their 'careful' style not their 'vernacular' style. This, still according to Ellis, will have a more evident effect in learners when they have to perform and use L2 in a planned task rather than in unplanned language use. In addition to the effects that formal instruction has on learner's careful style, Tarone suggests that there might be an indirect effect on learner's vernacular style.

Tarone's (1983) theory is an attempt to provide an explanation of how knowledge is acquired and of the changes taking place in learner's interlanguage.

He maintains that new forms enter the interlanguage system in two ways: in the vernacular style directly or in learners' formal style when learners are paying attention to speech production. He has defined the 'vernacular style' as a 'basic style'. First of all it represents unmonitored capability.

Secondly the form characteristic of this style are internalized spontaneously as they are the reflection of universal principles of SLA. Finally it is a style of unplanned discourse, which is the type of communication found in untutored acquisition.

Tarone (1983) claims that forms which enter learners' interlanguage in the careful style might gradually be available for unplanned use of language.

He also claims that the style that the learner uses is a function of the amount of attention that he his able to pay to his speech. Therefore it is the type of task that he has to perform that determines the type of language that will be observed.

Bialystok (1982) has proposed a framework to account for this variability in interlanguage. This framework is based on the assumption that language situations are driven by different cognitive,linguistic and social demands and the learner will be successful when his ability matches those demands.

Bialystok (1982) described these demands on the learner in terms of control over two factors: analysed representations of knowledge and automatic access to information. 
Bialystok describes the analysed factor as referring to learners' mental representation and the extent to which he is aware of the structure of the knowledge and its relationship to other aspects of knowledge.

Bialystok (1982:18) suggests that 'because the structure is apparent, the learner is able to operate on this knowledge by transforming it, comparing it to other events and using it as a means of problem solving'.

The automatic factor refers to relative access learners have to different items of linguistic knowledge, irrespective of its degree of analysis. According to Bialystock different tasks require different types of knowledge. Therefore a very difficult task would require knowledge that is marked on both factors (i.e + analyzed and + automatic) unlike a least difficult task which would be unmarked on both factors (i.e analyzed and - automatic).

Bialystok concluded that in developing learners' proficiency the unmarked forms precede the marked forms. As she claims (1982:205) 'instruction must consider the specific goals of the learner and attempt to provide the appropriate form of knowledge to achieve these goals'.

If the goal is to engage in natural conversation learners need to develop their vernacular style by acquiring L2 automatic knowledge. However if learners have to participate in discourse that requires careful and conscious planning, they need to develop a careful style by acquiring L 2 knowledge that is automatic and analysed.

This type of knowledge can be provided by formal instruction that focuses on the L2 grammar. The variablity hypothesis, as indicated by Ellis (1994:655) can account for several research findings (Felix 1981, Makino 1980, Wode 1981, Kaplan 1987, Weinert 1987, Van Patten 1990) on the effects of instruction on the route of acquisition. Instruction seems to be powerless to alter the 'natural' route of acquisition as this is evident only in the learner's vernacular style.

The variability position can also provide support for the positive effects of instruction on the rate and ultimate success of SLA (Long 1983, Weslander \& Stephany 1983, Spada 1986, Ellis \& Rathbone 1987) by assuming that the classroom settings offer a richer input than the naturalistic setting and therefore provide the growth of a variety of knowledge types other than just the vernacular style as this is the case for natural settings. 
In one respect, however the variability position cannot account for why in certain conditions instruction has shown positive effects on the route of acquisition (Pica 1983, Zobl 1985, Lightbown 1987, Eckman, Bell \& Nelson 1988). 


\subsubsection{The teachability hypothesis}

The teachability hypothesis has been defined' by Ellis (1994:656) as 'the most powerful account we have of how formal instruction relates to learning'.

This hypothesis has been advanced by Pienemann (1984) as a result of extensive research into the naturalistic acquisition of L2 German word order rules and L2 English acquisition .

The main aim of this research was to investigate whether formal instruction would alter the sequence of acquisition. The research has been based on a L2 theory called the Multidimensional Model that views L2 acquisition as a sequence of ordered developmental stages, but it emphasizes the considerable variation that is present in each stage. This model makes a clear distinction between two types of linguistic features: developmental and variational. The developmental are constrained by developing speech-processing mechanism. The variational are not so constrained. Pienemann and Meisel have advanced the following four main hypotheses in their model, concerning the effects of instruction on SLA:

1) instruction will not enable learners to acquire any developmental features out of sequence;

2) instruction will enable students to acquire developmental features providing that the processing operations required to produce those features that precede it in the acquisitional sequence have already been mastered;

3 ) instruction directed at developmental features for which the learner is not ready may interfere with the natural process of acquisition;

4) instruction will help learners to acquire variational features.

These hypotheses have been tested in several studies by Pienemann and his associates (Pienemann 1984 and Pienemann \& Johnston 1987) which showed that instruction cannot help the learner change the natural order of SLA, however instruction can promote language acquisition if the interlanguage is close to the point when the structure to be taught is acquired in the natural setting. The teachability hypothesis relies on the possibility that instruction could help the learner to alter the natural route of development, if the learner is psycholinguistically ready. 
Therefore, according to Pienemann (1984) instruction can facilitate the SLA process if it coincides with when the learner is ready; it can improve the speed of acquisition, the frequency of role application and the different contexts in which the role has to be applied.

In addition it allows for the positive effects that instruction can have on the acquisition of variational features. The teachability hypothesis has also been supported by a study carried out by Ellis (1989) who investigated whether or not formal instruction affected the sequence of acquisition of German word order rules. Thirty-nine beginner learners of German were involved in this study in which it was shown once more that instruction made no difference in the sequence of acquisition under investigation. The classroom learners followed the same sequence of acquisition of German word order as that reported for naturalistic learners. Ellis concluded that tutored learners follow their own 'syllabus' in the same way as untutored learners. The teachability hypothesis can account for some conflicting results found in studies on the effects of instruction in SLA:

first of all, for studies showing no effects and detrimental effects of instruction on the route of acquisition since it postulates that instruction is unable to alter the natural order of acquisition. However it cannot account for studies which have shown positive effects of instruction on the route of acquisition;

secondly, for studies which have shown positive effects on the rate of acquisition since it claims that instruction can improve the speed of acquisition as long as the learner is psycholinguistically ready.

Recently, Spada \& Lightbown (1997) have investigated the question of how learners' developmental readiness interacts with instruction to lead to progress in the acquisition of question forms with grade six learners in ESL programmes.

The findings in this study suggest that even learners who were psycholinguistically ready to acquire a specific structure may require more explicit instruction. 


\subsubsection{The selective attention hypothesis}

According to this view formal instruction would act as an aid to acquisition, not by actually making students internalise new linguistic features, but by providing learners with what Lightbown (1985) has termed 'hooks', 'point of access'

As Sharwood-Smith (1985: 275) has indicated 'instructional strategies which draw the attention of the learner to specifically structural regularities of the language, as distinct from message content, will under certain conditions significantly increase the rate of acquisition over and above the rate expected form learners acquiring the language under natural circumstances'.

Gass (1991) has reemphasised that instruction does prepare the path for acquisition although initially learners do not fully acquire what is taught when it is taught.

Instruction helps learners to pay selective attention to form and form-meaning connections in the input. This is done by devising different instructional activities: through pedagogical rules which constitute one type of tool for facilitating selective attention or interpretation tasks which aim to help learners to notice and comprehend feature in the input. A number of studies on this latter device for noticing and comprehension of a target linguistic feature will be reviewed (see chapter four section 4.2). These studies seem to suggest that such a tool is effective in promoting intake. This position, which accounts for studies which will be reviewed in chapter four suggest that selective attention is facilitated by devising instructional activities whose main aim is, rather than equipping learners with conscious rules, helping learners to interpret the meanings of some specific forms in the input. 


\subsection{Implications for this study}

Two main positions around the role of instruction in SLA have been presented and several empirical studies have been reviewed to account for these two views. Some considerations will be now drawn about this research which are relevant for this study. Firstly, despite the mixed results (no apparent effects, detrimental effects and positive effects) in the studies reviewed in this chapter on the effects of formal instruction on SLA, formal instruction seems to promote more rapid SLA and to contribute to higher levels of ultimate achievement (Long 1983, Ellis \& Rathbone 1987).

The positive effects of instruction in SLA have been stressed by some scholars (Seliger 1979, Stevick 1980, McLaughlin 1978, Bialystok 1981, Sharwood-Smith 1981), who challenged Krashen's view and posited an interface view according to which acquisition and learning are not two separated phenomena. However, it must be emphasised that there are psycholinguistic constraints (teachability hypothesis) which determines whether formal instruction is successful or not. It might be successful as claimed by Pienemann (1984) if learners have reached a stage in the developmental sequence that enables them to process the target structure.

Secondly, the empirical studies reviewed in this chapter have been mainly concerned with answering the question as to whether or not instruction affects the route, rate and ultimate success of acquisition rather than how instruction might impact in the L2 acquisition process. Despite several theoretical frameworks (regrouped in two main positions: non-interface position and facilitative position) which attempt to explain the effects of instruction on SLA, no one has been able to account successfully for the results of the empirical research, as Cadierno (1995) has emphasised.

Thirdly, the instruction that has been utilized in the research has worked on manipulating the output of the L2 learners

Fourthly, the nature of formal instruction in the empirical studies reviewed has not been explained in detail. In the studies reviewed in this chapter there has been little explanation about the type and quality of instruction that the subjects received. 
As a result of the overall research findings and the theoretical reflections reported in this chapter the implication for this study are threefold:

1) first of all, an explanation is needed at theoretical level of how formal instruction affects the language acquisition process. One possible research area in order to explain the effects of instruction on SLA, is to look more closely at the relationship between the type of instruction to which L2 learners are exposed and how such learners process the incoming linguistic data. This will be examined and discussed in chapter three where the question of how instruction can affect the way learners process input to create their knowledge system will be addressed and a new model of input processing presented;

2) secondly, a new approach to formal instruction is needed in language pedagogy.

The instruction adopted in the studies reviewed in this chapter consisted of the explanation of a particular grammar form or stucture and subsequently activities which involved learners in written or oral production. The type of approach to formal instruction which will be outlined in chapter four is directed instead at altering the way L2 learners process input and it is in contrast with the studies we have reviewed in this chapter which have been looking at manipulating learners' output;

3) finally, classroom studies investigating the effects of formal instruction should clearly and carefully describe the type of instruction used.

In the next chapter, studies carried out on the effects of different types of FFI on SLA will be reviewed. An evolution in classroom research investigating the role and effects of formal instruction has taken place in the last few years. One of the questions which has been addressed as a result of previous studies is not whether formal instruction 'per se' has a positive effect on SLA, but whether there are particular types of formal instruction more beneficial than others. These studies have carefully described how instruction is operationalised in the classroom. 


\section{CHAPTER TWO: THE CONTRIBUTION OF DIFFERENT TYPES OF FORMAL INSTRUCTION TO SLA: AN EVOLUTION IN CLASSROOM RESEARCH}

\section{Introduction}

In the last decade, we have witnessed an evolution in L2 classroom research and the question being asked by scholars (see Long 1983) is not whether instruction 'per se' has any effects on SLA but rather whether there are particular types of 'FFI' 'better' than others. This type of research has also provided a detailed description and careful explanation of the pedagogical interventions made by the instructors. Three main lines of classroom research which have recently emerged to explore different ways of integrating instruction on grammatical forms or structures in a communicative framework will be identified and some of the studies reviewed. Finally, in the light of the main findings of these studies some implications for the present study will be drawn.

\subsection{Defining FFI in classroom SLA.}

In order to look at whether there are particular types of focus on form which are better than others, we must first define what focus on form is, as this term has been used sometimes to express different meanings. In a seminal paper Long (1991) has distinguished between two types of focus on form: a 'focus on form' and a 'focus on forms'. As he has defined more clearly recently (Long \& Robinson 1998) a 'focus on forms' refers to a type of instruction that isolates a specific linguistic form in order to teach them one at the time. This is found on structural and notional-functional syllabuses, where the syllabus consists of inductively or deductively presented information about the L2. As Long \& Robinson (1998:16) pointed out, 'pedagogical materials and accompanying classroom procedures are designed to present and practise a series of linguistic items or forms'. A 'focus on form' involves a focus on meaning and a focus on form. This is to say that learners' attention is being focused on specific linguistic properties in the course of a communicative activity.

The distinction used by Long would appear to be restrictive in the case of this review, therefore the one presented by Spada will be adopted. 
Spada (1997:73) has defined more generally 'FFI' as 'any pedagogical effort which is used to drawn the learners' attention to language form either implicitly or explicitly'. This can include the direct teaching of language through a grammatical rule for example, and/or a reaction to errors (corrective feedback).

These types of techniques (e.g. discrete-point grammar presentation and practice) have been associated with traditional approaches and defined by Long as types of 'focus on forms'. However in many cases they have been incorporated in a primarily communicative approach to language teaching.

Therefore Spada's definition of FFI, and the one adopted in this study, differs from Long's definition of 'focus on form' which is restricted to meaning-based pedagogical events where attention to the formal properties of the L2 is provided only in a spontaneous way. The term FFI used by Spada is more comprehensive as it refers to a focus on the formal properties of the L2, within an overall meaning-based approach, provided through either spontaneous or predetermined ways.

The approach to formal instruction investigated in this study incorporates activities that focus on both meaning and form at the same time. This is in line with Spada's view (1997:77) which argues that FFI is generally more beneficial when L2 learners' attention is drawn to linguistic features in a more or less explicit way within a communicative teaching context. 


\subsection{Review of some studies on the effects of instruction.}

The question of the importance and contribution of formal grammar instruction to SLA has greatly evolved over the last ten years. In this section some of the studies that have been carried out in order to ascertain whether there are particular types of FFI which are more beneficial than others to SLA will be reviewed.

In describing the evolution of the contribution of formal instruction to SLA we have to use as starting point Long's paper (1983) in which he questions the relative effects of instruction on language acquisition.

As emphasised in the previous section (para 1.1) formal instruction is relegated to a fragile and peripheral role in Krashen's theory, according to which formal grammar instruction permits the learners to monitor their L2 production but does not have any effects on learners' competence. In order to determine whether instruction might have a more positive role, Long (1983) reviews the results of eleven studies examining the effect of formal instruction on the rate and success of SLA. On the basis of this comparison he concludes that instruction and a combination of instruction and exposure were more beneficial than exposure alone, as instruction seems to speed up the acquisition processes.

Long's conclusion on the beneficial effects of a type of instruction which represents a combination of focus on form and meaning echoes the findings from an early classroom experiment carried out by Savignon (1972), in which she measured the communicative and linguistic abilities of three groups of beginners enrolled in a French audiolingual programme. The experimental group which received within the four hours weekly one hour devoted to communicative tasks outperformed the other two groups in the communicative competence ${ }^{3}$ tests, and did not perform differently in the discrete point tests measuring linguistic competence.

\footnotetext{
${ }^{3}$ communicative competence consists of the knowledge internalized by L2 learners which enable them to understand and produce messages in the target language. Different models of communicative competence have been proposed, however these different models include different components such as linguistic competence (the knowledge of grammatical rules) and pragmatic competence (the knowledge of what constitutes appropriate linguistic behaviour in a specific situation).
} 
One of the implications of this study suggests that a combination of formal and informal instruction is very helpful in the development of communicative language skills in foreign language learners in a communicative programme ${ }^{4}$.

Two other studies provided support for this view. The first one carried out by Montgomery \& Eisenstein (1985), investigated the effects of combined CLT and form-focused instruction on L2 development on a group of students learning English enrolled in an experimental communicative programme. The group receiving the 'combined treatment' made greater gains on grammar and vocabulary than the group of adults who received only the grammar treatment. Montgomery \& Eisenstein concluded that a combination of focus on form and focus on meaning in language teaching is more beneficial than an exclusive focus on form.

In the second study Spada (1987) carried out an investigation using COLT (Communicative Orientation of Language Teaching), an instrument developed particularly to observe and describe particular aspects of instructional practices and procedures in the L2 classroom.

In this study she investigates the effects of different instructional programmes on learners' improvement in proficiency. She looked at the effects of instruction and exposure on intermediate level adult learners enrolled in a intensive English course at a Canadian University.

The evidence provided by Spada suggests again that learners make more rapid progress when they experience both form-focused and meaning-focused instruction.

\footnotetext{
${ }^{4}$ Communicative Language Teaching is a type of instruction rather than a method or an approach.There has been an attempt to clarify what the terms means by Johnson (1982) who suggests that we can define two main positions within the CLT framework. One called 'unificationist' which calls for communicative practice from the beginning with the exclusion of any type of formal instruction in the formal features of language. The other position is called 'separationist' which includes attention in both form and meaning in language teaching.

The classroom research reviewed in chapter one (para 1.1) provides support for Krashen's view according to which instruction which provides learners with metalinguistic information or pedagogical rules and corrective feedback is not an effective way to acquire a L2.

The impact of this research at pedagogical level was considerable and led support for the 'unificationist' position. We will refer again to CLT in chapter three when an alternative way to incorporate grammar instruction in a communicative programme will be discussed.
} 
As Spada (1987:160) commented: 'findings like Savignon's have been very often interpreted as evidence for the claim that grammatical instruction is 'bad' and communicative practice 'good'. On the contrary it is important to emphasize that in Savignon's and Montgomery \& Eisenstein's studies the findings must be considered as support for the argument that a type of instruction which includes a combination of form-orientated and meaning-orientated language teaching is more beneficial rather than the former alone.

It also should be noted that this is in accordance with the findings of the 'good language learner' ${ }^{5}$ which have indicated that successful learners pay attention to language form and also seek out opportunities for communicating in the L2.

The studies reviewed by Long (1983) served to raise a series of questions. Virtually no studies had been done at the time which included a description of the teacher and learner behaviour in the classroom.

Instruction was viewed globally and rather monolithically and Long himself raised this concern again when in another classic paper (1990) he compared the classroom to a 'black box' and made a call for more research to systematically describe instruction, practices and behaviours. Since then more research (as in the case of Spada 1987 and Montgomery \& Eisenstein 1985) has been carried out by researchers in different contexts, with different populations and in some cases from different perspectives. This research particularly addresses the question "are particular types of instruction more effective than others?".

As suggested by Ellis (1994) there is some evidence to support the thesis that formal instruction helps FL and L2 learners to develop greater L2 proficiency, particularly if opportunities for natural exposure are given.

The important question seems to be, not whether formal instruction 'per se' makes a difference, but whether types of FFI are more effective than others in SLA.

\footnotetext{
${ }^{5}$ The studies on 'good language learners' have proved to be a very sucessful way of investigating how strategies might affect language learning. In one of these studies Lennon (1989) indicates that learners' ability to switch to and fro in attending to meaning and form in language learners is a crucial feature of successful language learning.
} 


\subsection{Review of studies on the effects of particular types of FFI}

Some of the findings of classroom research (Savignon 1972, Montgomery \& Eisenstein 1985, Spada 1987) briefly reviewed in the previous paragraph seem to indicate that a type of instruction which includes attention to both form and meaning seems to be more beneficial to SLA than exclusive use of either one

In this section, studies carried out in an overall communicative context but where FFI is operationalised in different ways will be reviewed. Three main lines of research are identified:

- studies on the effects of an explicit type of instruction and corrective feedback

- studies on different types of input enhancement

- studies on the effects of consciousness-raising tasks

\subsubsection{Studies on the effects of an explicit type of instruction and corrective} feedback

In the 1980's a group of researchers at the University of McGill in Canada started a series of research projects with the intention of investigating whether different types of language instruction would have different or equal effects in language acquisition. Preliminary studies (Lightbown \& Paris 1986) were carried out with young francophone learners of English as a L2 enrolled in an intensive English programme in Quebec primary schools. Learners received intensive instruction all day for five days a week for a period of five months. This kind of instruction was highly communicative with virtually no attention to form and error correction.

An early observation of these learners' development in these programmes showed that although CLT contributed to their fluency and their confidence in using English, their language was characterized by many morphological and syntactical errors: these errors were highly frequent and similar among learners, due to the fact that they shared the L1.

Approximately at the time of this study similar research was under way in other programmes where learners' attention was focused on learning French as $\mathrm{L} 2$ in subject matter instruction. 
This type of research came about as a result of the criticisms the Monitor Theory had faced, over the last ten years, over the contention that comprehensible input is not the only element necessary to increase proficiency. Therefore there was concern among researchers that higher levels of accuracy or native-like language could not be achieved by second language adult learners whose unique experience in the second language is limited to such 'natural' contexts.

The Canadian-French immersion programme, which has been defined by Krashen (1982:170) as a 'communicative programme par excellence' since the emphasis is exclusively on meaning through instruction rather than form of the language itself provided further evidence that CLT does not lead to accuracy. Hammerly (1987) called 'the immersion programmes' a failure at linguistic level.

According to Hammerly these programmes have demonstrated that, while children learn to speak fluently and confidently, their accuracy is far below what one should expect from learners who have been exposed for several years to immersion programmes. First of all, both Higgs \& Clifford (1982) and Hammerly (1987) argued that L2 learners exposed to natural language acquisition or CLT without error correction and form focus will level off in their SLA.

One of the main disadvantages of a language learning experience which primarily consists of language use for communicative purposes, without attention paid to grammatical accuracy is, as Higgs \& Clifford pointed out, a situation where learners become relatively fluent and successful in terms of communicating the message, but produce consistently innaccurate grammatical and phonological forms of the language. Their apparent ability to communicate effectively in the spoken language is rarely matched in their scores in proficiency tests or in written work. These learners have become relatively successful in communicating using ungrammatical forms which become 'fossilized" ${ }^{6}$ and not amenable to change.

\footnotetext{
${ }^{6}$ Selinker (1972) has indicated that most $\mathrm{L} 2$ learners fail to reach target-language competence. 'Fossilization' refers to the fact that $\mathrm{L} 2$ learners stop learning while their internalized rule system contains rules different from those of the target system.
} 
These findings were related to the "changed " view on the role of FFI in CLT due to the concerns expressed by many instructors, over the last ten years on the exclusive implementation in the classroom of meaning-based instruction.

Among those expressing this concern are instructors who supported a CLT approach in the 1970s and 1980s and became disillusioned by the CLT experiment (see Harley 1989). These include also the instructors who refused to discard completely formbased instruction and sought to incorporate FFI in their communicative classroom. Harley (1989) observed that French immersion students attained a high level of functional practice in the L2 but continued to have problems with their accuracy. Harley investigated the effects of drawing learners' attention to the difference between the use of French imperfect and past simple. Among the theoretical positions relating to the role of formal instruction on L2 acquisition the case for FFI has strengthened.

In two studies, which deserve a more detailed analysis, by Spada \& Lightbown (1993) and White (1991) respectively, the following hypothesis was put forward: 'would FFI which included drawing learners' attention to the differences between L1 and L2 lead to a higher level of accuracy and development in learners?'

In these two studies the researchers targeted two separate linguistic features (questions and adverbs) that were likely to present a problem for these learners. This is due to the fact that these features work differently in English and French.

The students were provided with explicit information about how these forms work in English and how they are different from L1 learners and when they made a mistake, they were corrected. The metalinguistic explanation given to the students for nine hours over a period of two weeks was provided in a very simple way through easy pedagogical rules which could be easily comprehended and were accessible to the learners. The learners were tested on their knowledge of the use of these forms (use of adverbs and question formation) in pre and post-test measures.

In White's study (adverb placement) the conclusion was that FFI is more effective in helping learners to arrive at the appropriate properties of English than positive input alone. 
The instructed learners performed significantly better than the uninstructed learners immediately following the instruction, but their gains were lost in the long term. In the question-formation study (Spada \& Lightbown 1993) the instructed learners were also significantly better than the uninstructed after the treatment and they were also able to hold onto this knowledge over the long-term.

The type of instruction used in the two studies was the same but the effects were relatively different. White, Spada, Lightbown \& Ranta (1991) report on the extent to which FFI and EC contribute to learners' accuracy in question formation in a communicative programme. Two groups of francophone learners in grade five and six (aged 10 to 12) taking an intensive programme in English were studied. There were two groups, one instructed (receiving FFI instruction in question formation) and the other uninstructed. The findings on a pencil and paper post-test showed a significant difference in favour of the instructed group which was maintained in a follow-up test some weeks later.

Day and Shapson (1991) investigated the effects of a type of FFI which consisted of MI and EC (see next note for a definition of these two terms) in the use of the conditional with learners of French. Learners received explicit instruction on the use of the conditional over a six-week period.

In this study instruction showed positive effects (immediate and delayed effects) in a written task but not in an oral performance task.

Lyster (1993) carried out an investigation into whether controlled practice activities and corrective feedback over a five-week period contributed to learners' knowledge and use of sociolingistic style variations (this included the distinction between the use of the formal form 'vous' and informal 'tu' in French). The results of this study showed positive effects (particularly on young learners) for instruction (immediate and delayed effects) on productive and receptive tasks.

The overall results of this first line of classroom research reviewed in this section seem to suggest that a type of FFI, in a communicative programme, which consists of explicit information and lor corrective feedback may facilitate acquisition.

However some classroom research, which will be reviewed in the next paragraph, seems to indicate that less explicit approaches of FFI are also beneficial to SLA. 


\subsubsection{Studies on different types of input enhancement}

Considering the fact that a great deal of SLA takes place through exposure to language in the input, the effects of less explicit methods of FFI have been investigated in a second line of research. Doughty (1991) discovered that instruction, in the case of students at intermediate level taking an intensive course in English, had a positive effect on the rate of acquisition of relative clauses in English. This study supports the claim that there might be other ways of providing FFI.

In her attempt to ascertain whether different types of instructional procedures have a different effect on the acquisition of relativization in ESL, Doughty developed two different treatments. One treatment consisted of visual enhancement (capitalising and bolding the target features in the text) without any metalinguistic rule, and the other treatment consisted of visual enhancement + metalinguistic information.

The results of this study showed that learners benefitted equally from the two types of FFI and improved significantly more than a control group on immediate and delayed tests. Doughty's study is supported by Alanen's study (1994): a laboratory experiment investigating the acquisition of morphological features in a semi-artificial language.

One group received an enhancement treatment on the target feature while the other group received the same treatment together with the grammatical rule. The findings of this study showed no advantages for students who received grammatical rules in addition to the enhancement treatment.

This leads one to conclude that $\mathrm{MI}+\mathrm{EC}^{7}$ might not be necessary and that there might be other ways of drawing learners' attention successfully on how a target L2 works, and this is through an 'enhancement treatment'.

Doughty's findings support Schmidt's (1990) noticing hypothesis that claims that getting learners to attend to form in the input is the basic prerequisite for learning, and also the fact that there might be different but successful ways to get learners to 'notice' as suggested by Sharwood Smith (1991).

\footnotetext{
${ }^{7}$ Metalinguistic information refers to the explicit and technical information given about a target language. Error correction or 'feedback' as this term is more commonly used, refers to infomation given to the learners which they can use to revise their interlanguage.
} 
He has (1993) claimed that there are different ways of making input salient and different ways in which this might have an effect on the learner's knowledge and performance.

He distinguishes between 'negative enhancement' which consists of providing learners with information that a given form is incorrect (pointing out an error, making funny faces or offering a quizzical look when learners make an error, and 'positive enhancement' which could be achieved by simply boldfacing a form in a reading text so as to make it more salient.

The latter is the case in a recent study in which White (1998) examined the effects of typographical enhancement on the acquisition of possessive determiners in an English intensive programme. Three groups received a high level of exposure on personal pronouns and possessive determiners over a two week period. As described by White (1998:90) the three groups received three different treatment conditions: the first group received a typographically enhanced 'input flood' in addition to the extensive reading and listening; the second group received only the enhanced treatment; the third group received a typographically unenhanced 'input flood'.

The enhancement treatment was done through capitalising, bolding and italicising the target features in a reading text. No MI+EC was provided. The results showed that all three groups improved even if there were some short-term benefit. However, where the enhancement treatment was less explicit, the effects were not long-lasting . The overall results of this line of classroom research seem to indicate that a type of FFI which is implemented through different enhancement techniques (drawing learners' attention in meaningful ways to the use of target structures in context) may also facilitate acquisition. 


\subsubsection{Studies on the effects of consciousness-raising tasks}

A third line of classroom research is the one identified by Ellis (1991) who suggested that an alternative way of providing formal instruction is through 'consciousness raising' practice which differs from traditional language practice with regard to the fact that learners are not expected to produce the target structure. In consciousness raising practice learners are asked to understand the target structure by formulating some kind of cognitive representation of how it works. As pointed out by Rutherford (1987:24) consciousness raising cannot be compared to traditional instruction as traditional instruction is an attempt to instill a grammatical form in the learner. On the contrary consciousness raising does not instill anything as it assists the processes that underly acquisition. One main study (Fotos 1993) has been carried out to investigate the effects of consciousness-raising tasks on L2 learners. In Fotos's study one hundred and sixty Japanese university students of English as a foreign language participated in an experiment in which she investigated the amount of learners' noticing produced by two types of grammar treatment: consciousness raising treatment and traditional grammar lessons. The frequencies of noticing the target structure in communicative input one and two weeks after the grammar treatments were compared with the noticing frequencies of a control group. Three structures were chosen (indirect object placement, adverb placement and relative clause usage) on the basis that they are problematic for Japanese's learners of English. The consciousness raising tasks required learners to construct explicit rules from structured input data. The results of this study showed that the 'consciousness raising' group and the 'traditional grammar lesson' group were able to notice (three different tests were administered) the three structures in communicative input to a significantly greater extent than the learners in the control group. In her conclusions Fotos suggests that consciousness raising directed at specific structures results in learners being able to notice these structures in input. Furthermore, she also claims that this noticing may help retention of the structures. This study provides support for the effectiveness of grammar consciousness raising activities in promoting significant levels of noticing the target structures.

However this research remains very much untested and future research should seek to demonstrate that noticing structures in fact related to the emergence of the structures in learners' output. 


\subsection{Implications for this study}

The studies reviewed by Long (1983) showed overall a more positive role for instruction. However Long could not answer the question whether differences in type of instruction had a positive impact in SLA as there was no instructional data to describe the type of instruction operationalised in these studies at the time.

Since then a certain number of classroom studies have been carried out to investigate possible effects of different types of FFI within a communicative framework to explore the best way to integrate instruction. As a result of the overall findings of the three main lines of classroom research reported in this chapter the following implications for the present study are outlined:

1) first of all, the studies reviewed in this chapter (para 2.3.1) seem to support the view that a type of FFI that encourages learners to pay attention to the formal properties of language in a communicative context may facilitate acquisition. A type of FFI which is provided in the context of communicative instruction should aim at alternating a focus on meaning and a focus on form.

The overall results of these studies (see for example Lightbown \& Spada 1990) seem to show that in those cases where a focus on form component has been included in a CLT programme there have been positive benefits in terms of learners' knowledge and performance;

2) secondly, a type of FFI approach is more likely to succeed if rules are presented more explicitly. Explicit FFI might be particularly effective with young learners and in L2 classrooms which are communicatively-based, however some findings in classroom research (para 2.3.2) seem to indicate that less explicit approaches of FFI are also beneficial to SLA;

3) thirdly, the study reviewed in paragraph 2.3.3 seems to indicate that an effective way to integrate grammar instruction with the provision of opportunities for meaningfocused use of the target language is through consciousness raising activities in which instruction is aimed at developing explicit knowledge. 
The overall research on the effects of different types of FFI stimulates another question relevant to the role of FFI. Operating from Van Patten's model (see chapter three and four) which claims that instruction helps learners to build up a cognitive representation of the $\mathrm{L} 2$, the question is whether FFI would be more effective when provided via one modality or another (i.e comprehension vs production).

Van Patten has argued that a type of FFI which encourages learners to process information via comprehension practice is more effective than an approach which requires learners to produce target language utterances.

This new approach called by Van Patten 'processing instruction' will be presented in chapter four. Van Patten (1996:85) defined processing instruction as a 'manifestation of grammatical consciousness-raising'.

It is a type of explicit instruction whose aim is to get learners to attend to forms in the input as it is a prerequisite for acquisition, particularly if the instruction is directed at enabling L2 learners to establish form-meaning connections during comprehension.

In chapter four empirical studies on the relative effects of different modalities of instruction (comprehension vs production) will be reviewed in the attempt to support the view that 'processing instruction' is a very effective way to incorporate FFI in a CLT framework. 


\section{CHAPTER THREE: THE INPUT PROCESSING MODEL}

\section{Introduction}

In chapter one some empirical studies around the role and effects of grammar instruction on SLA have been examined and presented. Two of the considerations made were: that these studies were mainly carried out to seek an answer to the question as to whether or not instruction affects the route, rate and ultimate success of acquisition rather than how instruction might interact with the SLA process; second that the bulk of classroom research that has examined the effects of formal instruction on L2 learning dealt with learners' output. The purpose of this chapter is threefold:

1) firstly, to present a new avenue of research called 'input processing' - an investigation into the possible relationship between instruction and how learners process the linguistic data. As recently suggested by Ellis (1994), an explanation as to how instruction affects the language acquisition process is now needed;

2) secondly, the characteristics and the principles of the input processing theory will be illustrated;

3) finally, a number of stages involved in converting input into acquisition will be identified. This will include a discussion on the processing strategies one of which has been specifically investigated in this study. This chapter will provide the general background for this investigation in two ways: by presenting the input processing model and by providing some evidence for one strategy used by L2 learners to process input.

\subsection{From the bindinglaccess framework to a model of input processing.}

Cadierno, (Cadierno 1995:180) has pointed out that research in SLA has been mainly concerned with whether or not instruction has an effect on different aspects of language acquisition neglecting the fundamental questions of why and how instruction would make a difference in SLA. 
Therefore, one possible way of researching the causes of the effects of instruction on SLA is to look at the interaction between instruction to which learners are exposed and the way learners process input.

Terrell (1991) has examined a possible interaction between grammar instruction and the acquisition process itself and has proposed a bindinglaccess model.

He has proposed this framework in order to determine the possible contributions of instruction in the acquisition process. According to Terrell (1991:53) explicit grammar instruction is 'the use of instructional strategies to draw the student's attention to or focus on form and/ or structure'.

He has indicated the need to examine the process and the product involved in acquisition. He posits (Terrell, 1991:56) two main questions:

1. 'what psycholinguistic processes are utilized in input processing?'

2. 'how is the resulting information organized and accessed by the learner?'

Terrell has acknowledged that the primary source of acquisition is the input and he has defined (Terrell 1986:220) acquisition as 'the ability to comprehend and to produce meaningful utterances in the target language'. He has suggested in a later paper (Terrell 1991:56) that acquisition 'consists of at least two paired components: 'comprehension strategies and binding and production strategies and access'.

Terrell has described the ability to understand utterances in the input as characterised by two components:

1. the use of strategies to make sense of unknown forms in the input;

2. the association of meaning with new forms.

This latter component is defined by Terrell with the term 'binding'. With this term he is proposing to describe the cognitive and affective mental process of linking a meaning to a new form in the target language. This process might be complex, particularly in the case of, for example, acquiring the Italian adjectives bello $\backslash$ bella (beautifullmasculine or beautifullfeminine). 
Learners have to bind both words to the concept 'beautiful' and in addition the word bello must be linked to the grammatical concept 'masculine' and the word bella to 'feminine'. L2 learners have to access these words so that bello is used to describe masculine nouns and bella used to describe feminine nouns.

L2 learners have to posit a grammatical connection of gender between bello and bella and between each of the two adjectives with other masculine or feminine adjectives.

The production of an utterance also involves two components:

1. the ability to express a particular meaning with a particular form, which is called 'access';

2. the ability to string forms together in an appropriate way, which as Terrell (1986:215) claims involves 'production strategies'.

Terrell's framework which includes these two notions of binding and access provides a possible explanation as to how a form is acquired in the target language. He defined the acquisition of a form 'as establishing a connection between concept and form' (Terrell 1991:57). In order to talk about meaning-form relationship, as in the case of adjectives in Italian, linguists use a metalinguistic explanation and speak of semantic and grammatical rules. In the case of Italian, adjectives must be made to agree in gender with the nouns they modify. In the binding-access framework, the cognitive processes which take place during speech comprehension and production are different from the concept of rule use. According to this view, the acquisition of forms consists of the positing and storing of pairs of meaning-form relationships and the restriction placed on the appropriate access of these forms to express an intended meaning. What learners must perceive and store during the acquisition process are not the grammatical rules, but single and correct meaning-form pairs. Consequently, as pointed out by Terrell, the ability to generalise patterns to new forms and contexts is not due to learners' having formulated (subconsciously) a rule, but rather is based on a network of meaning-form associations. According to this view, L2 learners may understand the concept of a given form, but acquisition depends on positing meaningform connections for individual items. 
Terrell (1991:58) proposes three essential steps taken by learners to acquire a complex morphological form ${ }^{8}$. These three steps are (as follows):

1. isolation of a given form;

2. ascertaining its meaning;

3. establishing associations between the two.

This is clearly the learner's task when he is confronted with 'input', however the question arises: what is the role of explicit instruction?

Krashen has argued that learners do not need explicit instruction to acquire a target form if they receive enough comprehensible input in a low anxiety environment. This does not reflect the context in a typical foreign language course at University where students receive only between 70 to 100 hours of exposure to the target language a year. Therefore, it is not clear whether given this small number of hours of exposure most grammatical morphemes would appear in the input often enough to permit complete binding. Terrell seems to draw on some emprical research (see para 1.2.1) carried out on the effects of formal instruction in SLA which shows that explicit instruction might help to speed up part of the acquisition process.

Terrell (1991:60) has suggested three ways in which explicit grammar instruction might indirectly support and affect the normal acquisition process:

1) as an advance organizer by giving learners information about some forms and structures of a target language that will help them to process input. This could be achieved by providing comprehension strategies that highlight key grammatical elements that learners should pay attention to and use of appropriate gestures and visuals.

Terrell offers an example of advance organizers for college-level learners which refers to the Italian person-number verb morphemes:

\footnotetext{
${ }^{8}$ a definition of 'complex morphological forms' will be given on page 45
} 
Italian adds endings to its verbs to tell you who is doing the action. For example the verb parlo ends in -o and means I speak while parliamo ends in -iamo and means we speak.

At first you will want to concentrate on listening for the verb stem to understand what someone is saying to you. Later you will find these endings are quite helpful in understanding exactly who is doing what.

2) as a meaning-form focuser for complex morphology, which can help the learner to establish a meaning-form relationship for morphologically complex forms.

By a morphologically complex form, Terrell means forms non salient or non- essential for understanding the meaning of an utterance. This is the case of many inflections. Inflections marking grammatical meanings such as tense are redundant since they are usually accompanied by temporal adverbs which indicate the temporal reference. Due to the high perceptual saliency of these temporal adverbs, learners tend to pay more attention to the adverb marker of a given sentence and ignore the grammatical tense verb morphemes.

For example, if the learner knows the Italian word for 'domani', then in the utterance domani incontrero' Paolo al bar, the future tense is a redundant future marker.

Furthermore, since 'domani' has marked the sentence as future, the future markers on subsequent verbs are also redundant.

Terrell provides some suggestions to how instruction might help to make redundant and non-salient grammatical meaning-form relationship salient in learner's input.

Terrell underlines two requisites: first of all we should provide a meaningful input and secondly that the input should contain many instances of the same grammatical meaning-form relationship. An example from Italian (present tense first person verb form ending in $o$ ) of Terrell's instructional technique would be the following: I am going to describe a typical day in my life, notice that all verbs I use end in -o ( Italian uses this ending to refer to the speaker).

'La mattina mi alzo e faccio colazione. Poi alle nove prendo la macchina e porto mia figlia a scuola. Dopo vado all'Universita 'dove lavoro tutto il giorno......'. 
The question asked by Terrell (1991:60) is 'does this concentration of many examples of a single meaning-form relationship in one activity result in the students being able to focus on meaning and form at the same time?'

Van Patten (1990) has provided some evidence to suggest that particularly early-stage learners do not find it easy to attend to both meaning and form in the input. As a number of scholars have pointed out (Van Patten \& Cadierno 1993 b, Hulstijn 1989) L2 learners must attend to linguistic features in the input as well as to messages. However, excessive demands should not be put on learner's attentional resources.

In Van Patten's study three levels of Spanish learners at University level in four groups were asked to process information under four conditions:

a) simultaneous attention to meaning and an important lexical item

b) simultaneous attention to meaning and a grammatical function

c) simultaneous attention to meaning and a verb form

d) attention to meaning alone

It has to be remembered that the observations made by Van Patten concern the processing of grammatical morphology in the input. However, the results showed that, as pointed out by Van Patten (1990:296), 'conscious attention to form in the input competes with conscious attention to meaning, and, by extension, that only when input is easily understood can learners attend to form as part of the intake process'.

The results of Van Patten's study are echoed in Terrell's paper (1991) in which he suggests a remedy to make learners attend to grammatical markers. He claims that only when learners are familiar with the major lexical items in the input are they able to process the grammatical markers. He suggests that in a grammatically focused input activity the lexical load should be light so that students do not have to expend much process time in general form-meaning access. Terrell (1991:60) concludes that instruction with little lexical load coupled with a high frequency of a single meaningform relationship would result in helping learners to pay more attention and process non-salient, redundant grammatical forms. 
3) as a monitor', to improve learners' accuracy. This is the only role that Krashen has attributed to instruction. However, Krashen has underlined that is quite difficult to monitor one's speech in normal and spontaneous conversation. Terrell (1991:61) suggests that monitoring would aid the learner not only to produce more accurate sentences but also to interact with acquisition. This is justified if we consider the fact that learners' own output can serve as input to the acquisitional process. This is also supported by other scholars (Sharwood-Smith, 1981). Terrell seems to support the 'facilitative position' since grammar instruction is seen by him as an aid to the learner in the acquisition process. Grammar instruction can make some forms more salient and help learners to establish correct meaning-form connections. As he suggested, the learners seem to work on an internal schedule when it comes to grammatical developments. Therefore to investigate the role of instruction in SLA we should seek to explain the psycholinguistic processes utilized in input processing. To that extent, Terrell's proposal is closely linked to input processing theory.

Van Patten has proposed a similar role for instruction in the acquisition process, as instruction can make certain grammatical forms more salient in the input and help learners to establish correct meaning-form connections.

Despite the fact that Van Patten recognizes the essential role of input in L2 acquisition, he takes the view that form-focused instruction or information provided via input modes can be beneficial. This is in opposition to Krashen's view (Krashen, 1985:10) who suggests that comprehensible and meaning-bearing input should not be grammatically or form focused.

Van Patten's model of acquisition (Van Patten, 1996:7) process is characterised by three main phases as depicted in figure 3.1( adapted from Van Patten, 1996:41).

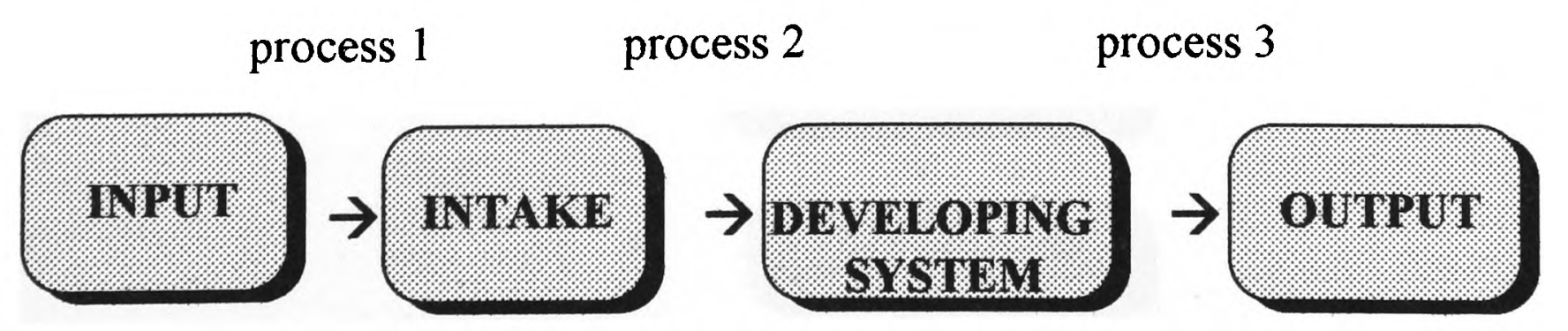

figure 3.1 Van Patten's model of acquisition

\footnotetext{
9 'Monitoring' is the process used by L2 learners to correct the mistakes they make.
} 
As discussed by Van Patten (1996:8) what learners do to input during comprehension, which is how intake is derived, is called input processing (process 1 ).

Intake is what learners have perceived and processed in the input. Initially, only a portion of the input is processed due to processing limitations. This, from a psycholinguistic perspective, is explained by the fact that input does not automatically enter learners' brains during their exposure to it. Learners filter input through internal processors they possess. The second process (2), implies all those processes to allow the intake to become acquired. Although it is not the focus of the present study, those processes involved in the incorporation of intake into the developing system are called 'accommodation' and 'restructuring'. The third process (3) consists of a set of processes that acts on the acquired L2 system and determines what is available at a given time for productive use. Only part of the input is passed through intake into the developing system and eventually into output by the learner. The recognition of the essential role of learners in processing input and intake has raised a number of questions on the nature and role of input processing. One question is: 'can input processing be manipulated, altered or enhanced in order to make intake grammatically richer?' Central to our discussion is the development of processing principles that offer an answer as to how learners derive intake from input. Changing the way learners process input might have an effect on the developing system that subsequently should have an inpact on how learners produce the L2. Van Patten's model shares some common characteristics to the model put forward by Gass (1988) who presents a five-stage model from ambient speech to output (see figure 3.2 adapted from Gass 1988:200).

stage 1

stage 2

stage 3

stage 4

stage 5

figure 3.2 Gass five stage model
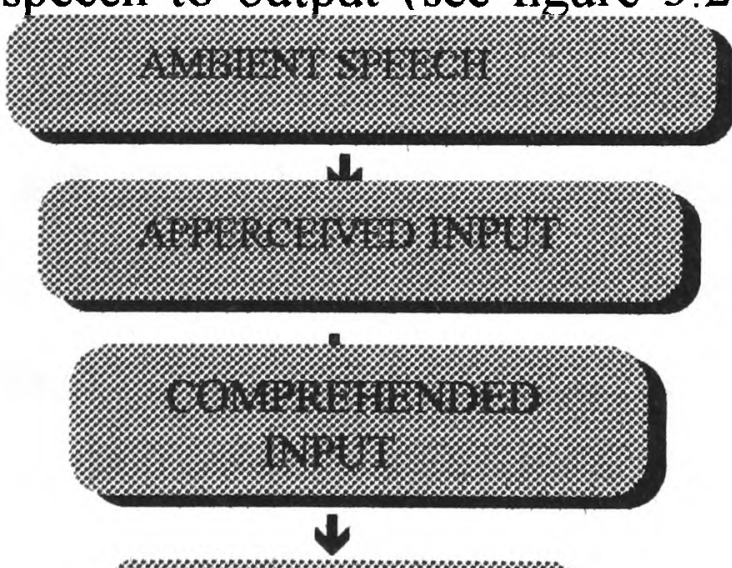

1.1.

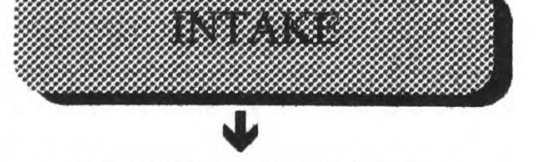

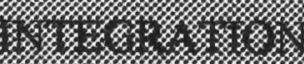

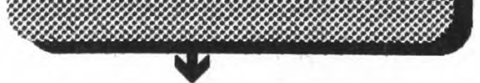

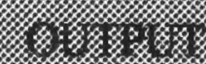


Ambient speech refers to the input L2 learners are exposed to. However, as in the case of Van Patten's model not all the language data is available and utilized by the learner.

Some of the data is noticed ${ }^{10}$ and some not. As pointed out by Gass (1988:202) the first stage of this model (apperceived input) represents a phase in which 'a bit of language is noticed in some way by the learner because of the saliency of some particular features'. However, not all input that is 'apperceived' is 'comprehended' by the learner (stage two).

In stage 3 the separation of comprehended input from intake takes place since not all the input which is comprehended by $\mathrm{L} 2$ learners becomes intake.

In stage four (integration stage) Gass indicates two possible outcomes: the storage of the grammatical information and the development of one's L2 grammar.

The final stage (output stage) represents the availability of acquired L2 knowledge for productive use.

The first thing in common between the two models (Gass \& Van Patten) is that they both show a progressive reduction in the amount of information processed, as (in the case of Gass) is evident graphically in figure 3.2. Secondly, in both models, acquisition is viewed as several interrelated processes rather than a single one. Thirdly, both models emphasize the fact that learner's interaction with the input is the point of departure for acquisition to take place.

In the input processing theory that will be examined in the next paragraph the psycholinguistic aspect of SLA will play a key role, as studies have examined how learners process and make use of the input to create linguistic systems and strategies that L2 learners use to decode and store linguistic information .

${ }^{10}$ noticed is used in relation to the fact that some features are noticed by the L 2 learners in the input because of their saliency. 


\subsection{The input processing theory.}

The psycholinguistic aspects of input and input processing have been investigated in recent years from an information processing perspective. At the heart of this theory, which has drawn from cognitive psychology (of which the main focus is systeminternal factors), is the concept of the brain as a central processor of information and of the human being as a limited capacity processor.

As claimed by Shiffren \& Schneider (1977) the brain can process a limited amount of information and this is due to constraints at different levels: working memory, levels of accessibility to stored knowledge and attentional capacity.

Recently, information processing theory has been applied to SLA as input processing theory (McLaughlin 1978,1987, McLaughlin, Rossman \& Mcleod 1983, Van Patten 1990, 1996). This research has focused on issues such as how learners process input, what part of the input becomes intake, an insight into the processes involved and strategies used by learners to decode and store linguistic information and finally the role of attention required. According to McLaughlin, Rossman \& Mcleod (1983) the limitations that exist on how people process information can be described along two dimensions. First of all, the way learners focus their attention. Learners tend to select their attention when processing input. This is required by the limited capacity of our mind to process information and determined by the demands of the particular processing task. Secondly, the information-processing ability of the individual learner. As the amount of attention required varies according to the type of task, the knowledge and experience of the learner will impact on how input will be processed. Two modes of information processing have been defined: controlled and automatic.

Shiffrin \& Schneider (1977) claim that a task sometimes requires a great amount of processing capacity or it can demand little processing capacity and proceeds automatically.

They also view memory as a large connection of nodes that become associated through learning. These nodes become activated in two ways: through automatic processing or controlled processing.

Automatic processing is unconscious and makes little demand for attention, however controlled processing, as claimed by McLaughlin (1983:139) 'involves the activation of certain nodes in memory every time the appropriate inputs are present'. 
Given the fact that humans are limited in their information-processing abilities, the attention they give to complex tasks is limited.

In the framework of input processing, attention is a crucial construct. It has been examined in both $\mathrm{L} 1$ and $\mathrm{L} 2$ research and in L1 acquisition Slobin (1985) has argued that the only linguistic 'materials' that can be acquired and can certainly attract L2 learners attention is the one noticed and held in memory.

Therefore, for data to become part of learners' linguistic system, learners have to 'attend"11 to the language data. Schmidt (1990) has argued that L2 learners require attention to the forms in the input, otherwise acquisition will not take place. Learners must attend to a form in order for that form to become intake.

He claims that ' you can't learn a foreign language through subliminal perception' (1990:142). Schmidt claims that as far as input processing in SLA is concerned, adult learners have to pay attention to form in the input in order to acquire a foreign language.

Tomlin \& Villa (1994:192) have recently defined the construct 'attention' by identifying three main components:

a.alertness, which represents learners's readiness to deal with incoming stimuli;

b. orientation, which is the specific aligning of attention to a stimulus;

c. detection, which is 'the process that selects, or engages, a particular and specific bit of information'.

As underlined by Schmidt (1994) detection is a sub-process of attention and can be defined as identical to the construct known as focal attention.

According to Tomlin \& Villa (1994) detection is a very important construct as it constitutes the process by which data are registered in working memory and is what makes a particular piece of data available for further processing. It is not enough that learners simply attend to data: particular data have to be detected for acquisition to take place.

11 'attention' is a very important construct for acquisition to take place. Researchers in cognition believe that people do not learn unless they attend the stimulus to be learned. 
In this sense detection is the aspect of input processing more directly related to the derivation of intake. Detected information would be available, for instance, in the case of memory-based tasks such as identifying temporal reference of an event described. Two of the features of detection are crucial: 'information detected causes great interference with the processing of other information' and 'information detected exhausts more attentional resources than orientation of attention' (1994:192).

As previously discussed, (McLaughlin, Mcleod \& Rossman 1983) humans are limited in what they can pay attention to in a given point of time. What Tomlin \& Villa (1994) suggest is that if a piece of data is attended to by a L2 learner the internal processors might not detect all of the linguistic data.

Van Patten (1996:17) has suggested that the central issue for SLA is 'how learners' internal processors allocate attentional resources during on-line processing'.

Therefore, the question to be asked is what causes certain stimuli in the input to be detected and not others? The input processing capacity of L2 learners is limited as only certain features will receive attention at any given time during the processing of a sentence. Van Patten (1996) has identified some strategies used by learners to decode input and he has addressed the question of which features learners attend to in the input and if attention is directed in a principled way.

Van Patten (1996:14-15) has proposed a set of principles concerning what learners attend to in the input. He has indicated two main principles of which the first one is composed of three corollaries. The two principles are:

P1. learners process input for meaning before they process for form;

P2. for learners to process form that is not meaningful, they must be able to process informational or communicative content at no or little cost of attention.

For the present study the first principle is very relevant and is presented by Van Patten in the following corollaries: 
a) learners process content words in the input before anything else;

b) learners prefer processing lexical items to grammatical items for semantic information;

c) learners prefer processing 'more meaningful' morphology before 'less' or 'non meaningful morphology'.

Overall the first principle which states that learners are driven to look for the message in the input before they look at how that message is grammatically encoded, is consistent with the observations by other researchers, in particular Sharwood-Smith (1993) who argues that adult second language learners' attention is directed towards meaning when they are processing input.

The question addressed by Van Patten $(1996: 18)$ is: when the learners aim to extract meaning from the input, 'which apects of the input will aid them'?

As indicated both by Sharwood-Smith (1986) and Van Patten (1990), learners will be directed toward the detection of content words in order to grasp the meaning of an utterance. Early stage learners will use words as building blocks of meaning. The first corollary (a) is borne out in first and second language research. Evidence in L2 research comes from both an introspection study (Mangubhai 1991) and experimental studies (Hulstijn 1989, Van Patten 1990, Bransdorfer 1991).

In particular Van Patten (1990) has shown that learners can be directed to attend to the key lexical items without loss of propositional content when processing input but cannot be directed to attend to grammatical markers without loss of propositional content. This evidence has been supported by a subsequent study carried out by Bransdorfer (1991) on the Spanish copular verbs 'ser' amd 'estar'.

In the second corollary ${ }^{12}$ (b), Van Patten claims that learners prefer processing lexical items to grammatical items (e.g. morphology) for semantic information. This principle is a direct consequence of the first principle (a) proposed by Van Patten.

A great number of grammatical features encode some kind of semantic information. In the case of verbal inflection the Italian verbal inflection ato encodes past as in parlato.

\footnotetext{
12 this principle has beeen explained in para 3.1,although from a different angle, when the concept of 'morphologically complex form' was analysed.
} 
However, this semantic notion is also expressed in Italian by words such as 'ieri' or 'l'anno passato'. Given, as postulated in the first corollary (a), that learners are driven to process content words before anything else, they would attend to temporal reference of 'pastness' before verbal inflection of the past tense.

This corollary (b) has received support from two types of evidence in second language research. This evidence will be presented in the next section in which we will focus on this strategy used by L2 learners, as it is relevant to the present study.

In the third corollary (c) Van Patten (1996:24) suggests that it is the relative communicative value of a grammatical form that plays a major role in determining the learner's attention to it during input processing and the likelihood of its becoming detected and thus part of intake'. Van Patten has stated that L2 learners prefer processing more meaningful morphology rather than less or nonmeaningful morphology.

Communicative value refers to the contribution made to the meaning of an utterance by a linguistic form. In order to establish whether a linguistic form has low or high communicative value, we need to follow two criteria:

1. inherent referential meaning

2. semantic redundancy

Inflections on adjectives $(o \& a)$ in Italian are low in communicative value because they are redundant and lacking inherent semantic value. As we mentioned previously, 'la penna rossa', rossa ends in - $a$ - because it is feminine and does not carry any semantic meaning in this sentence. In addition $-a$ - is spread across three words in the noun phrase, making it highly redundant.

This corollary (c) was positively tested in a study by Bransdorfer (1989) in which he tested the subject's ability to process meaning and form simultaneously in the preposition de or the definite article la in Spanish. 


\subsection{Evidence for the primacy of lexical items over grammatical markers during input processing}

The lexical processing strategy suggests that 'learners prefer processing lexical items to grammatical items for semantic information' (corollary b. from Van Patten). According to Van Patten (1996:21) this is a strategy used by early stage learners who give precedence to adverbials of temporal reference over morphological markers when interpreting tenses. This strategy is well documented by both empirical studies (Musumeci 1989, Cadierno \& Glass 1990, Lee, Cadierno, Van Patten \& Glass 1997) and research into the acquisition of tense (Bardovi-Harlig 1992, Klein 1986). The studies on the acquisition of tense have focused on how tense is first encoded in learner's output, and have shown that tenses can be encoded in two ways: through lexical items or expressions (today, tomorrow...); or through grammatical forms (I will go, I went...). This research has provided evidence that learners typically mark time early in the acquisition of verb morphology through lexical items (oggi, domani...) and only subsequently add verb tense markings.

The empirical research carried out by Cadierno, Glass, Lee \& Van Patten (1991) reports on the effects of providing L2 learners of Spanish with two types of discourse level input - one listening passage in which temporal adverbials were present and one in which they were absent.

The results showed that the group who received the lexical item in the passage performed better in term of recognising the temporal reference of an event (present, past or future) compared to the other group who received verb inflection only. The results of this empirical research are also important considering that it cannot be dismissed on the grounds that the grammatical items investigated are 'nonsalient' as, in Spanish, verb morphemes are syllabic and receive strong stress.

Musumeci (1989) has conducted a crosslinguistic study in which she examined the ability to assign tenses at sentence level under different conditions.

She predicted that the group of learners receiving a lexical marker of tense in the input would perform better than a group which did not. She also hypothesised that the presence or absence of a temporal adverbial would be the main factor for learners to be able to assign tenses correctly. 
In Musumeci's study, learners of Italian, French and Spanish were asked to assign tense to input sentences. Learners had to indicate whether what they heard and saw referred to the present, future or past. The input was delivered orally through four conditions:

1.verb morphology + adverbs of time

2. verb morphology + teacher physical gestures

3. verb morphology + adverbs + gestures

4. verb morphology only

Overall, the results of an assignment task administered to L2 learners at different proficiency level, were very clear as the main factor determining correct tense assignment was the presence or absence of temporal adverbials in the input sentences (Musumeci 1989:127). The presence or absence of the lexical item generally affected early-stage learner's performance. However its effects were not identical across tenses for each language group.

Another general finding of this study (Musumeci 1989:128) is that the inclusion of the lexical item at sentence level seemed to have the most effect on learners performance on future tense (across the three languages targeted in this study).

In the case of Italian, cues to tenses such as temporal adverbials provided in the input in addition to verb morphology had positive effects in facilitating learners' ability to assign tenses.

According to Musumeci (1989:150) learners tend to rely on lexical items to indicate tense but only when the verb morphology does not appear to be a reliable cue. Italian might provide learners with certain phonological and morphological characteristics in a L2 which might effect learners' ability to assign tense as in the case of the final accented vowel ( $\dot{a}$ and $\dot{o}$ ) on the Italian future tense. 
This is supported by the 'operating principles' ${ }^{13}$ (Slobin 1985, Peters 1985) theory according to which there might be some morphological endings or phonological properties more salient to learners than others. However Musumeci's study revealed that early stage learners use lexical items in order to assign tense and she suggests that lexical items provided in the input improved significantly learners' ability to assign tenses. This is also proved, in Musumeci's study, in the case of the Italian future tense by first semester learners (Musumeci 1989: 90) ${ }^{14}$.

In addition to that, Musumeci points out that learners appear to assign tenses on a binary option (present vs future) ${ }^{15}$ with present tense a constant option. In the case of Italian, Musumeci identifies a pattern used by L2 learners to assign tenses on the basis of present lpast or presentlfuture but not pastlfuture. In a morphology recognition task first semester learners of Italian were not able to distinguish between present and future tense. The purpose of the morphology recognition task in Musumeci's study was to examine the relationship between learners' ability to recogize tense in a paper and pencil test and their ability to interpret sentences in order to assign tense. As already stated the scores of the Italian first semester learners for future tense showed that future tense was the most difficult tense for learners to interpret. Musumeci (1989:125) concluded that a hierarchy exists across the four features investigated with feature number 1 (verb morphology + adverbs of time) being the easiest and feature number 4 (verb morphology only) the most difficult.

This is evidence that the presence or absence of the lexical item might affect learners' assignment of tense, and subsequently it was proved that this effect is significant for early-stage learners and not for later-stage learners.

\footnotetext{
${ }^{13}$ According to Peters (1985) morphemes are more salient to early stage learners when they are both phonologically distinct and consistent. According to the operating principles an accented final syllable is a highly salient position. In Italian the morphological ending to mark the verb as 'future' is different for each grammatical subject.

Therefore, the morphological marking is not consistent as it is in the case of the Italian past participle.

${ }^{14}$ According to Musumeci (1989:156) processing for tense is affected by the presence or absence of lexical cue for tense at early stages of language development but this effect is less evident at later stages.

${ }^{15}$ The data collected by Musumeci showed a difference in learners' performance by tense which provides a hierarchy of difficulty level, from present tense (least difficult) to future tense (most difficult).
} 


\subsection{Implications for this study}

In this chapter, two models (Van Patten 1996 \& Gass 1988) which have stressed the link between input processing and acquisition have been identified.

In view of the important role of input processing, the main purpose of the present study is to carry out an investigation on the effects of a particular type of instruction on how L2 learners process the input linguistic data.

More specifically, this study aims to investigate whether one effective way to improve SLA is by altering the means by which L2 learners process input. The two empirical studies mentioned previously (in para 3.3) provide evidence of a common strategy used by early-stage L2 learners in processing tenses. The results of these classroom studies (Cadierno, Glass, Lee \& Van Patten 1997 and Musumeci 1989) and the studies carried out by by Sharwood-Smith (1986) and Van Patten (1990) indicates that learners' focal attention during input processing is on meaning and precedence is given to lexical items for the conveyance of that meaning.

As a result of what has been said in this chapter some pedagogical implications for instruction in a processing framework will be also drawn.

First of all, instruction should take into account the psycholinguistic processes used in input processing. Therefore it should take into consideration strategies followed by learners to process input. In practical terms, instruction should provide learners with comprehension strategies to help learners to establish accurate meaning-form connections. This concept, as will be shown in the next chapter, is different from the concept which underlies output-based instruction.

Considering the important role of input processing in SLA, manipulating learners' input should have a greater impact on their developing system. Therefore instruction within a processing framework would aim to alter strategies used by learners when processing input. In the case of the lexical processing strategy, this new approach to grammar instruction called 'processing instruction' can affect the acquisition process as a meaning-form focuser for complex morphology.

This also implies that, first of all, learners will receive a more meaningful input, and secondly that learners will be provided in the input with many instances of the same grammatical meaning-form relationship. 
In the next chapter these pedagogical implications for instruction and the main characteristics of processing instruction will be presented

The empirical studies on the effects of 'processing instruction' on the acquisition of some features of the Spanish linguistic system will be reviewed. 


\section{CHAPTER FOUR: REVIEW OF STUDIES ON THE EFFECTS OF PROCESSING INSTRUCTION}

\section{Introduction}

In the present chapter the pedagogical implications for instruction in the processing framework presented in the previous chapter will be discussed. First of all, the characteristics of processing instruction will be examined. This is in order to provide some background to the instructional treatment researched in this study and other empirical studies on the effects of processing instruction. Secondly, empirical studies of the effects of processing instruction will be reviewed and in relation to some of the results of previous research the main contributions of the present study will be outlined. Thirdly, the research questions as well as the hypotheses that will guide this study will be formulated.

\subsection{Processing instruction: a comprehension type of grammar instruction}

One of the main implications for instruction drawn from the previous chapter in an input processing framework is that it should take into account the psycholinguistic processes utilized in input processing (strategies and mechanisms used by L2 learners to process input). One of the questions addressed by scholars who have carried out research on the effects of instruction from a processing perspective is: 'can input processing be manipulated, altered or enhanced in order to make intake grammatically richer?' This question has directly led to the development of the type of approach called 'processing instruction', whose main aim is 'to push to get L2 learners to make form-meaning mappings in order to create grammatically richer intake' (Van Patten 1996:55), through structure input activities. Another important reason for the development of this approach to grammar instruction is the one outlined by Van Patten (1996:8) which concerns the open criticism of the traditional, output-based approaches to grammar instruction. Despite the fact that language classrooms are becoming more and more 'communicative' the way grammar is presented is still very traditional. It consists of grammatical explanations (paradigmatic presentation) followed by output practice (grammar rules and paradigms). The output-led path is still of central importance in foreign language courses at Universities, despite the fact 
that one can assume that pedagogical principles and practices should reflect theory and research in SLA.

Unlike traditional instruction ${ }^{16}$ where the focus of instruction is in the manipulation of the learners' output to effect changes in their developing system, input processing aims to change the way input is perceived and processed by language learners.

As pointed out this approach to grammar instruction is consistent with the input processing perspective in SLA. In figure 4.1 and figure 4.2 the arrow goes from left to right indicating the different processes in SLA. It is therefore evident, that processing instruction (see figure 4.2) in its attempt to alter the way L2 learners process input should have a greater impact on learners' developing system than an output-based approach to grammar instruction (see figure 4.1) whose aim is to alter how L2 learners produce the target language. Unlike output-based instruction which emphasised grammar rules and orallwritten production practice, the purpose of processing instruction is to alter how learners process input and to encourage better form-meaning mapping that results in a grammatically richer intake. In the case of tense markers, processing instruction can make these redundant and non-salient grammatical meaning-form relationships more salient in the learner's input. Given the emphasis on learners' input rather than focusing in on the output, the type of practice provided by the processing instruction approach consists in activities which offer the opportunity to interpret meaning-form relationship correctly without any practice in producing the targeted form or structure. This is accomplished (as also suggested by Terrell 1991) by providing learners with meaningful input that contains many instances of the same grammatical meaning-form relationship.

${ }^{16}$ In most of the traditional approaches to grammar instruction L2 learners are given an explicit explanation of the rules of a formistructure of a target language, and then they practise these rules through various output exercises. Paulston (1972) has described a typical sequence of oral grammar practice in which mechanical practice precedes meaningful and communicative practice. This hierarchy reflects the way grammar and practice is still taught in the foreign language classroom, despite language classroom becoming more and more communicative. 
This seems to be a step forward compared to Sharwood-Smith's position (1993) according to which, a way to provide formal instruction is to make some forms more salient in the input so that they come to learners' attention. Processing instruction does this but it also provides opportunities for form-meaning mapping in activities.

As outlined by Van Patten (1996: 84) 'simply bringing a form to someone's attention is not a guarantee that it gets processed..... for acquisition to happen the intake must continually provide the developing system with examples of correct form-meaning connections that are the results of input processing'. Processing instruction, contrary to 'negative enhancement', does not address the role of output errors since it is solely concerned with the processing of input data.

Processing instruction might be considered, as mentioned earlier, as a type of 'consciousness-raising'; in the sense that as indicated by Van Patten (1996: 85) it 'does not seek to pour knowledge of any kind into learners' heads; it assists certain processes that can aid the growth of the developing system over time'.

However, the ultimate scope of processing instruction is not about raising learners' consciousness about a grammatical form but rather to enrich learners' intake.

Processing instruction is as Van Patten (1997) claimed: 'a psycholinguistic motivated approach to focus on form' whose main aim is to teach grammar without sacrificing either communication or learning-centred activities and ultimately gets learners to practise grammar.

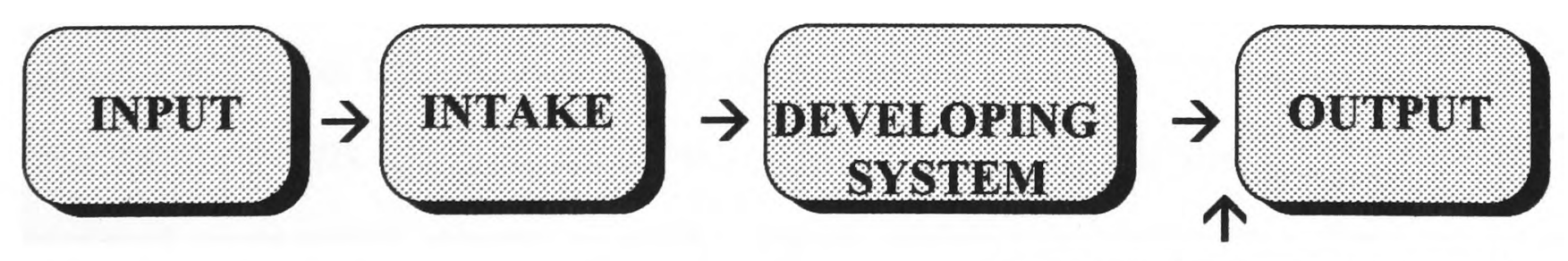

(figure 4.1 Output-based instruction that output-based practice focuses on output) 


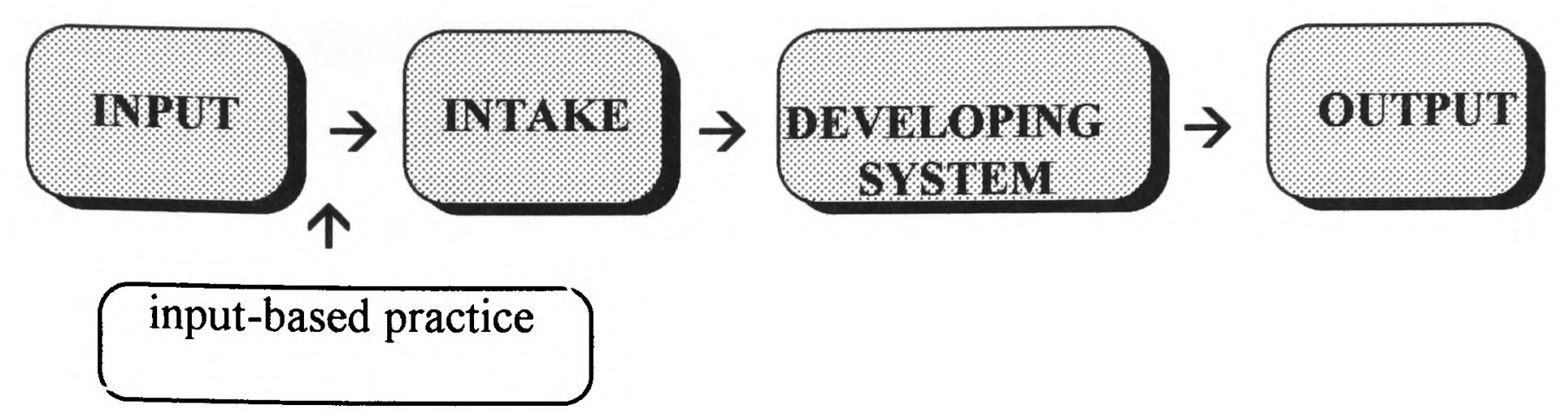

(figure 4.2 Processing instruction that focuses on input)

In fact the type of input L2 learners receive in processing instruction is meaningful as it should help them to make correct meaning-form connections. The key components of processing instruction are the following:

1. to provide subjects with some information about processing strategies used by L2 learners. Learners receive a clue in processing instruction about paying attention to form in the input. In the present study, for instance, students were told how to pay attention to tense cues in the input by the tutor's explaining to them how the future tense is formed and reminding them that the appearance of accent marks in Italian indicates strong stress on the final vowel, the $\grave{o}$ and $\grave{a}$ in Italian marking the future for the 1 st and 3 rd person singular. This is a good clue to recognizing the future tense particularly considering the fact that processing instruction is directed at altering the ways in which the L2 learners process L2 input (lexical strategy);

2. to explain the relationship between form and meaning of linguistic features. An explanation (some information about grammatical form) of the relationship between a given form and its meaning is given. This is a focus on form approach, therefore structural properties about a grammatical form are given, by linking form and meaning;

3. to use structured input activities. Structured input activities consist of a type of practice in which learners process form in the input in a controlled situation so they are able to make better form-meaning connection. 
Input refers to the fact that during the activities learners do not produce the target grammatical form, but they are engaged in actively processing input sentences. The term 'structured' refers to the fact that input has been manipulated in particular ways. Van Patten \& Sanz (1995) have produced guidelines for structured input activities. Some of these guidelines (adapted from Van Patten \& Sanz 1995) have been used (some variations in their application was made) to develop structured input activities in the present study:

1. paradigms and rules should be broken down into smaller parts and taught one at the time during the course of the lesson. In the case of the present study subjects in the processing instruction group were presented with the third person singular future tense verb in Italian and work through some structured input activities before moving to another person;

2. learners should be encouraged to make form-meaning connections through structured input activities. As pointed out by Van Patten (1996:68) 'if meaning is absent or if learners do not have to pay attention to meaning to complete the activity, then there is not enhancenent of input processing'. In all the processing instruction activities of this study meaning was always kept in focus;

3. learners must be engaged in processing the input sentences and must respond to the input sentence in some way (through referential and affective types of activity, as in the case of the present study);

4. activities which combine oral and written input should be used as some learners respond better to one than the other. This is in order to account for individual differences;

5. learners' attention should be guided not to rely on natural processing strategies. Activities in which the input is structured to alter learners reliance on one particular strategy should be created. In the case of this study, the presence of the adverbial actually would detract from the role of the tense marker on the verb since learners prefer to process the adverbial (lexical item) rather than the grammatical form (inflection) when both encode the same semantic information. Therefore Van Patten and Sanz's suggestion is to keep the psycholinguistic processing mechanisms in mind when preparing structured input activities. 


\subsection{Empirical studies on the effects of processing instruction}

As Van Patten has indicated (1996:87) the peculiarity of processing instruction is that it is a type of FFI and not a methodology ${ }^{17}$, therefore it is readily researchable.

Four major empirical studies (syntax, verb inflections, lexical items, communicative output monitoring, see table 4.3 ) on the effects of processing instruction have been conducted at the University of Illinois and all of them involve the learning of Spanish. The first study on the effects of processing instruction was carried out by Van Patten \& Cadierno (1993 a) who investigated whether processing instruction would alter a strategy used by L2 learners who as postulated by Van Patten (1996:32) possess a default strategy that assigns the role of agent to the first noun they encounter in a sentence. This strategy is also known as 'the first noun strategy'.

Van Patten \& Cadierno conducted their research among American students learning Spanish in their second year of language study with the purpose of showing that this strategy (rely on the lexical item) might cause learners of Spanish a number of problems as learners seem to misinterpret sentences containing direct object pronouns in Spanish. In particular, they investigated the impact of processing instruction on the acquisition of direct object pronouns. As stated earlier, Van Patten \& Cadierno identified the possible misinterpretation of object pronouns as subjects as L2 learners assign the first noun of an input sentence to the role of subject. In the following case learners would misinterpret a sentence such as 'La visita el chico' as 'She visits the boy' rather than the correct 'The boy visits her'.

The two main questions addressed by this study were:

1. does altering the way in which learners process input have an effect on their developing system?;

2. if there is an effect, would that effect be observable in learners' output?

\footnotetext{
${ }^{17}$ As pointed out in chapter two classroom research which has investigated the effects of particular types of FFI like processing instruction represent an evolution in the empirical research on the effect of formal instruction, as previous research was carried out to compare different methodologies. This is the case of Savignon's study (1972) which compared the audiolingual method and the communicative method.
} 
Van Patten \& Cadierno compared three groups of students of Spanish at intermediate level who received different two different instructional 'treatments' ( 2 hours instruction on two consecutive days).

One group receiving a very 'traditional' type of instruction based on a widely adopted college-level textbook which emphasised grammar explanation and oral-written production; the second group receiving input processing instruction; and a third group used as a control receiving no instruction.

A total of eighty second year students learning Spanish at university level participated in this study in which a pre-testlpost-test design was used to measure the possible effects of instruction. Two different assessment tasks were developed by the researchers. The first was an interpretation task in which learners heard ten sentences along with five distractors. Five of these sentences were of the order, object pronounverb subject and the other five were of the order object marker + noun-object pronoun-verb subject. The five distractors were simply subject-verb-object sentences. The groups, after hearing a sentence, had just a few seconds to select one of the drawings projected on an overhead screen in front of the class. In the case of the sentence 'A la chica la abraza la mama' which means 'The mother hugs the girl' subjects had to choose between a picture describing a woman hugging a child and a picture of a child hugging a woman (Van Patten 1996: 91).

The other assessment task was a sentence-level written production task in which the three groups were given five items to complete. Each item consisted of a two-part sentence that corresponded to a two-part drawning. The second part of the sentence was incomplete and the student's task was to complete it based on the visual cues. One of the item was ' El chico piensa en la chica y entonces.....'

which means 'The boy is thinking about the girl and so......', and the connected pictures show the boy thinking about the girl in the first frame and in the second he is calling her. The correct answer would be to write 'y entonces la llama' which means 'and so he called her'. In this study which had an enormous impact in subsequent studies, Cadierno and Van Patten (1993 a) showed that processing instruction is very beneficial for learners. The two research questions postulated at the beginning of this study were fully answered. 
First of all, this approach to grammar instruction seemed to improve learners' ability at interpreting object pronouns in Spanish correctly and furthermore the study demonstrates the positive effects of processing instruction on learners' production, as the effects are not limited to input processing but are also observable in output. Finally, processing instruction seems to be superior overall to a more traditional instruction as the group who received input-based instruction performed better or at least the same in the production task when compared with a group who received a more traditional type of explicit instruction.

One of the limitations pointed out by Van Patten \& Cadierno (1993 a) in their study is the fact that the study investigated only one aspect of input processing, namely the 'first noun strategy'. The question was: 'what of the other principles of input processing and the effects they have on acquisition?'

This was one of the main reason behind Cadierno's (1995) study which was very similar to the one conducted by Van Patten \& Cadierno. She investigated the effects of processing instruction on the acquisition of morphological linguistic items of Spanish. She researched the impact of processing instruction on the acquisition of Spanish 'preterite tense' (simple past). Cadierno's study, unlike the previous one, was based on 'lexical processing strategy', which states that 'learners process lexical items as opposed to grammatical form when both encode the same semantic information' (Van Patten 1996:97). The aim of processing instruction was to push learners to attend to elements in the input that might be otherwise missed. This is particularly relevant, if we consider that the Spanish 'preterite tense' is very difficult morphologically for L2 learners (English native speakers). In comparison to English, there are 16 different forms for the regular 'preterite tense' owing to the inflections for both tense and person-number and the type of verb being inflected.

The design of Cadierno's study is identical to the previous one in terms of: proficiency level of the subject pool used for the experiment (intermediate), type of treatment (processing instruction vs traditional instruction), assessment tasks (interpretation \& production written task) and procedures for data collection (pre-test and post-test). 
Cadierno's research questions differ in the fact that she investigated the possible effect of processing instruction on altering the 'lexical processing strategy' used by learners to process input.

Sixty intermediate Spanish learners at university level were involved in this study. As outlined by Cadierno the results showed that the group who received the input-based type of instruction in the 'preterite tense' never engaged in production type activities during instruction, and then they were able to perform as well as the more 'traditional' group in the production task, which, as in the case of Van Patten \& Cadierno 's study (1993 a), consisted of a written completion task. The processing instruction group was also significantly superior to the other two groups in the interpretation task. Another important finding in this study is that the effects of processing instruction are measurable after a month of instruction as Cadierno administered a posttest to the three groups after a month to look for possible delayed effects. These findings support the hypothesis that processing instruction might have an effect in learners' developing system and eventually in their output. As a result of both these two studies we might conclude that:

a) processing instruction as a type of explicit grammar instruction is superior to 'traditional instruction' in the case of the object pronoun and past tense in Spanish;

b) processing instruction does affect the way in which learners process input and these effects are observable in the learner output, in the case of intermediate learners of Spanish;

c) the effects are durable, at least in the case of Cadierno's study, even though the three groups have been tested only after one month of instruction.

Overall these results give support to the key role of input processing in SLA. The results on the interpretation task are discussed in detail by Van Patten \& Cadierno (1993 a). 
The 'traditional' group managed to perform the production task but were not able to perform in the interpretation task. Traditional instruction seems to have little effect on interpretation. This is an interesting but problematic finding as pointed out by Van Patten \& Cadierno who outline two possible explanations.

According to Van Patten \& Cadierno (1993 a: 238) a possible explanation is that the group receiving traditional instruction 'learned to perform the task and did not acquire any new language'. Another possibility, which is more tenable, is that grammar explanation and practice 'do not enhance how learners process input and therefore do not provide intake for the developing system'. This latter hypothesis would support Krashen's position (1982) that learners might have two separated systems of knowledge: the acquired and learned competence. This is also supported by Schwartz (1993) who distinguishes two separate knowledge systems and he argues that explicit practice and negative evidence can only result in learned linguistic knowledge. Therefore traditional instruction would feed the learned competence type of system. This issue will be discussed later in the light of the results of the present study. Although the empirical research showed beneficial effects for processing instruction on two distinct items of Spanish linguistic system, one syntactic and the other morphological, one of the limitations of these studies as suggested by Van Patten himself (1996: 97) is the fact that the effects of processing instruction were assessed through highly controlled sentence-level tasks.

The question which arose from this research was: 'can learners access their developing system on less controlled and more communicative tasks?'

This is the the main question addressed by a study (Van Patten \& Sanz 1994) carried out as a partial replication of Van Patten and Cadierno's study and which examines whether the effects of processing instruction are observable in a variety of communicative tasks. The main question in Sanz's study was 'whether the effects observed for processing instruction' on the sentence level task in the two previous studies we have reviewed could be obtained on other language production communicative tasks.

Sanz (Van Patten \& Sanz 1995) set out to investigate this question by utilizing two groups, one receiving processing instruction and a control group. 
The effects of instruction were measured on three different tasks:

1. the same sentence-level task used by Van Patten \& Cadierno (1993 a);

2. a structured question-answer interview;

3 . a video narration task.

The subject pool of this study consisted of 44 students of Spanish in their third year of a university language programme. The focus of instruction was the same as Van Patten \& Cadierno's study: preverbal object pronoun in Spanish.

The data collection procedure was very similar to the other two empirical research studies mentioned in this paragraph and consisted of two days of instruction.

The findings of Sanz's study showed that processing instruction is still effective even when measured on less controlled and discourse type of tasks.

Although the results of this study seems to emphasise the fact that altering the processing strategies used by L2 learners when they are processing input leads to a change in knowledge which is available for use in different kinds of production tasks, the effects of processing instruction were more significant in more controlled oral tasks (completion task) rather than less controlled ones (video narration task).

This study provided further evidence on the positive effects of processing instruction in syntax (object pronouns an word order) and the fact that the effects are observable in more communicative and discourse-oriented types of tasks rather than only sentence-level tasks.

A final study worth mentioning is the one carried out by Cheng (1995) to measure the effects of processing instruction on a different kind of linguistic item of the Spanish linguistic system: namely 'ser' and 'estar'. Her study was conducted to find evidence of the effects of processing instruction on the acquisition of two copular verbs in Spanish (ser' and 'estar'). Processing instruction was related to two of Van Patten's principles (1996:14) :

a) learners process content words in the input before anything else;

c) learners prefer processing 'more meaningful' morphology before 'less' or 'non meaningful morphology'. 
The second principle was particularly relevant for this study as copular verbs in Spanish are of low communicative value for L2 learners and redundant features of Spanish. The two main research questions adressed by this study were:

1. whether processing instruction and traditional instruction had the same effects on the acquisition of' ser' and 'estar';

2. whether the effects are short or long-lasting.

Over one hundred subjects studying Spanish in their third year of University college level course were involved in this study. Cheng used a very similar reserch design to that of Van Patten \& Cadierno (1993 a) comparing three groups in a pre-postest format including three type of tasks:

1. interpretation

2. sentence completion

3. guided composition

The results of this further study on the effects of processing instruction showed that students receiving processing instruction outperformed those receiving no instruction and traditional instruction. Once more the effects of processing instruction are observable on output tasks, whereas the effects of the traditional type of instruction are not observable on interpretation tasks.

Another study was recently carried out by Van Patten \& Oikkenon (1996) to address the question posed by Van Patten himself of whether 'monitoring' was the cause of the positive effects observed in processing instruction on learners developing system. The superiority in terms of performance of the processing groups could have been due to the conscious knowledge gained by the processing instruction groups during the explanation part of the instructional treatment and not to any effect that the activities might have in helping learners to restructure the developing system. 
The main question of this study was whether results obtained in previous studies were due to learner's conscious knowledge gained during the explanation part of the instructional treatment or to the positive effects of structured input activities.

Subjects involved in this study were from a secondary school in Illinois. They were all (59 subjects in total) studying Spanish in their second year.

The item investigated was the same as in Van Patten \& Cadierno's study (1993 a): namely object pronoun in Spanish. The materials, design, assessment tasks were also the same as the main purpose of the research was to establish which of the following variables is the most significant in accounting for the post-tests results:

1. explanation;

2. structured input activities;

3. combination of the two.

Explicit instruction usually provides learners with explicit information about how the language works. Processing instruction is not exempt from this characteristic as it provides learners with information on how the language works and how natural processing strategies might be getting in the way of acquiring a form.

Krashen (1982) has claimed that explicit information can be stored only as a conscious knowledge. The device that learners possess to store that knowledge is called by Krashen 'Monitor'. This device would edit output when task demands allow for monitoring to happen. For the 'monitor' to be engaged, he claims that the most important feature of task demands is time. The tasks used in processing instruction research (interpretation and sentence-level production), are tasks where learners have, according to Krashen, the time to monitor. Therefore, the question asked by Van Patten \& Oikkenon (1996) in their study was: 'is monitoring responsible for the outcomes of previous research, or are the structured input activities responsible for learners gains?' The other possibility explored by Van Patten \& Oikkenon (1996) was whether a combination of explicit instruction and structured input activities together were the main factors for acquisition to happen. 
Three groups were tested followed the same design as Van Patten \& Cadierno (1993 a), one receiving only explicit instruction, the other structured input activities and the third processing instruction.

The results of this investigation showed that 'monitoring' is not the significant variable for the gains obtained by the groups of learners who received the input processing treatment. The gains made (on both the interpretation and production tasks) by both the processing instruction and the structured input activities group were greater than the group receiving only explicit instruction on the targeted form. A very significant finding of this study is that the structured input activities group performed as well as the processing instruction group.

As indicated by Van Patten (1996: 126), these findings strongly suggest that it is the structured input activities itself and the form-meaning connections being made during input processing that are responsible for the relative effects observed in the present and previous studies. 


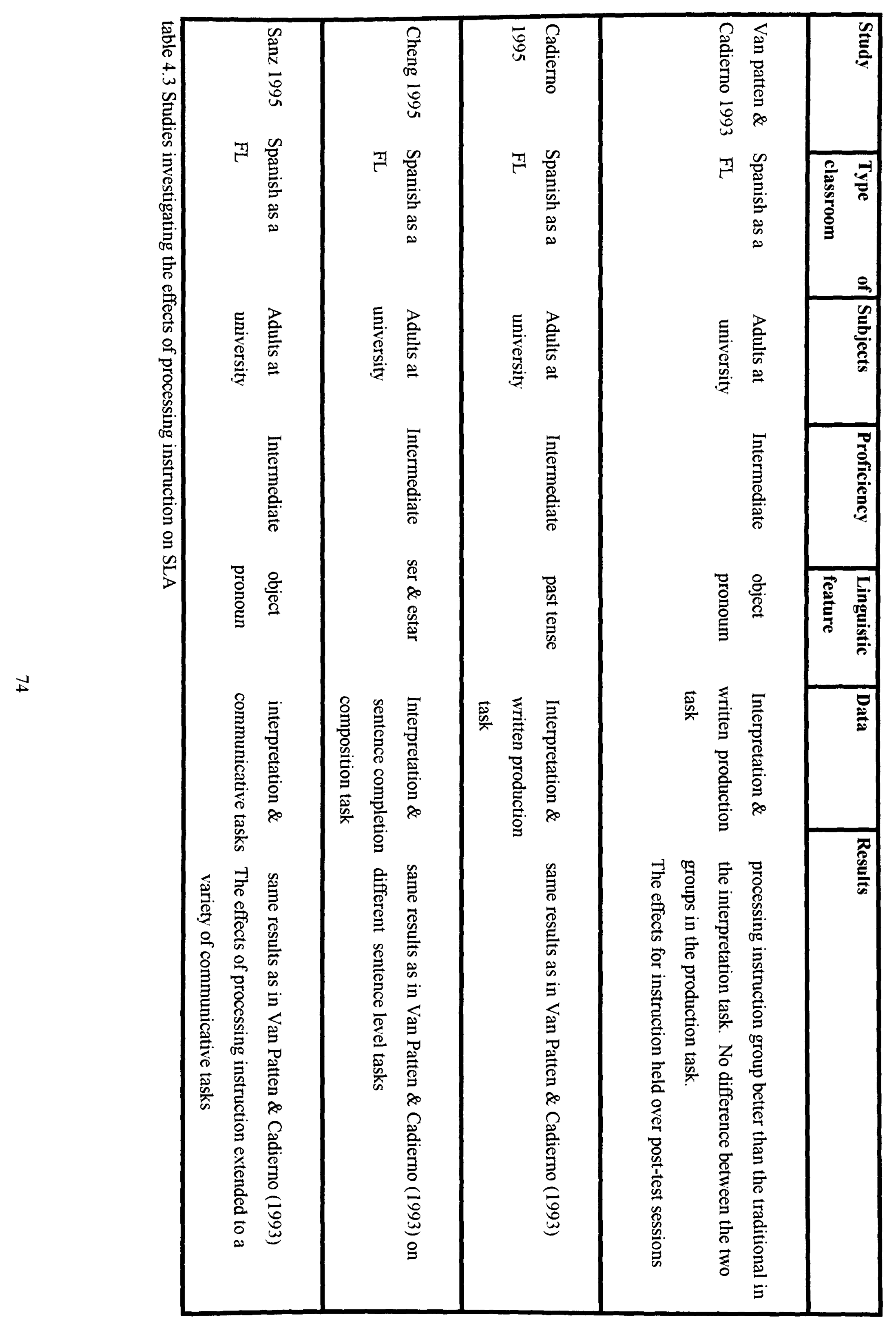




\subsection{Summary of results from previous research and contribution to the present study}

The five studies carried out to investigate the effects of processing instruction on the acquisition of certain linguistic features in Spanish have produced the following conclusions:

1) these effects are not limited to learners' ability to process input better, but have a direct effect on their developing system and eventually L2 learners can access the targeted linguistic feature when making output;

2) these positive effects have been observed in three linguistic items (object pronoun, past tense and 'ser' and 'estar') and assessment tasks of Spanish at both sentence and discourse-level;

3) these effects are due to the actual structured input activities which, within processing instruction, represent the most significant variable. As indicated by Van Patten (1996:126), structured input activities and the form-meaning connections being made during input processing are responsible for the relative effects observed.

Despite the fairly robust picture that is emerging in the studies carried out to investigate the relative effects of processing instruction and the strong theoretical reasons for an approach based on interpretation, we can identify some limitations and some questions which have not been addressed fully.

Firstly, the effects of processing instruction have been investigated only on a few linguistic items of the Spanish linguistic system which would suggest that research in processing instruction should be carried out to measure its effects on other romance languages and on different linguistic items of both syntax and morphology.

Secondly, the effects of this explicit input-based type of grammar instruction should be investigated to provide further support for its effects at altering strategies used by learners to process input, as for example only one study has been carried out on the 'lexical processing strategy'. 
Thirdly, evidence should be provided for the effects of processing instruction on different assessment production tasks at sentence level, as for instance Van Patten \& Cadierno's study (1993 a) provides evidence of the effects of processing instruction only on a controlled completion written task, while there is no evidence of its effects on a oral production task.

Fourthly, the effects of processing instruction should be tested with students from a different level of proficiency as all the studies carried out in Spanish have involved a subject-pool at intermediate level.

Finally, although Van patten \& Cadierno (1993 a) showed that the effects of instruction held over a one month period and in the case of Cheng over a three weeks period, further studies should investigate whether its effects are more durable.

\subsection{Research questions \& Hypotheses of this study}

This study builds up on the work of Van Patten and his colleagues at the University of Illinois on processing instruction and seeks to investigate the relative effects, at sentence level, of processing instruction on one linguistic item of the Italian verbal system: namely the future tense. In the present study, it is my intention to shed some light on some of the issues pointed out. The main contributions of the present research to the ongoing debate on the effects of processing instruction on the acquisition process and its implications at pedagogical level are the following:

1. to provide evidence of the effectiveness of processing instruction on the acquisition of Italian by beginner, adult learners;

2. to provide evidence of the positive effects of processing instruction on a different linguistic item of the Italian morphological system;

3. to offer further evidence of the effectiveness of processing instruction at altering the 'lexical processing strategy' used by L2 learners when processing input;

4. to demonstrate that the effects of processing instruction on L2 learners' developing system on the acquisition of verbal inflections are measurable in both a written and oral limited response production task at sentence level;

5. to provide further evidence of the durability of the effects of processing instruction. 
Based on the research aims previously outlined and with the specific intent to compare the effects of processing instruction and output-based instruction on one linguistic item of the Italian verbal system (future tense) a set of four specific questions were formulated:

1. Will there be any differences in how two groups of learners of Italian exposed to two different types of instruction (processing instruction vs output-based instruction) interpret sentences where future is only expressed by verb morphology?

2. Would learners receiving processing instruction produce sentences to express future meaning in a written production task as well as learners receiving the output-based type of instruction?

3. Would learners receiving processing instruction produce sentences to express future meaning in an oral limited response production task as well as learners receiving the output-based type of instruction?

4. Would the possible positive effects for instruction be retained over time by the two instructional groups?

Based on the results of previous research the following hypotheses are formulated:

a) The group of learners receiving the processing instruction should be better than learners receiving the output-based type of instruction and the control group which received no instruction at interpreting sentences in which future temporal reference is only expressed by verb morphology.

b) There should be no difference in performance between the group receiving processing instruction and the group receiving the output-based type of instruction at producing correct future tense forms on the written production task. This particular result should be confirmed in the performance of both groups in the oral limited response production task.

c) Learners receiving processing instruction will retain the positive effects of instruction for both the interpretation and the production tasks over a delayed test administered three weeks later. 


\section{CHAPTER FIVE : RESEARCH DESIGN AND METHODOLOGY}

\section{Introduction}

The main aim of this chapter is to describe the experimental design used to investigate the effects of two types of instruction on the acquisition of the Italian future tense. The followings items will be described in detail: the general plan and objectives of the experiment; the target linguistic feature chosen for this investigation; the experimental design including the subjects and programme of study; the nature of the teaching materials and procedures used for this experiment (processing instruction vs outputbased instruction); the tests (pre-test and post-test design), scoring procedures and data collection procedures adopted; the three pilot studies; the statistical analysis procedures used.

\subsection{The plan}

The purpose of this study was to compare a group of students of Italian who had been taught grammar through an output-based type of instruction with those who had received processing instruction.

My aim was to determine whether at the end of a two day period of instruction the group receiving processing instruction on the acquisition of the Italian future tense, would surpass the group of students receiving an output-based type of instruction in an interpretation task, a written completion production task and an oral limited response production task. A secondary purpose, which was developed during the course of this study, was to establish whether the effects of the two types of instruction would hold after a three week period of instruction. The experiment was designed to make the results as objective as possible within the constraints of a college language programme. A 'One-shot' design pilot was carried out to establish the effectiveness of the materials developed for the two instructional groups.

The final experiment was carried out in May 1998. Second semester students of Italian at the University of Greenwich were subjects of this study . 
In order to compare the effects of two different types of explicit grammar instruction on the acquisition of the Italian future tense three groups were set. Two experimental groups received respectively processing instruction which was comprehension-based and output instruction which was production-based. A third group was used as a control group and received no instruction on the target features but were subject to a comparable amount of exposure to the target feature which consisted of activities very similar to the one used in the Naturak Approach (use of various techniques and activities to promote comprehension and communication requiring minimal response). Two different packs of materials were produced by the researcher and used during the instructional treatments over a period of two days instruction (3 hours). As the main aim of this study was to argue for benefits for the inclusion of an explicit focus on form via comprehension versus a focus on form via production, the instructional materials were balanced in all every way except the type of practice the students received (i.e. input vs output practice)

To examine short term effects of instruction a pre-test and post-test procedure was adopted. Pre-tests were administered to the subjects before (three weeks before) the beginning of the instructional treatment and post-tests immediately after the end of the instructional treatment and a follow-up battery after three weeks (see table 5.1 Overview of the experiment).

\begin{tabular}{|l|l|l|}
\hline Randomization & Instructional Treatments: & Posttests \\
Three Groups & a) processing instruction & Interpretation \& \\
$\mathrm{a}-\mathrm{b}-\mathrm{c}$ & b) output instruction & Production Tasks \\
$\downarrow$ & c) control group & (written + oral) \\
Pretests & $\downarrow$ & $\downarrow$ \\
Interpretation \& & Two consecutive days & Delayed Post-tests \\
Production Tasks & (3 hours instruction) & (three weeks later) \\
written + oral & & \\
& & \\
& & \\
& & \\
\end{tabular}

table 5.1 Overview of the experiment 


\subsection{The target linguistic feature}

The future tense in the Italian language was chosen for two main reasons: the fact that it is meaning-bearing and for its morphological and phonological characteristics. Italian allows the use of the present indicative to indicate near future action (when accompanied by a temporal adverb), however this particular use was not included in the present study. The Italian simple future is equivalent to the English 'will + verb' (compound tense). The Italian future is formed by adding different endings to the infinitive minus the final ' $e$ '. However the 'are' verbs change the ' $a$ ' of the infinitive ending to an ' $\mathrm{e}$ '. The future is used (as in this study) to express future action, make plans, express probability or possibility, make resolutions.

One of the characteristics of the Italian language is that the verb stem encodes the actionlevent. Verb morphology encodes tense, aspect and the grammatical subject.

The verb form, to a much greater extent than in English, carries a high semantic load by virtue of its morphology. Italian is considered a null-subject morphologically . Verb forms are both morphologically and phonologically distinctly marked for grammatical subject. The appearance of a subject pronoun is not essential.

In the future the appearance of accent marks (first and third person singular) indicate strong stress on the final vowel. However, as indicated in Musumeci's (1989) study (she examined the ability to assign tenses at sentence level under different conditions), despite the morphological and phonological properties of the future tense, the presence or absence of a temporal adverbial was the main factor for learners to be able to assign tenses correctly.

Mosumeci's findings revealed that early stage learners use lexical items in order to assign tense and this in particular was the case for the future where the effects of the adverbial were strongest for early-stage learners.

Musumeci concluded that the future, despite the clues ( $\dot{o}$ and $\grave{a})$, is the least accessible for early-stage learners. Also, Musumeci points out that learners appear to assign tenses on a binary option (present vs future). 


\subsection{The groups \& the programme: subjects $\&$ comparability.}

A pool consisting of 39 students enrolled in a second semester of an undergraduate basic Italian course at the University of Greenwich ( University-wide languages programme) participated in the final experiment. Two main considerations were taken into account when deciding to select the second semester students :

1. vocabulary familiarity and level of study

2. no exposure to the future tense

This experiment, as any other experiment which seeks to assert the possible effect of a particular treatment, must be designed to ensure that the groups exposed to different treatments are comparable. The initial plan was to match the three groups for various characteristics (GCSE results, sex, age and so forth) in order to increase their comparability in this study. This was the case of an early pilot (see pilot studies paragraph 5.6), however it was found that the number of variables was too high for matching successfully three groups. Therefore, in the end a randomization procedure (by drawing names out of a box) was preferred as it is a procedure that is more effective at reducing the effects of extraneous variables. The original sample of subjects (52) was reduced to 39 subjects (final data pool) as they went through a series of filters before the three groups were randomized: subjects who might have had some previous experience in the target language or were able to practise the target language and in this case the linguistic feature under investigation outside classroom instruction were taken out from the experiment.

Two of the criteria established for subjects to be included in the data pool were:

1. subjects's learning was limited to classroom instruction

2. subjects who had previous experience or linguistic knowledge of the target language were excluded from the study.

This information was obtained through the administration of a profile questionnaire which was submitted to the original pool of subjects to collect data on their background and learning experience (see questionnaire in Appendix D). 
For the final study all the subjects (39), randomly assigned to three groups (see section 5.6 pilot studies in which how randomisation of sample groups obviated the need to consider individual variations is discussed), were English speakers. The non-English students were excluded from this experiment as a different $\mathrm{L} 1$ could interfere with the result of the experiment. This was the case of a pilot which was carried out including some Greek students in the three groups, however for the final experiment the necessity to ensure that the groups exposed to different treatments were comparable dictated my decision to include only English speakers.

The course in Greenwich met once a week for a block of three hours contact and 1 hour self-access learning accomplished by the students in a language centre supervised by an assistant. The course would also require a minimum of three hours a week of private study in which students are asked to work on a portfolio of activities.

The same coursebook (Avanti) and a workbook (Ritocchi) are used.

These books put emphasis on communication in the language through contextualised dialogues, listeninglcomprehension activities and role play. Classroom activities were devoted to listening and speaking. There was an emphasis on vocabulary and basic functions (as the book is structured in this way). It is a comprehension-based programme which emphasised the role of comprehensible input.

However, the materials used in the programme at this level do not resemble the processing instruction approach. Both interpretation and production activities are present and balanced in this programme.

Grammar instruction was limited to the textbook exercises and were performed as part of the 'private study' component. The experiment took place during during the normal class hours, however the block of three hours was split over two days instruction.

The course did not cover instruction on the future tense before the experimental period. In addition for the time period of the experiment, subjects did not receive explicit instruction in the future tense outside the classroom hours.

The three groups received exactly the same materials, textbooks, syllabus and exams during the course. 
For the purpose of this experiment the three groups were taught twice for 1 hour and a half each time, on two consecutive days (Monday \& Tuesday mornings) and the self access hour + homework was suspended during the experiment period which corresponded to week 9 of the second semester. The two blocks of one and a half hours on two consecutive days would have been the amount of time that a language curriculum in Italian would devote to the explicit learning of the future tense. A splitblock design was used for the two instructional groups as they were taught during the same hours. Group A (Input) was taught for an hour and half Monday (9-10.30) and Tuesday (12- 1.30) and group B (output) Monday (12-1.30) and Tuesday (9-1030). The control group met both Monday and Tuesday at the same time (10.30-12). 


\subsection{Teaching procedures \& Materials}

Since the aim of this study was to investigate the relative effects of two different types of explicit instruction on the acquisition of Italian future tense (only regular verbs), two sets of materials were developed.

One for the output-based type of instruction group which consisted of traditional grammar explanation of rules and oral practice (including some meaning-oriented output activities), and one for the input processing group which involved providing pedagogical rules and teaching the subjects to process input sentences.

The two sets of materials were piloted before their use in the final experiment in order to balance them in terms of activity types, use of visuals, and vocabulary used during the instructional period. At the end of each pilot some adjustments were made to balance the two sets of teaching materials. Vocabulary was altered in the activities so that it was roughly the same and consisted in highly frequent and familiar vocabulary for second semester Italian students.

In the processing instruction treatment temporal adverbs were removed from the structured input activities so that the learners' attention was directed toward the verb endings as indicator of tense. Learners would rely on verbal morphology as indicator of tense since the lexical indicators of tense would be absent.

The two treatments differed only as to whether they were receptive or productive ${ }^{18}$. Although the way grammar was explained was different in the two instructional treatments (paradigmatic vs non-paradigmatic) the time allocated to grammatical explaination was exactly the same in the two treatments.

The activities present in the processing instruction group were almost all meaningful and communicative, whereas the activities in the output-based treatment contained some mechanical form practice. However, some of the activities in the treatment were meaning-based and required the subjects to use the future to convey meaning. This was accomplished to make the two groups comparable as far as meaning-oriented activities were concerned.

\footnotetext{
${ }^{18}$ The processing instruction treatment could be defined 'receptive' as practice focused on comprehension activities. Whereas the output-based instruction treatment is defined as 'productive' as practice focused on production activities.
} 


\subsection{Input-based treatment with pedagogical rules.}

A pack of materials for processing instruction was constructed and created by the researcher. This pack reflects one approach to the teaching of grammar which encourages learners to focus their attention on future tense endings in the input.

Processing instruction also provides learners with practice on how to assign tense (future vs present) at sentence level and 'affective' activities in which learners have to respond in some ways to the content of sentences.

In contrast with the output-based treatment where the presentation of the future tense endings was followed by subsequent practice in how to make sentences in the future tense, processing instruction aims at teaching learners how to interpret and comprehend the form. In presenting the future forms (broken down and presented one at the time) some emphasis was placed on stressing some of the cues to recognise future verb forms in contrast with present verb forms. It was also emphasised that although temporal adverbs usually accompany a verb to indicate when the action takes place, these adverbs are not always present in the input. Therefore it is important to recognise future forms without relying on adverbs. This input-based treatment had the following characteristics:

1. presentations of all future forms in a non-paradigmatic way (third person singular first, followed by 1 st and 2 nd singular and third plural);

2. use of activities (referential and affective types) in which learners have to respond to the content sentences.

The presentations of the future verb forms involved presenting the forms (providing learners with some information about the grammatical form and at the same time link form and meaning ) separately and then contrasting those with the present verb forms (see Appendix A). Two things were especially emphasised:

1. the differences in stress between future and present verb forms;

2. the fact that although generally temporal adverbs indicate that the action of the verb occurs at the moment or will occur in the future, these adverbs are not always present in the input. Therefore it was extremely important for the students to recognize future tense forms without relying on adverbs. 
In the presentation of the target forms the relation between form and meaning was always in focus.

Never during instruction were students belonging to this group asked to produce a sentence with the future tense, but they were engaged in processing input sentences in a control situation so that they could make better form-meaning connections.

The materials for this group (see Appendix A), prepared by the researcher, included two of the types of processing instruction activities described by Van Patten \& Lee (1995): binary option activities and matching activities.

The activities which followed the explanation about the future verb forms were different compared to the one used in the 'output' treatment. Overall they provided learners with opportunities to practise correctly interpreting tense. For the inputbased instructional treatment three main types were used. The types of activities used were as follows: a) referential activities where learners have to identify at sentence level either the time when the action had happened or the subject of the sentence;

b) affective activities where learners have to perform different types of tasks based on the informational content of the input; c) use of visuals or cartoons where learners' attention was directed to the targeted items. Samples of these three types of activities for the processing instruction group are presented in table 5.2. In this type of activity lexical items and discourse that would indicate a time frame were not present. Only the verb ending encoded tense in the input sentence. This is in order to encourage learners to attend to the grammatical markers. The input was 'structured' so that the grammatical form carries a meaning and the learner must attend to the form to complete the task.

Processing instruction aims at making learners interpret and comprehend the linguistic feature in oral and written form and not producing it.

In the input processing instruction group the students were asked to pay attention to future endings in the input and providing practice on how to assign tense (future vs. present). In the activities where the students were involved the focus was on meaning and they had to respond to the content of sentences. In other words they were taught how to interpret and comprehend the targeted items. 
The amount of instruction about the linguistic form subjects received, was exactly the same for the two treatments. The two groups received the same amount of information about how the future works in Italian, however they would differ from the way the future is presented: paradigmatic vs non-paradigmatic

a) You are going to hear some sentences in Italian. Select whether each sentence you hear occured in the present or the future. Keep in mind that future tense forms have the spoken stress in the vowel of the endings (3rd person)
1. a) present
b) future
2. a) present
b) future
3. a) present
b) future
4. a) present
b) future
5. a) present
b) future

b) The fortune teller's message is rather confused. Can you help her to sort it out? She talks to you about the future of your brotherlsister.
a.
b
c.......
d

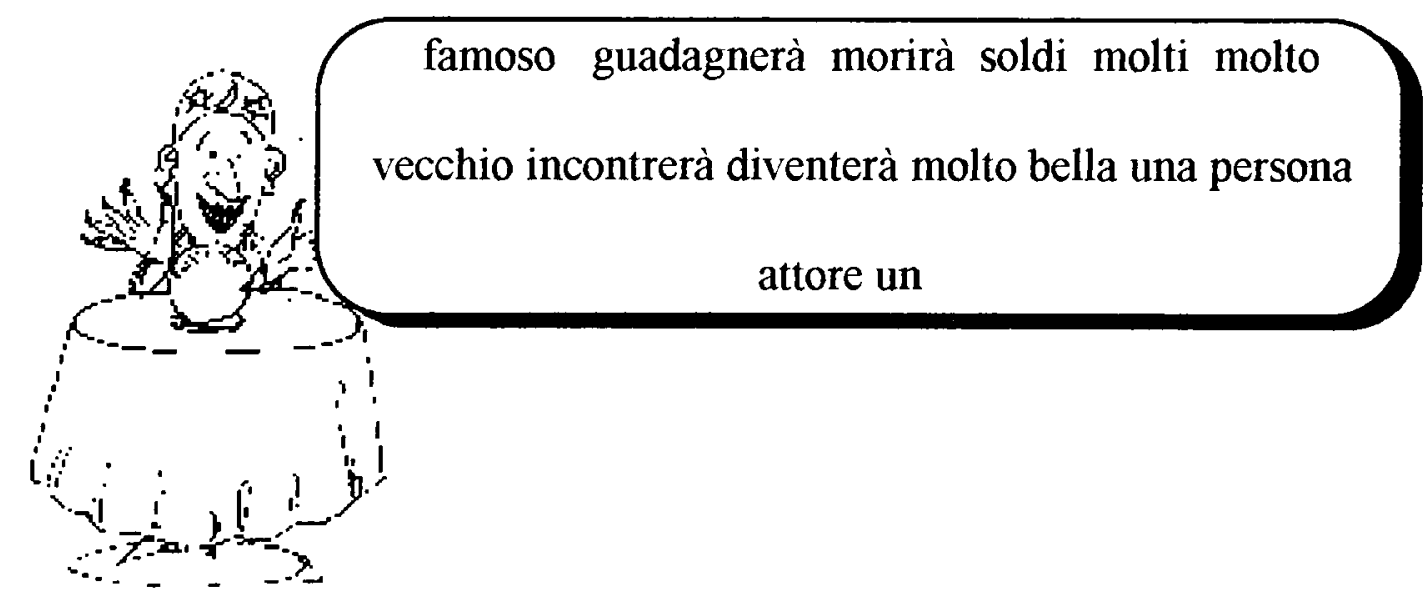

Can you now make a list, possible in a cronological order of the fortune teller 's predictions about your brotherlsister's future. Notice that the verbs are all expressed in the future tense (3rd person).

1.

2.

3.

4.

c) Here is a cartoon called 'I buoni propositi'. In which circumstances would you do 'I buoni propositi'? 


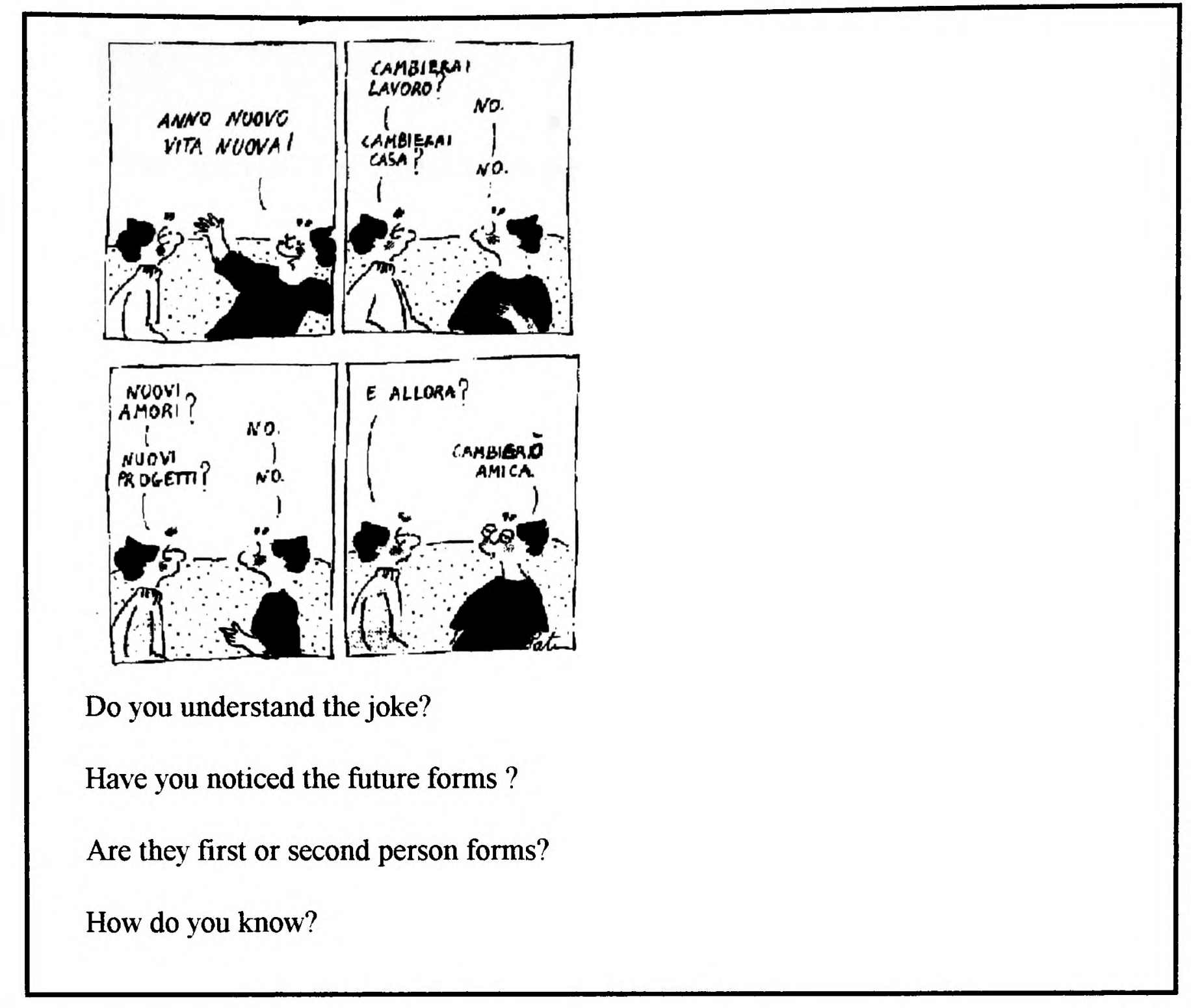

table 5.2 Sample of activities for the processing instruction group

The amount and types of activities (visuals, pair and whole class) and actual utterances learners were asked to perform in both treatments were almost the same (see table 5.3).

\begin{tabular}{|l|l|}
\hline Number of activities & 18 \\
\hline Number of utterances & 179 \\
\hline pair activities & 5 \\
\hline whole class activities & 13 \\
\hline visuals & 5 \\
\hline
\end{tabular}

table 5.3 Number and types of activities for the processing instruction group

Vocabulary and verbs used were approximately the same. Only regular verbs were used (see lists of verbs in Appendix $\mathrm{H}$ ). 
Overall the instructional materials were similar in all respects except the input vs output practice. That is to say practice through processing activities vs practice production activities.

\subsubsection{Output-based treatment.}

A second pack (only regular forms of future tense) was constructed to be used for the output-based group. This pack (see Appendix B) reflects one approach to the teaching of grammar which involves the presentation of the future tense endings and the subsequent practice in how to make sentences in the future tense.

Almost all of the activities used for the implementation of this approach were constructed to make learners produce the future tense forms at sentence level.

The output-based type of instruction used for this experiment had the following characteristics:

1. presentations of all future forms in a paradigmatic way;

2. use of activities in which learners have to practise producing the correct future forms (written and oral).

The amount of instruction about the linguistic form was exactly the same for the two treatments. The two groups received the same amount of information about how the future works in Italian, however it differed in the way the future is presented paradigmatic (output-based type of instruction, see table 5.4) vs non-paradigmatic for the processing instruction group (see table 5.5).

The instructional materials were similar in all respects except the input vs output practice. That is to say practice through processing activities vs practice production activities. Therefore the difference between the two instructional packs is qualitative not quantitative given that the researcher controlled the number of activities, and items practiced. In the output-based type of instruction subjects were required to produce the target item. 


\section{Future Tense.}

Just like verbs in the present tense, verbs in the future tense in Italian change their endings depending on the subject of the verb (Io, tu , lui lei, noi, voi, loro).

The endings are the same for Verbs in are-and ere and ire (see chart). Note the accent on 1st and 3rd person singular. The stress always falls on the endings. There are two main points to remember when forming the future tense:

1) Take the infinitive and cross off the final $e$ and add the future endings. However the are verbs change the a of the infinitive ending to an $e$.

2) Verbs in -are- and -ere have the same endings .

Unlike the English future the Italian future is not a compound tense

it translates the future simple in english: eg. I will arrive, I will take, I will leave.

\begin{tabular}{|c|c|c|}
\hline ARRIVARE & PREND-ERE & PARTIRE \\
\hline 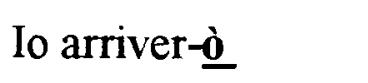 & 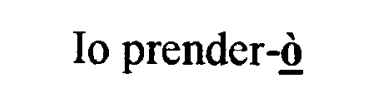 & Io partir-ò \\
\hline I will arrive & I will take & I will leave \\
\hline tu arriver-âi & tu prender-ai & tu partir-âi \\
\hline you will arrive & you will take & you will leave \\
\hline luillei arriver-à & luillei prender-à & luillei partir-à \\
\hline helshe will arrive & helshe will take & helshe sleeps leave \\
\hline noi arriver-emo & noi prender-emo & noi partir-emo \\
\hline we will arrive & we will take & we will arrive \\
\hline voi arriver-ete & voi prender-ete & voi partir-ete \\
\hline you will arrive & you will take & you will leave \\
\hline loro arriver-anno & loro prender-anno & loro partir-anno \\
\hline they will arrive & they will take & they will leave \\
\hline
\end{tabular}

The use of the future tense in Italian corresponds to its use in English. For example: Domani lavorerò tutto il giorno $=$ Tomorrow I will work all day

The future expresses an action the has not yet taken place.

You can use the future tense to talk about things you plan to do in the future:

- things you definitely intend to do- make arrangements, predictions and resolutions used to express possibility

table 5.4 Paradigmatic presentation of future tense 
Future Tense Third person singular form

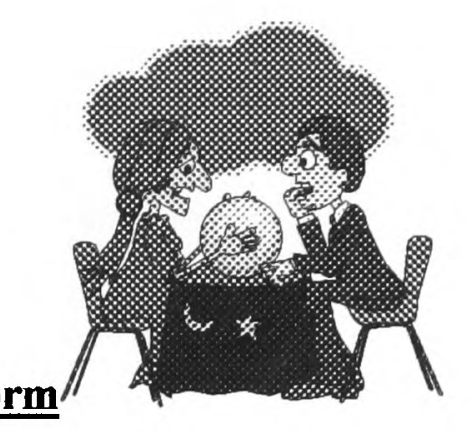

The future is used to to talk about an action that has not yet taken place or making plan (in the picture above the future is used to make predictions.... Cosa succederà nel futuro...?)

Third person singular future forms are formed by adding the future ending à to the infinitive of the verb(however the are verbs change the a of the infinitive ending to an e). Here you are presented with the third person singular form for regular verbs:

FUTURE

\begin{tabular}{|l|l|l|l|}
\hline & arrivare & prendere & partire \\
\hline \multirow{2}{*}{ luillei } & arriver-à & prender-à & partir-à \\
\hline
\end{tabular}

Paolo arriverà la settimana prossima

(Paolo will arrive next week)

Laura partirà alle sette

(Laura will leave at seven o'clock)

There are two clues that will help you to recognize future tense forms:

1. the future tense (third person) of regular verbs is formed by adding the ending $\underline{\mathrm{a}}$ to the infinitive minus the final $e$. The future endings of verbs in are ere and ire are the same.

\section{2. the spoken stress on 3rd persons singular is on the final accented vowel of the} ending.

The second clue will be very useful in order to distinguish future forms from those forms of the present tense. An important difference is in the spoken stress of the final vowel of the future tense.

table 5.5 Non-paradigmatic presentation of future tense

Whereas in the input-based group, subjects were required to interpret and react to sentences which contained the target feature, for the output-based instructional treatment the types of activities used were as follows:

a) completion activities in which learners have to write a sentence in the future form and subsequently participate in an oral activity and use that form;

b) activities in which learners have to rewrite a sentence in the future. The sentence is given in the present or in the infinitive;

c) meaning-oriented activities in which learners have to create meaningful output by using future tense forms.

Samples of the types of activities used for the 'output' treatment are provided in table 5.6 . 
a) At the beginning of every year we make a new year's resolution.

These are Francesco e IO 's resolutions. Complete the sentences by using

the infinitive of the verbs in brackets in the future tense.

Francesco: (smettere) di fumare $\backslash$ (studiare) ogni sera $\backslash$ (tornare) a casa presto la sera $\backslash$ (non arrivare) a scuola in ritardo $\backslash$.

Now you have to say what you and your partner will do and report to the rest of the class. (Che decisioni prenderai per il prossimo anno?)

IO

1.

2.

b) Change the verbs in the future tense

1. Compro un amacchina nuova

2. Lavoro alle otto di sera

3. Guarda la partita di calcio

4. Ascoltano il notiziario alla radio

5. Aspettiamo il tram delle due

6. Telefoni a Paolo

7. Parlate tutti il francese bene

8. Visiti il Museo d'arte moderna

9. Torno a casa alle tre

I0 Cambio casa

\section{IL TUO COMPAGNO}

1

2.

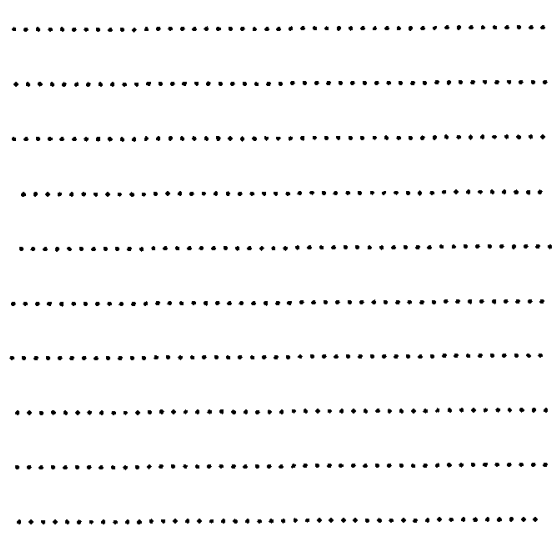

c) You want to know what your partner will do next summer.

You need to use these verbs, prepare the questions first and then write the answer beside.

domande

risposte

I.Come passare le prossime vacanze?

2.Come viaggiare?

3. Quanto restare a ......?

4.Dove abitare?

5.Cosa visitare a ......?

6.Quando ritornare a casa? 
Now is your turn to answer your partner's questions about your holiday.

You have to answer your partner's questions with the help of the pictures.

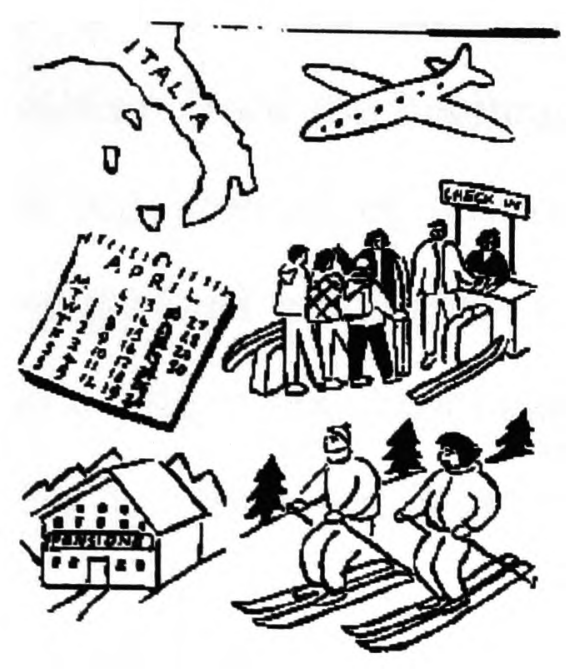

5. Now, what will you really do next summer? Ask your partner and answer the same questions

10

1.

2.

3.

4.

5.

6.

.

3.

4.

.

\section{IL TUO COMPAGNO}

.

table5.6 Sample of activities for output-based type of instruction group

As previously pointed out, the amount and types of activities as well as the vocabulary, learners received in both treatments were almost the same (see table $5.7 \&$ lists of verbs in Appendix $\mathrm{H}$ ).

\begin{tabular}{|l|l|}
\hline Number of activities & 19 \\
\hline Number of utterances & 184 \\
\hline pair activities & 5 \\
\hline whole class activities & 14 \\
\hline visuals & 4 \\
\hline
\end{tabular}

table 5.7 Number and types of activities for the output-based group 
This approach to the teaching of grammar consisted in presenting the subjects with the future tense endings and giving them practice on how to produce the correct future tense forms. The main emphasis of this type of instructional treatment was on production from the beginning. In some activities students had to produce language which was devoid of any referential meaning, however some of the activities were meaning-based since they involved the students in producing their own responses based on their real experience. The main differences between processing instruction and the output-based type of instruction used in this study are summarised in table 5.8.

\begin{tabular}{||l||c||}
\hline processing instruction & output-based instruction \\
\hline \hline a) Explanation of rules in a & a) Explanation of rules in a \\
non paradigmatic way & paradigmatic way \\
b) practice in processing input & b) practice in output \\
c) always focus on meaning through & c) some focus on meaning through \\
processing instruction & meaning-oriented output practice \\
\hline
\end{tabular}

table 5.8 Main differences between processing instruction and the output-based type of instruction 


\subsection{Tests \& Scoring Procedure}

To assess the effects of instruction a battery of two post-test procedures was adopted. Three tests were designed and used for this experiment, one for the interpretation task and two for the production task (a written completion task and an oral limited response task). The fact that both interpretation and production tasks were present in all the tests is clear evidence of the fact that neither instructional group was favoured. This possible task bias factor was taken into account before the design of the experiment as it could invalidate the outcomes of the study.

The output-based group was familiar with the production tasks as a number of activities were based on them. However, it was not familiar with the interpretation task. On the contrary, the input-based group was familiar with the interpretation task, but not with the production tasks, as subjects from this group were not engaged in output activities. Therefore, equal unfamiliarity of groups with the other's task was achieved.

The tests (pre-test and post-test) were piloted to make sure that they were at the same level of difficulty. The three tests were administered respectively immediately after instruction and three weeks after the treatment ended by the researcher. Pre-tests were administered sometime before the beginning of the experiment. Distracting activities (one translation exercise and one gap filling exercise) were used between the administration of the three different tests. The interpretation task and the production tasks were time-limited, however, while the interpretation task was measuring realtime comprehension, the productions tasks were developed to elicit subjects' best performance. Therefore in the case of the production tasks it was decided to allow enough time for the subjects to accomplish the tasks as if too little-time is made available stress might effect subjects' performance.

The delayed post-test was administered three weeks after the end of the instructional period, as the semester end on week 13. The subjects were not avare of the fact that they would have been retested.

\subsubsection{Interpretation task}

An interpretation task (an aural test of simple sentences without adverbial indications of temporal reference, see Appendix E-F-G) was used as a pre-post treatment measure of knowledge gained at interpreting future tense at sentence level. 
This test consisted of twenty aural sentences (ten in the present which served as distractors and ten in the future) in which temporal adverbs and subject nouns or pronouns were removed, so that the students could not rely on those elements to assign tenses but had to focus on verb morphology as the only indicator to establish when the action was taking place. The verb was never placed at the beginning of the sentence. The tests were recorded by a native speaker of Italian and presented to the subjects on a tape player.

No repetition was provided so that the test would measure real-time comprehension.

Subjects had only few seconds to establish whether the sentence was taking place in the present, in the future or they could not tell. The reason why the receptive task was time-limited is that it was developed to access spontaneous competence. Subjects were asked to establish whether the sentence expressed an action which was taking place now or in the future. The pre-tests and post-tests were balanced in terms of difficulty and vocabulary.

Tests were separated by distracting activities. In the interpretation task (20 sentences) the raw scores were calculated as follows: incorrect response $=0$ point, correct response $=1$ point. Only the future sentences were counted for the raw scores for a maximum score of 10 .

\subsubsection{Written completion task}

A written completion task was developed and used to measure learners' ability to produce sentences in the future. The written production task (see Appendix E-F-G) consisted of a text with 5 future tense sentences to complete. The students were required to complete the text producing the future with the verbs provided in brackets in the infinitive form. Five minutes were allocated to complete this task. The two productive tasks were not developed to measure the impact of instruction on spontaneous communication as the intent was to measure the accuracy (in a with which subjects All the verbs were regular verbs. In the written task ( 5 sentences) the raw scores were calculated as follows:

fully correct future tense $=2$ points;

partially correct (wrong spelling but right ending, such as for the first person singular parlarà instead of parlerà $)=1$ point;

incorrect $=0$ point . 


\subsubsection{Oral limited response task}

For the oral task (Appendix E-F-G) a sequence of five pictures were prepared representing a story. This task was administered in order to measure learner's ability to produce sentences containing the future tense orally. Subjects were asked to familiarise themselves with the vocabulary before the beginning of the task in which they were required to produce one sentence containing the future tense to express the meaning of each single picture. As stated, the verbs (given in the infinitive form) and the vocabulary were provided before the beginning of the test. The subjects were given five minutes to familiarise themselves with the verbs and the vocabulary and five minutes as a maximum for their oral production task which was recorded on tape. This test was administered in a Language Laboratory where subjects, sitting at individual booths with headphones and microphones were asked to complete the oral test. Their answer was recorded for transcripts. Students were supposed to produce correct future tense forms (right endings and spelling). The same scoring procedure adopted for the written completion task was used for the oral limited response task. 


\subsection{Pilot studies}

Three pilot studies were conducted to collect data for this study before the final experiment. The three pilot projects were instrumental in determining the design and procedures of the final experiment. The design of the final experiment, which has been described in detail in this chapter, is known as 'true experiment' and it is the best way to provide internal validity for a classroom study. Internal validity is one of the main issues experimental researchers are particularly concerned with.

\subsubsection{Pilot study 1}

In the first pilot, in which 30 subjects participated, two groups were formed to compare the effects of the two types of grammar instruction. No control group was used for this first pilot and only a post-test was administered after the end of the instructional period ( 2 hours in this first pilot). The two groups were given a vocabulary test before the beginning of the instructional treatment. Two tests were used, an interpretation and a written production task, which were similar in format to the one used for the final experiment. However, no oral task was administered at this stage, because the main purpose of the pilot study was to assess the possible differences of the two types of instructional treatments by using two assessment instruments which were not biased towards either of the treatments. Despite the good results obtained in this first collection of data (the processing instruction group outperformed the output-based group in the interpretation task and performed as well as the the output-based in the written production task) some methodological limitations were highlighted.

First of all, the need to include a control group in the experiment and to adopt a pretest and post-test procedure was established. In the first pilot the reason behind the adoption of a vocabulary test as a pre-test measure was the attempt to avoid the groups becoming familiar with the assessment tasks. However, it was decided to introduce a pre-test and post-test procedure as it is more effective to test group performance before and after the instructional period.

Secondly, it was observed that the subjects' first language and their course of study could have influenced the results of the first pilot, as some of the subjects were Greek. 
In addittion to that, because the data were collected in two different campuses at the University of Greenwich where students are studying different subjects, it was thought that 'site' and 'subject of study' effect might have influenced the final results.

Therefore, it was decided to exclude the Greek students and any other students whose first language was not English for the next pilot and collect the data in only one campus of the University where the students study Humanities related subjects.

Thirdly, it was noticed that 2 hours of instruction were not enough to cover all the activities prepared for the two instructional treatments.

As a result, it was decided to extend the instructional period from two to three hours. This was also justified, given the proficiency level of the students (beginners second semester) which require more instructional time to cover a given form or structure.

At this stage it was decided that a matching procedure would have ensured that the groups exposed to the different treatments were comparable. The initial plan was to match subjects on a number of variables such as: GCSE results, sex, and so forth. In the case of the age factor, however, it should be pointed out that formal learning environments do not provide learners with the amount of exposure neededfor the age advantage of young learners to emerge (see Singleton 1989).

However, it was finally thought that in matching subjects it is always difficult to establish which variables will serve best in an experiment and which ones should be left out and therefore this plan was abandoned. From the beginning of this experimentation it was thought that affective variables (see Skehan 1989) might have had an impact and eventually influence the outcomes of this study. Two of the questions asked by the researcher were: would the three groups be similar in their ability to learn? and would anxiety play an important role in influencing the results of the assessment tasks? Ellis \& Rathbone (1987) recognized the fact that individual learners vary enormously in their rate of learning and their level of achievement and some internal factors such as motivation and aptitude might affect achievement and contribute to this variation. They found evidence that different levels of acquisition can be explained in terms of various factors to do with the nature of individual learners' predispositions and and capacities to learn. 
One of the chief concerns of any experiment is whether the subjects on whom the measures are obtained do or do not represent the general population well enough to permit generalization. In order to resolve the issue of the comparability of the three groups it was decided to adopt a random precedure.

Despite the practical difficulty, the randomization of sample groups obviates the need to consider individual variation (Skehan 1989) and it is the most effective way to assure group comparability. It was identified that without using a randomization procedure the research design was not rigorous enough to be able to claim that there is a casual relationship between the treatments and the subjects' test scores. There is the possibility that other internal factors such as motivation, intelligenge or aptitude (as identified in the Ellis \& Rathbone study) could have contaminated the results.

Therefore the best way of increasing the soundness of the present research design was to adopt a randomization procedure which would allow the argument that any differences in the groups were due to the treatments because one can assume that other variables which might have affected the results exist in equal quantities in the groups as they cancel one other out.

In an academic setting it is very difficult to assign subjects randomly to the different sections. For this reason this procedure was only utilised in the last pilot and the final experiment. As for the early pilots, it was decided to use the natural random assignment of students which eventually result from the usual registration procedure. Krashen (1982: 31 ) refers to to a variety of affective variables that might have an impact on the SLA process. Although Krashen emphisises the crucial role of comprehensible input in successful SLA, he points out that anxiety might be a factor which directly relates to acquisition. In the 'Affective Filter Hypothesis' (Krashen 1982: 30) he claims that our goal as language teachers is not just to supply comprehensible input but to create a situation that encourages a 'low filter'. Classrooms that encourage low filters are those in which teachers promote low anxiety among subjects through activities which keep subjects 'off the defensive' (Krashen 1982: 32). In this sense processing instruction activities are congruent with the concept of 'low filter' as subjects are not 'forced'to produce immediately (either orally or in writing) the targeted linguistic feature but to comprehend the linguistic item through a certain amount of comprehensible input. 


\subsubsection{Pilot study 2}

In the second pilot 44 subjects (all English and all from one campus at the University of Greenwich) were involved using a research design very similar to the one adopted for the final experiment.

A pre-test and post-test procedure was adopted, and the materials were adjusted to be used for three hours instruction over a period of two consecutive days. For this second pilot, some minor changes were made in rephrasing and reordering activity items. The oral task was introduced this time as a new hypothesis was formulated. It was thought that a picture description would have been appropriate in eliciting obligatory contexts for the target form.

However, the main purpose of this pilot study was to determine whether the tests were clearly written and appropriate as the assessment tasks are crucial in order to measure the effects of instruction.

For the interpretation and the written production task any item that $60 \%$ or more of the subjects responded to correctly was changed since such as easy item does not measure the knowledge gained after the instructional treatment. The interpretation task was modified for the final version used in the experiment as the listening comprehension was designed to make sure that learners would easily understand the content of each sentence. In the production oral task any item that failed to elicit the target structures from more than $60 \%$ of the subjects was eliminated and replaced, including drawings that confused the subjects.

The revised assessment tasks were used for the third pilot which involved 36 subjects. All the subjects were randomized to the three groups. This procedure was adopted only at this stage. No statistical analysis was carried out, however from a first reading the results were encouraging and seemed to confirm the positive results of the first pilot and the hypotheses of this study.

At the time the pilot in Greenwich was carried out, some data were collected at Queen mary and Westfield College. Sixteen subjects were included in this small pilot carried out with the intent to test the effectiveness of the materials for both instructional treatments and to balance the amount and type of information about how the future tense works in Italian. 
This was done to make sure that the subjects received exactly the same amount of instruction about the linguistic feature in each group and differed only in what subjects did with it afterwards (practice through processing activities or practice through production activities). No control group was used as the main aim of this pilot project was to balance the activities in the two treatments. The students were all English native speakers and were studying Italian as an option on their degree.

Although no randomization of sample groups was carried out, the questionnaire administered to subjects (see Appendix D) showed that some of them were studying Spanish as a major subject. Therefore, because of the similarity of Italian and Spanish in forming the future tense it was decided to exclude those students. This step was also taken in the other pilot and in the final experiment in the attempt to avoid possible interactions between Italian and other L1's in the analysis.

The two sets of instructional materials were balanced in terms of number of activities, vocabulary involved and number of visuals used, and particularly the instructional materials were similar in all respects except the input versus output practice. Some of the activies were changed as they proved too difficult or too easy for the subjects involved. 


\subsubsection{Pilot study 3}

This final pilot was conducted with the addition of a delayed post-test as one of the hypotheses was to test delayed effects (three weeks after the end of the instructional period) of the instructional treatments.

In this final pilot 30 students were involved (all English and a mixture of Business and Humanities students) and randomized to three groups.

A crucial question asked at this stage was: 'Do the three tests used for each of the assessment tasks have the same level of difficulty?' At the end of the second pilot pretests and post-tests were balanced in terms of vocabulary, verbs and general level of difficulty.

However, in order to confront the issue of the level of task difficulty between pre-tests and post-tests, it was also decided to use the same battery of pre- and post-tests used for this final pilot, in the final experiment. This was achieved by using the pre-test in place of the delayed post-test, the post-test in place of the pre-test and the delayed post-test in place of the post-test. The results of the final experiment and this last pilot were proportionally very similar. This proved that the assessment tasks in the pre- and post-test format were comparable in terms of difficulty.

Another issue that was taken into consideration at this stage was the 'Hawthorne effect' (see next section). During the pilot studies subjects were aware of the nature of the experiment and this could have had an effect on their performance. The experimental groups could be expected to be highly motivated as they could have had a more enthusiastic attitude toward the study of the target feature.

Future experiments should probably include motivational indices early enough so that differences could not be attributed to other experimental variables.

Real-life experiment inevitably suffers from unwanted differences produced along with the desired experimental manipulation. However, the procedures (randomly assigning subjects to groups + administering pre- and post- treatment tests) adopted for the final experiment would permit the claim that the experiment has internal validity. 
At the end of this final pilot a statistical analysis was carried out on the pre-test and post-test results for the three tests. Separate one-way Anova were conducted on each task using raw scores as the dependent variable and instruction (the treatments) and time (pre-test vs post-test) as independent variables. A first set of Anovas on the pretest scores revealed no significant differences between the three groups before the instructional period. The results of the Anovas carried out for the interpretation task and the production tasks were identical to those obtained in the final experiment and described in the next chapter. In the interpretation task, Anova showed a main effect for instruction, time and a significant interaction between instruction and time. The post hoc test indicated that the effects were due to the following contrasts: the processing group improved its performance from the pre-test to the post-test, whereas the control did not. In addition the output group improved on interpretation but the processing group improved more.

For the production tasks (written \& oral), the Anova yelded the same results as in the case of the interpretation task, however the following contrasts were revealed through the post hoc analysis: the processing group and the output group improved significantly, whereas the control did not.

The final experiment (described in this chapter) was the result of what was learned in the three pilots described in this section. The three pilots were carried out to improve and refine the research methodology used in designing this study. This was achieved (in the final experiment) by:

1. using a randomisation procedure to make groups comparable;

2. introducing a pre-test and post-test procedure;

3. balancing the materials in terms of difficulty and other items (vocabulary, verbs, activities);

4. balancing the tests in terms of difficulty and familiarity;

5. balancing the amount of explicit instruction to which learners were exposed;

6. using a quantitative (Anova) and qualitative (production tasks) type of statistical analysis. 


\subsection{Instructional \& data collection procedures}

The three groups were enrolled in the second semester course at Greenwich and the experimentation took place during two consecutive days .

They were taught by the same instructor (the researcher) during the period of instruction who was also the 'subjects' regular classroom instructor. All the subjects had to sign a consent form (see Appendix C). As I was aware of the bias factor of being the instructor and the researcher in a classroom experiment the following steps were taken:

1. The teacher acted as a facilitator during the experiment. He presented the linguistic feature under investigation by explaining how it works in the target language and he followed the two instructional materials to the letter. As far as the control group is concerned he continued with normal topics and activities outlined in the teaching programme which, in week nine, correspond to the use of the future to express future meanings.

2. The subjects were aware of the comparative nature of the study. This increased the possibility that the subjects understanding the nature of the experiment (in this particular case a pedagogical research involving a comparison of teaching methods) could be affected by the 'Hawthorne' effect .

This effect consists in the influence that the experimental conditions might have on the subject's performance. Therefore, the fact that the subjects were aware of the nature of the experiment and that they were receiving special attention might have improved their performance. In the case of this study the researcher made all possible efforts to pay the same amount of attention and show the same enthusiasm across the groups to remove such an effect. Ideal experiments require identical groups differing only in teaching methods, however in real life it is almost impossible to control everything fully. Any attempt to interpret the results of this study must take into account some possible impurities which might have occured. 


\subsection{Statistical analysis: quantitative and qualitative level.}

One-way Anova was conducted on the raw scores for the interpretation and the production tasks to assess whether there were any statistically significant differences among the class means of any of the pre-tests measures. This was in order to establish that the three groups were part of the same population at the beginning of the treatment's period.

A two-way Anova (Repeated Measures) with one between subject factor and one within subject repeated measures factorial design (test $\mathrm{x}$ instruction) was carried out on the raw scores of each assessment task (production and interpretation tasks).

The raw scores were used as the dependent variable (three levels, the pre-test and the two post-tests) and instruction (three levels corresponding to the three treatments) as the labels for the independent variables.

Separate two-way Anova with one between subject factor and one within subject repeated measure factor design were carried out for the interpretation and production tasks on the the two post-tests to answer the time effect question.

In addition a post-hoc Tuckey's Honestly Significant Difference test was carried out to establish the contrasts of the effects of instruction in the three groups.

Finally a one-way Anova was performed on the raw scores (2') of the production tasks to establish possible qualitative difference in the groups.

The results of the statistical analysis carried out in this study will be presented and analysed in the next chapter. 


\section{CHAPTER SIX: RESULTS}

\section{Introduction}

In this chapter the statistical analysis used in this experiment to answer the specific questions addressed in this study will be presented.

The results are shown in two sections: the first section reports on the results of the statistical analysis on the interpretation task; in the second section the results of both production tasks (written $\&$ oral) are presented. One-way Anova was conducted on the raw scores for the interpretation and the production tasks to assess whether there were any statistically significant differences among the class means of any of the pretests. In order to ascertain as to whether processing instruction and the output-based type of instruction had an impact on the acquisition of Italian future tense morphology, the raw scores of the interpretation and production tasks were analysed using analysis of variance (two-way Anova) with one between subject factor and one within subject repeated measures factorial design(test $x$ instruction). Separate two-way Anova with one between subject factor and one within subject repeated measure factorial design were carried out for the interpretation and production tasks on the the two posttests to answer the time effect question. Finally, in order to establish possible qualitative differences in the production tasks two separate one-way Anova were performed on the raw scores of the production tasks. A system was used to give higher score to the 2's in the production tasks. A summary of the results will be presented at the end of this chapter. The individual scores for the three groups in the three tests will be presented in Appendix I.

\subsection{Interpretation data}

Data were collected for the interpretation task to address the first research question of the present study. The question asked was whether there would be any differences between the two instructional treatments in how university level learners of Italian will interpret sentences where future temporal reference are removed and replaced only by verb morphology. A pre-test was administered to the three groups, three weeks before the beginning of the experiment. 
A one-way Anova conducted on the pre-test alone revealed no significant differences among the three class means before instruction. Table 6.1 shows that there is not a statistically significant difference between the groups $(p<.7913)$.

One-way Anova summary table for Interpretation task (pre-test)

\begin{tabular}{|c|c|c|c|c|}
\hline $\begin{array}{l}\text { Source of } \\
\text { variation }\end{array}$ & D.F. & $\begin{array}{l}\text { Sum of } \\
\text { Squares }\end{array}$ & $\begin{array}{l}\text { Mean } \\
\text { Squares }\end{array}$ & $\begin{array}{cc}\text { F } & \text { F } \\
\text { Ratio Prob. }\end{array}$ \\
\hline Between Groups & 2 & .6667 & .3333 & $.2356 \quad .7913$ \\
\hline Within Groups & 36 & 50.9231 & 1.4145 & \\
\hline Total & 38 & 51.5897 & & \\
\hline
\end{tabular}

table 6.1

Means and Standard Deviations for the Interpretation task (pre-test)

\begin{tabular}{lllll} 
Variable & \multicolumn{1}{l}{ Value Label } & Mean & Std Dev & Cases \\
\hline For Entire Population & 3.8974 & 1.1652 & 39 \\
GROUP & 1 input & 3.8462 & 1.4051 & 13 \\
GROUP & 2 output & 4.0769 & 1.1152 & 13 \\
GROUP & 3 control & 3.7692 & 1.0127 & 13 \\
& & & &
\end{tabular}

table 6.2 
In table 6.2 the means and standard deviations of the three groups in the pre-test is shown. There is not any considerable variation in the standard deviation and means of the three groups. Unequivocally the results of the pre-test on the interpretation task indicate that any comparative effect attributed to instruction will not be attributed to prior knowledge of any of the groups.

A two-way Anova with one between subject factor and one within subject factor repeated measures factorial design (test $\mathrm{x}$ instruction) was used on the raw scores of the interpretation data to establish the possible effects of processing instruction on the way learners interpret sentences where the future tense is only expressed by verb morphology. The dependent variable, within subject (test), included three levels, the pre-test and two post-tests. The independent variable, between subject (instruction), also included three levels (input-based, output-based and no instruction).

The results of the two-way Anova for the interpretation task are summarised and displayed in table 6.3. This table shows that there is a significant effect for instruction $(\mathrm{p}<.001)$, a significant effect for test $(\mathrm{p}<.001)$ and a significant interaction between test and instruction $(p<.001)$.

Two-way Anova (Repeated Measures) summary table for Interpretation task (pre-test, post-test 1, post-test 2)

$\begin{array}{lrrrrr}\text { Source of Variation } & \text { SS } & \text { DF } & \text { MS } & \text { F } & \text { Sig of F } \\ \text { INSTRUCTION } & 184.68 & 2 & 92.34 & 42.29 & .001 \\ \text { TEST } & 107.50 & 2 & 53.75 & 100.22 & .001 \\ \text { INSTRUCTION BY } & 89.88 & 4 & 22.47 & 41.90 & .001 \\ \text { TEST } & & & & & \end{array}$

table 6.3 
Figure 6.4 shows graphically the interaction effect of test $\mathrm{x}$ instruction. The three groups are very similar after the first pre-test and then after the first post-test the input group is clearly superior to the other two groups, however the output group is also superior to the control. These effects are maintained in the final post-test.

Interaction Plot for instruction and time for the Interpretation task

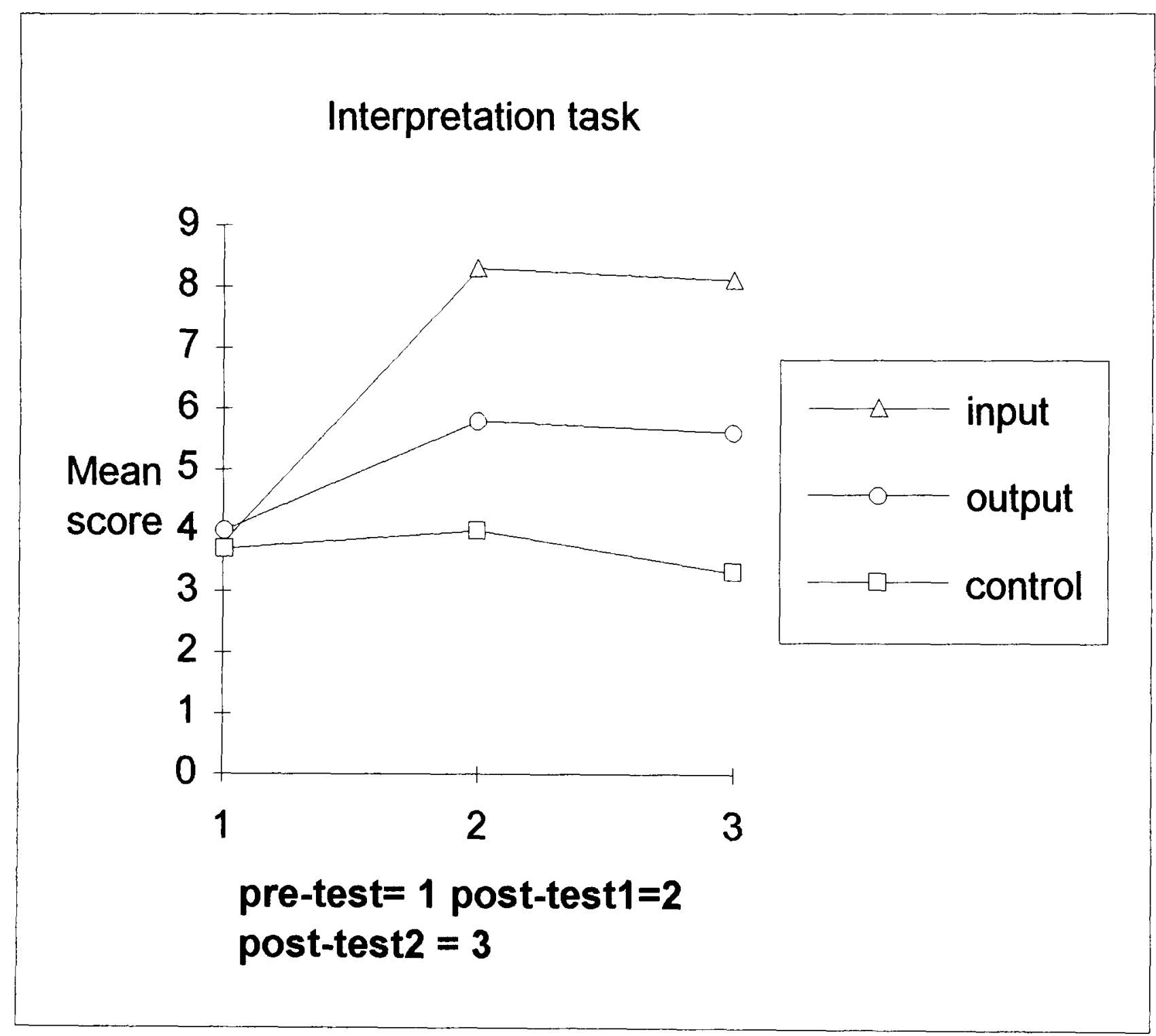

figure 6.4 
A post-hoc Tuckey test was conducted on the raw score of the first post-test for the interpretation task. This is in order to show the contrast among the three groups. The results showed in table 6.5 indicate that the effect of instruction were due to the following contrast: processing instruction is significantly better than output-based instruction and no instruction. However, the results also indicate that output-based instruction is significantly better than no instruction.

In short input processing instruction was superior to the other type of instruction and no instruction for the interpretation task. However, as has been said, output-based instruction was superior to no instruction.

Summary table for Post-hoc analysis on the interpretation task (post-test 1)

\begin{tabular}{|l|l|l|l|l|}
\hline Mean & group & control & output & input \\
\hline 4.0000 & control & & & \\
\hline 5.8462 & output & $*$ & & \\
\hline 8.3846 & input & $*$ & $*$ & \\
\hline
\end{tabular}

table 6.5

Another two-way Anova with one between subject factor and one within subject factor (post-test 1 and post-test 2) repeated measures factorial design (test $\mathrm{x}$ instruction) was used on the raw scores of the the two post-tests to answer the question of possible time effect.

The results of the two-way Anova in table 6.6 showed a significant effect for instruction $(p<.000)$, a significant effect for test $(p<.005)$. However the interaction between test and instruction is non-significant $(p<.201)$. This last finding shows that the interaction (test $\mathrm{X}$ instruction) is not statistically significant. Based on this finding the answer to the last research question is that there is no difference between posttest 1 and post-test2, therefore the positive effects (however different) of both instructional treatments are mantained. 
In table 6.7. the means and standard deviations of the three groups in the pre-test and two post-tests for the interpretation task are presented. In figure 6.8 the performance of the three groups in the pre-test and the post-tests are shown graphically.

Two-way Anova (Repeated Measures) summary table for Interpretation task (post-test 1 , post-test 2)

$\begin{array}{lrrrrr}\text { Source of Variation } & \text { SS } & \text { DF } & \text { MS } & \text { F } & \text { Sig of F } \\ \text { GROUP } & 273.10 & 2 & 136.55 & 85.09 & .000 \\ \text { TESTS } & 2.17 & 1 & 2.17 & 9.14 & .005 \\ \text { GROUP BY TESTS } & .79 & 2 & .40 & 1.68 & .201\end{array}$

table 6.6 
Means and Standard Deviations for the Interpretation task (pre-test, post-test 1, post-test 2)

Variable Value Label Mean Std Dev Cases

pre-test

\begin{tabular}{llccc} 
GROUP & 1 input & 3.8462 & 1.4051 & 13 \\
GROUP & 2 output & 4.0769 & 1.1152 & 13 \\
GROUP & 3 control & 3.7692 & 1.0127 & 13 \\
& & & & \\
\hline
\end{tabular}

post-test 1

$\begin{array}{lllll}\text { GROUP } & 1 \text { input } & 8.3846 & .9608 & 13 \\ \text { GROUP } & 2 \text { output } & 5.8462 & .9871 & 13 \\ \text { GROUP } & 3 \text { control } & 4.0000 & .8165 & 13\end{array}$

post-test 2

$\begin{array}{llrrr}\text { GROUP } & 1 \text { input } & 8.1538 & 1.0682 & 13 \\ \text { GROUP } & 2 \text { output } & 5.6923 & .9473 & 13 \\ \text { GROUP } & 3 \text { control } & 3.3846 & .9608 & 13\end{array}$

table 6.7 
Performance in the Interpretation task

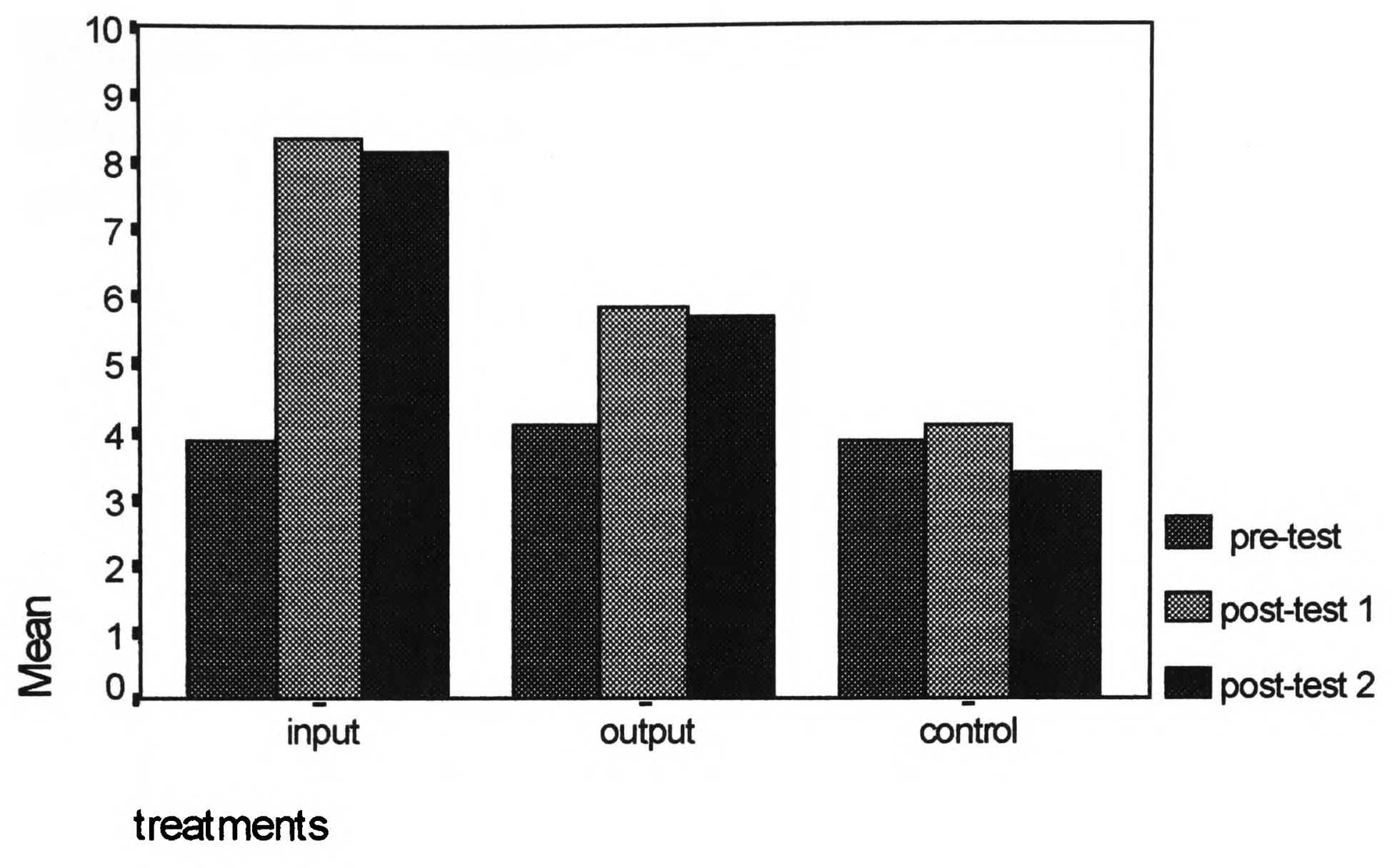

figure 6.8 


\subsection{Production data (written and oral)}

The production data were collected through two types of tasks: one written completion ask and and oral limited response task. In this section the results will be presented separately for the written and the oral production task.

\subsubsection{Written data}

A written production task was administered to the three groups to address the second research question of the present study. As in the case of the interpretation data statistical analyses were performed on the raw scores of the written completion text. A pre-test was administered to the three groups, some time before the beginning of the experiment. A one-way Anova conducted on the pre-test revealed no significant differences among the three class means before instruction. As shown in table 6.9 there is not a statistically significant difference between the groups $(p<.8798)$.

In table 6.10 the means and standard deviations of the three groups in the pre-test are also shown. The results of the pre-test on the written production task indicate that any comparative effect attributed to instruction will not be attributed to prior knowledge of any of the groups. As in the case of the interpretation task, independent and dependent variables included three levels.

A two-way Anova with one between subject factor and one within subject factor repeated measures factorial design (test $\mathrm{x}$ instruction) was used on the raw scores of the production written task to establish the possible effects of processing instruction on the way learners produce written sentences to express future meaning.

The results from the two-way Anova revealed, as summarised in table 6.11, a significant main effect for instruction $(p<.002)$, a significant main effect for test $(p<$ $.002)$ and a significant interaction between test and instruction $(p<.002)$.

The interaction effect of test $\mathrm{x}$ instruction are shown in the graph in figure 6.12 . 
One-way Anova summary table for the Written task (pre-test)

\begin{tabular}{lrrrrr}
\multicolumn{1}{c}{ Source } & D.F. & Squares & Squares & Ratio & Prob. \\
& & & & \\
& & & & \\
Between Groups & 2 & .1538 & .0769 & .1286 & .8798 \\
Within Groups & 36 & 21.5385 & .5983 & & \\
Total & 38 & 21.6923 & & & \\
& & & & &
\end{tabular}

table 6.9

Means and Standard Deviations for the Written production task (pre-test)

$\begin{array}{lcrrr}\text { Variable } & \text { Value Label } & \text { Mean } & \text { Std Dev } & \text { Cases } \\ \text { GROUP } & 1 \text { input } & 2.5385 & .8771 & 13 \\ \text { GROUP } & 2 \text { output } & 2.3846 & .7679 & 13 \\ \text { GROUP } & 3 \text { control } & 2.4615 & .6602 & 13\end{array}$

table 6.10 
Two-way Anova (Repeated Measures) summary table for written production task (pre-test, post-test $1 \&$ post-test 2)

Source of Variation $\quad$ SS DF $\quad$ MS F Sig of F

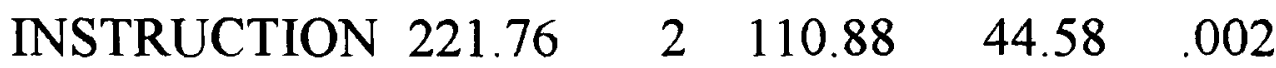

$\begin{array}{llllll}\text { TEST } & 312.94 & 2 & 156.47 & 187.28 & .002\end{array}$

TEST BY

$\begin{array}{llllll}\text { INSTRUCTION } & 112.91 & 4 & 28.23 & 33.79 & .002\end{array}$

table 6.11

Interaction Plot for instruction and time for the Written task

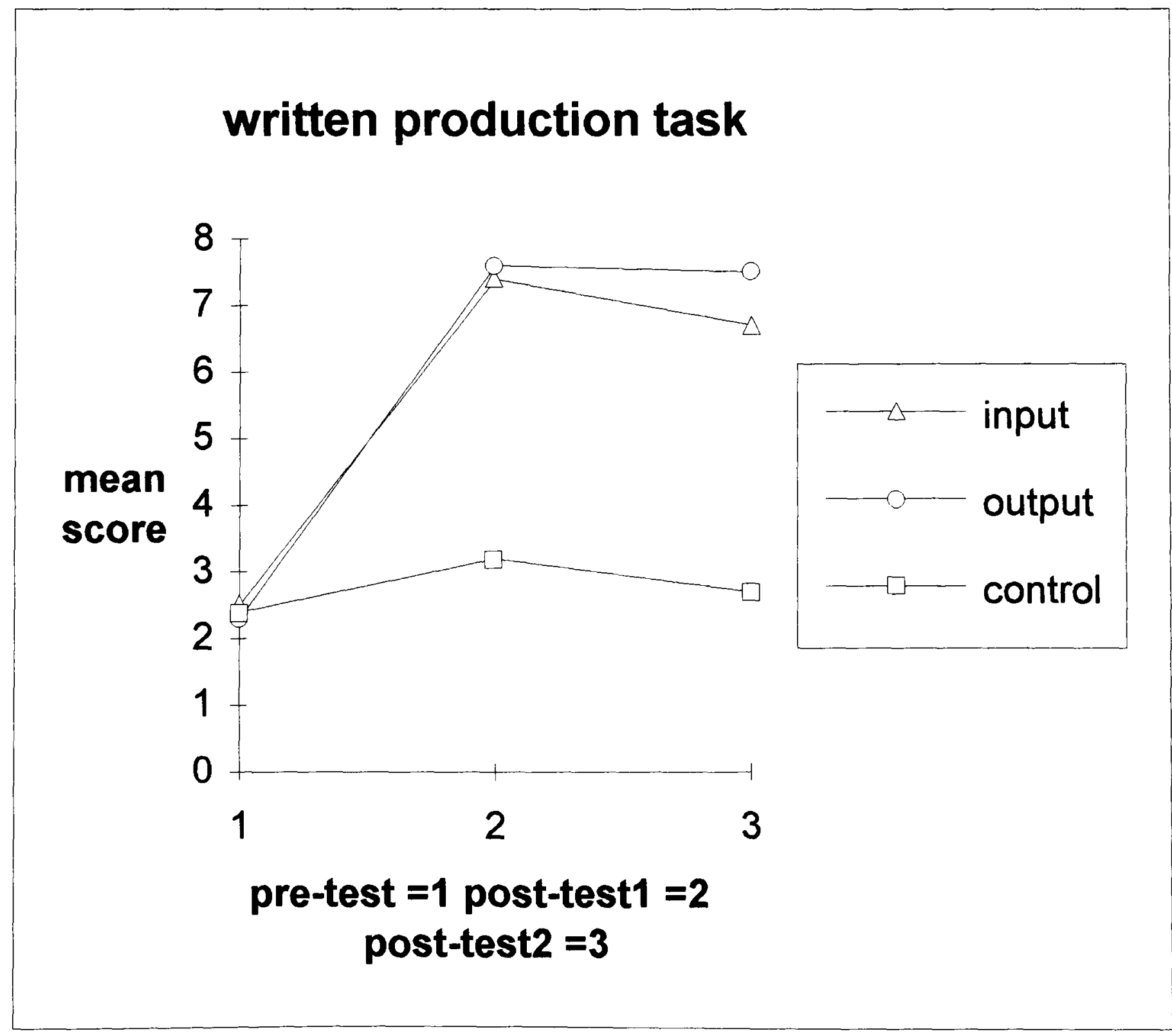

figure 6.12 
The three groups appear to be very similar after the pre-test and the two instructional groups are clearly superior to the control group in the first and second post-test.

A post-hoc Tuckey test was conducted on the raw score of the first post-test for the production task. This is in order to show the contrasts among the groups. The results shown in table 6.13 indicate that processing instruction is not significantly inferior to output-based instruction. The results also indicate that both output-based instruction and processing instruction were both significantly better than no instruction. In short, both output and input-based instruction were superior to no instruction and there was no significant difference between the two instructional treatments in the written task.

A second two-way Anova with one between subject factor and one within subject factor (post-test 1 and post-test 2) repeated measures factorial design (test $\mathrm{x}$ instruction) was used on the raw scores of the the two post-tests to answer the question of possible time effect. The results shown in table 6.14 indicate a significant effect for instruction $(p<.000)$ and test $(p<.004)$. However the interaction between test and instruction is not significant $(\mathrm{p}<.303)$. Therefore we are able to conclude that there is no statistical difference between the two post-tests for the written tasks. The effects of instruction are maintained over the second post-test.

The means and standard deviations of the three groups in the pretest and two posttests for the written production task are shown in table 6.15 and the performance of the three groups in the pre and post-tests are graphically shown in table 6.16. 
Summary table for Post-hoc analysis on the written task (post-test 1)

\begin{tabular}{||l|l|l|l|l||}
\hline Mean & group & control & output & input \\
\hline 3.2308 & control & & & \\
\hline 7.4615 & input & $*$ & & \\
\hline 7.6923 & output & $*$ & & \\
\hline
\end{tabular}

table 6.13

Two-way Anova (Repeated measures) summary table for

Written production task (post-test 1 , post-test 2)

Source of Variation $\quad$ SS $\quad$ DF $\quad$ MS $\quad$ F Sig of F

$\begin{array}{lrrrrr}\text { GROUP } & 333.56 & 2 & 166.78 & 52.53 & .000 \\ \text { TEST } & 3.71 & 1 & 3.71 & 9.63 & .004 \\ \text { GROUP BY TEST } & .95 & 2 & .47 & 1.23 & .303\end{array}$

table 6.14 
Means and Standard Deviations for the Written production task

Variable Value Label Mean Std Dev Cases

pre-test

$\begin{array}{lllll}\text { GROUP } & 1 \text { input } & 2.5385 & .8771 & 13 \\ \text { GROUP } & 2 \text { output } & 2.3846 & .7679 & 13 \\ \text { GROUP } & 3 \text { control } & 2.4615 & .6602 & 13\end{array}$

post-test 1

\begin{tabular}{llrrr} 
GROUP & 1 input & 7.4615 & 1.6132 & 13 \\
GROUP & 2 output & 7.6923 & 1.6525 & 13 \\
GROUP & 3 control & 3.2308 & .5991 & 13 \\
\hline
\end{tabular}

post-test 2

$\begin{array}{llccc}\text { GROUP } & 1 \text { input } & 6.7692 & 1.5359 & 13 \\ \text { GROUP } & 2 \text { output } & 7.5385 & 1.5064 & 13 \\ \text { GROUP } & 3 \text { control } & 2.7692 & .5991 & 13 \\ & & & & \end{array}$

Table 6.15 
Performance in the Written task

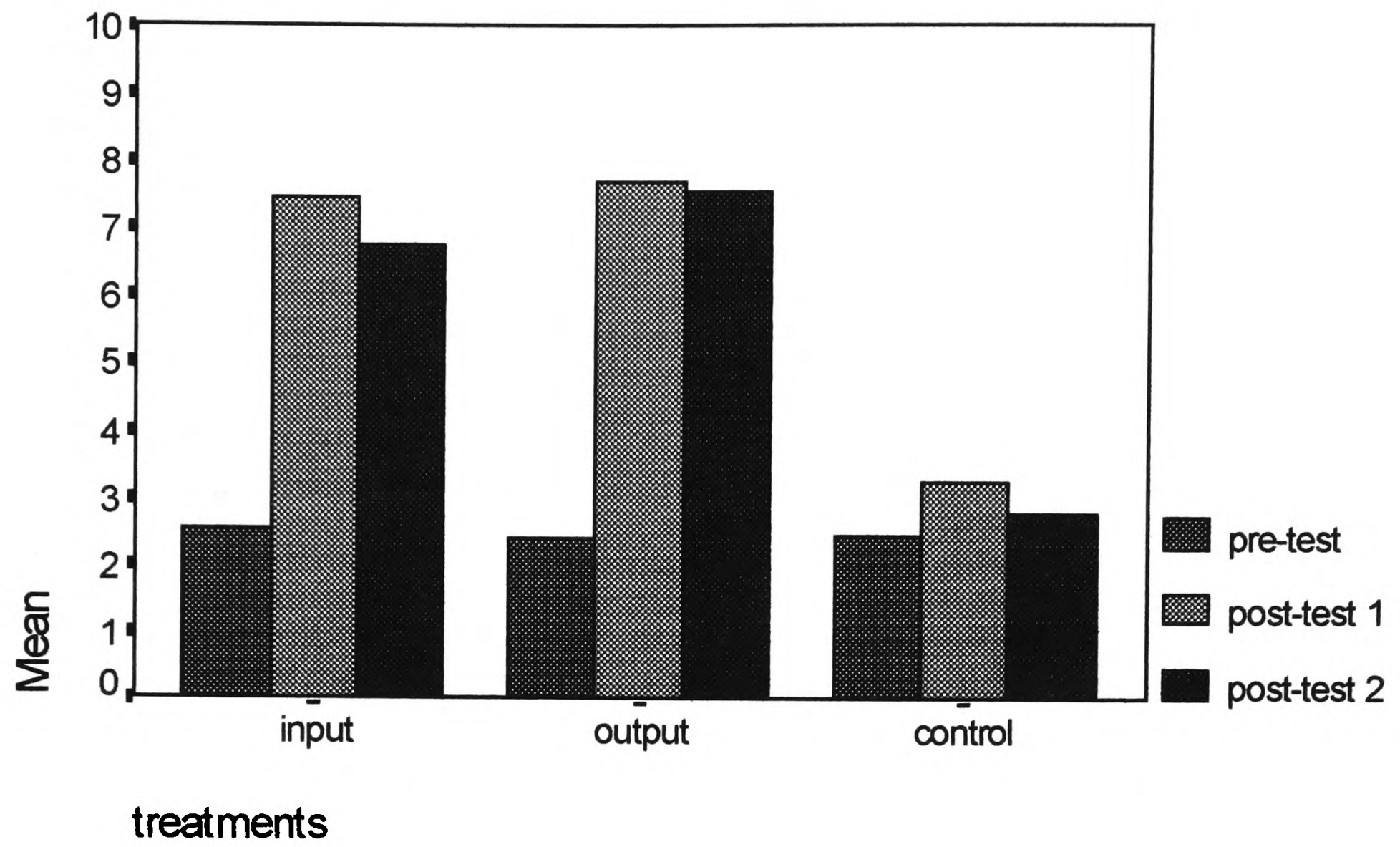

table 6.16 


\subsubsection{Oral data}

An oral production task was administered to the three groups to address the third research question of the present study which sought to find evidence of the possible effects of processing instruction in an oral production task (limited response). As in the case of the previous two analyses, the raw scores of the oral completion task were submitted to an analysis of variance. A preliminary one-way Anova conducted on the pre-test revealed no significant differences among the three class means prior to the instructional treatments. As shown in table 6.17 there is no statistically significant difference between the groups $(p<.0428)$ in the pre-test. In table 6.18 the means and standard deviations of the three groups in the pre-test are presented. The results of the pre-test on the oral production task indicate that any comparative effect attributed to instruction will not be attributed to prior knowledge of any of the groups. A two-way Anova with one between subject factor and one within subject factor repeated measures factorial design (test $\mathrm{x}$ instruction) was used on the raw scores of the oral production task to establish the possible effects of processing instruction on the way learners produce oral sentences to express future meaning.

The repeated measures Anova revealed, as summarised in table 6.19, a significant main effect for instruction $(p<.004)$, a significant main effect for test $(p<.004)$ and a significant interaction between test and instruction $(p<.004)$. The results of the interaction between instruction and time are graphically shown in the plot in figure 6.20. This graph clearly indicates that the three groups were similar before instruction and then after the first post-test the two instructional groups improved considerably and similarly, whereas the control group does not show any improvement as it experiences a very small change of scores over time. In the second post-test these effects for the instructional group seem to be maintained with again no significant difference between the input and the output group.

A Tuckey test was conducted on the raw score of the first post-test for the production task. The post-hoc analysis confirmed as indicated in table 6.21 that there is no significant difference between processing instruction and output-based instruction in the case of oral production. 
One-way Anova summary table for Oral task (pre-test)

\begin{tabular}{lccccc}
\multicolumn{1}{c}{ Source } & \multicolumn{2}{c}{ Sum of } & Mean & F & \multicolumn{1}{c}{ F } \\
& D.F. & Squares & Squares & Ratio Prob. \\
Between Groups & 2 & 4.7692 & 2.3846 & 3.4444 & .0428 \\
Within Groups & 36 & 24.9231 & .6923 & & \\
Total & 38 & 29.6923 & & & \\
& & & & &
\end{tabular}

Table 6.17

Means and Standard deviations for the Oral task (pre-test)

\begin{tabular}{lcccc} 
Variable & Value Label & Mean & Std Dev & Cases \\
\hline GROUP & 1 input & 2.6154 & .8697 & 13 \\
GROUP & 2 output & 2.9231 & .7596 & 13 \\
GROUP & 3 control & 2.0769 & .8623 & 13
\end{tabular}

table 6.18

Two-way Anova (Repeated Measures) summary table for

Oral production task (pre-test, post-test $1 \&$ post-test 2 )

Source of Variation $\quad$ SS $\quad$ DF $\quad$ MS $\quad$ F Sig of F

$\begin{array}{llllll}\text { GROUP } & 286.89 & 2 & 143.44 & 142.03 & .004 \\ \text { TESTS } & 254.43 & 2 & 127.21 & 384.93 & .004 \\ \text { GROUP BY } & & & & & \\ \text { TESTS } & 88.44 & 4 & 22.11 & 66.91 & .004 \\ & & & & & \end{array}$

Table 6.19 
Interaction Plot for instruction and time for the Oral task

\section{Oral production task}

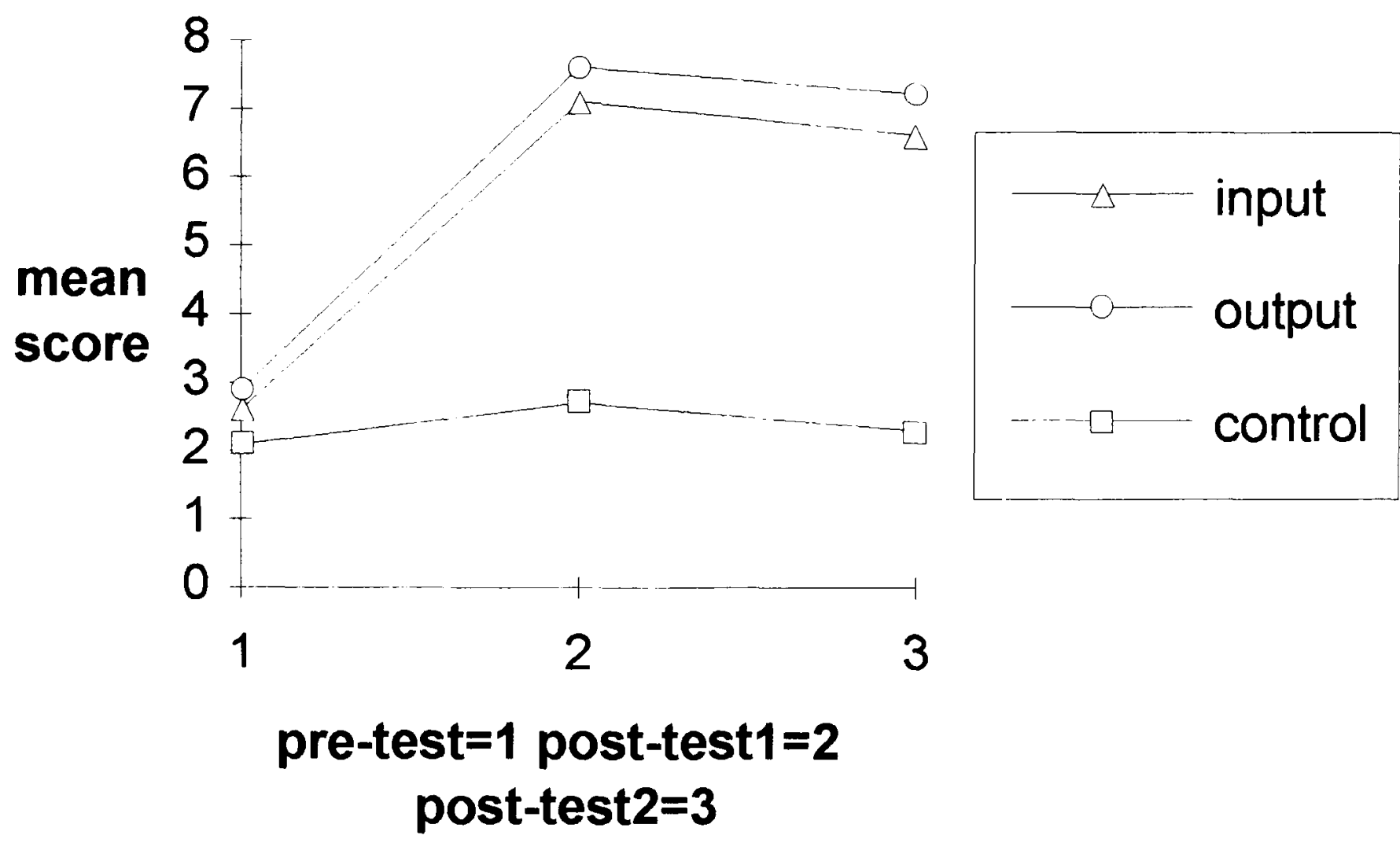

figure 6.20

In this case, as in the case of the written task, the two instructional groups improved significantly whereas the control group did not. However there was no significant difference between the processing group and the output-based group.

A second two-way Anova with one between subject factor and one within subject factor repeated measures factorial design (test $\mathrm{x}$ instruction) was used on the raw scores of the the two post-tests to answer the question of possible time effect. The results shown in table 6.22 indicate a significant effect for instruction $(p<.000)$ and test $(p<.000)$, however the interaction is not significant $(p<.908)$.

Therefore it can be concluded that the two post-tests are not significantly different and the main effects of instruction are mantained.

The means and standard deviations of the three groups in the pretest and two posttests for the written production task are shown in table 6.23 and performance of the three groups in the pre and post-tests sessions are summarised in the graph in figure 6.24 . 
Summary table for the Post-hoc analysis on the oral task (post-test 1)

\begin{tabular}{||l|l|l|l|l|}
\hline \multicolumn{1}{|l|}{ Mean } & group & $\begin{array}{c}\text { contro } \\
1\end{array}$ & output & input \\
\hline 2.7692 & control & & & \\
\hline 7.1538 & input & $*$ & & \\
\hline 7.6923 & output & $*$ & & \\
\hline
\end{tabular}

table 6.21

Two-way Anova (Repeated Measures) summary table for

Oral production task (post-test $1 \&$ post-test 2)

$\begin{array}{llllll}\text { Source of Variation } & \text { SS } & \text { DF } & \text { MS } & F & \text { Sig of F }\end{array}$

$\begin{array}{lrrrrr}\text { GROUP } & 375.56 & 2 & 187.78 & 335.43 & .000 \\ \text { TEST } & 3.71 & 1 & 3.71 & 27.97 & .000 \\ \text { GROUP BY TEST } & .03 & 2 & .01 & .10 & .908\end{array}$

table 6.22 
Means and Standard deviations for the Oral task

\begin{tabular}{|c|c|c|c|c|}
\hline Variable & Value Label & Mean & Std Dev & Cases \\
\hline \multicolumn{5}{|l|}{ pre-test } \\
\hline GROUP & 1 input & 2.6154 & .8697 & 13 \\
\hline GROUP & 2 output & 2.9231 & .7596 & 13 \\
\hline $\begin{array}{l}\text { GROUP } \\
\text { post-test }\end{array}$ & 3 control & 2.0769 & .8623 & 13 \\
\hline GROUP & 1 input & 7.1538 & .9871 & 13 \\
\hline GROUP & 2 output & 7.6923 & .6304 & 13 \\
\hline $\begin{array}{l}\text { GROUP } \\
\text { post-test }\end{array}$ & 3 control & 2.7692 & .5991 & 13 \\
\hline GROUP & 1 input & 6.6154 & .6504 & 13 \\
\hline GROUP & 2 output & 7.2308 & .5991 & 13 \\
\hline GROUP & 3 control & 2.3846 & .6504 & 13 \\
\hline
\end{tabular}

table 6.23 
Performance in the Oral task

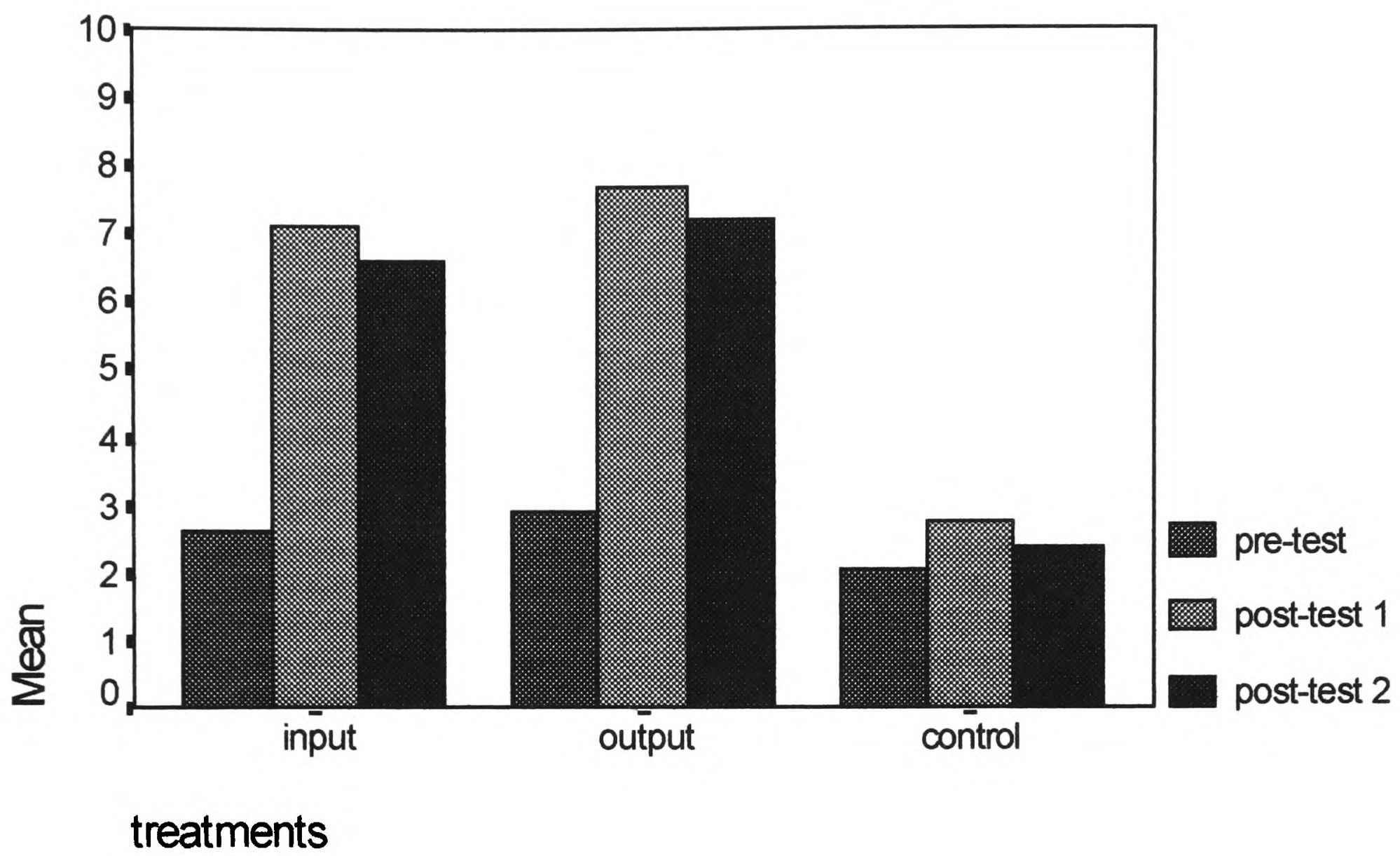

figure 6.24 


\subsubsection{Qualitative analysis: the production data}

The analysis used in the present study is essentially quantitative in nature. However, there might be some qualitative differences within the groups.

The scoring procedure used for both the written and oral production tasks was the ' 2 $1-0$ ' type (' 2 ' for a completely accurate response, ' 1 ' for a partially correct response and ' 0 ' for an incorrect response).

It was pointed out that the scoring procedure used for the two production tasks might obscure possible qualitative difference between the groups. The scoring procedure adopted does not allow the numbers of 2's, 1's and O's scored by each subjects in the three groups to be distinguished. One subject might have scored 6 with two fully correct responses and two partially correct response. However the same score might have been obtained by another subject through three fully correct responses.

In order to tackle this methodological objection a new variable was created for both the written and the oral task. This new variable was created by rescoring the first post-test (as it was thought that it was not necessary to do the same for the delayed post-test as the two post-tests were very similar and not statistically different) both the written and the oral data.

The principle followed was that the 2's should be given an extra point (therefore 3 points instead of 2 were given for a fully correct answer) and the 1's and 0's kept the same score.

One-way Anova summary table for qualitative

differences in the Written task (post-test 1 )

$\begin{array}{llllll} & & \text { Sum of } & \text { Mean } & \text { F F } \\ \text { Source } & \text { D.F. } & \text { Squares } & \text { Squares } & \text { Ratio Prob. } \\ \text { Between Groups } & 2 & 388.3590 & 194.1795 & 36.5845 .0000 \\ \text { Within Groups } & 36 & 191.0769 & 5.3077 & & \\ \text { Total } & 38 & 579.4359 & & & \\ & & & & & \\ \end{array}$

table 6.25 
In the case of the subject who scored 6 in two different ways (two fully correct responses and two partially correct responses, or three fully correct responses) the subject who managed to get three fully correct responses was distinguished from the previous one by the fact that he had produced more fully correct responses.

Therefore in the new set of scores he would get a total of 9 and the other subject with only two 2's and two 1's a total of 8 .

The new variable was the subject of a one-way Anova for the written task and for the oral task. The written task data are summarised in table 6.25 and the oral data in table 6.26. The results of both analysis confirmed the results obtained in the quantitative analysis.

The three groups were found to be statistically different $(p<.000)$ for both production tasks and a post-hoc analysis revealed the same patterns as in the case of the quantitative analysis where the two instructional groups outperformed the noinstruction group.

One-way Anova summary table for qualitative

differences in the Oral task (post-test 1)

\begin{tabular}{|c|c|c|c|c|}
\hline Source & & $\begin{array}{l}\text { Sum of } \\
\text { Squares }\end{array}$ & $\begin{array}{c}\text { Mean } \\
\text { Squares }\end{array}$ & $\begin{array}{l}\text { F F } \\
\text { Ratio Prob. }\end{array}$ \\
\hline Between Groups & 2 & 305.4359 & 152.7179 & 76.3590 .0000 \\
\hline Within Groups & 36 & 72.0000 & 2.0000 & \\
\hline Total & 38 & 377.4359 & & \\
\hline
\end{tabular}

table 6.26 


\subsection{Summary of results}

In this paragraph, the results will be summarised in relation to the four research questions which motivated this study and the subsequent hypotheses formulated.

The overall findings of this study will be discussed in the next chapter where the evidence collected in the present study will be also compared to the previous studies on processing instruction and some conclusions and implications will be drawn.

\section{1) Research Question one (supported):}

Will there be any differences in how two groups of learners of Italian exposed to two different types of instruction (processing instruction vs output-based instruction) interpret sentences where future is only expressed by verb morphology?

Based on previous research it was hypothesized that the group who received processing instruction would perform better in the interpretation task than the other instructional group and the control group.

The instructional data collected through the interpretation task and the subsequent statistical analysis revealed that the differences among the three groups under investigation were statistically significant. The Anova analysis used in the case of the interpretation tasks on student's raw scores showed a significant main effect for instruction $(p<.001)$ and for test $(p<.001)$ and the interactions between the two $(p<$ $.001)$. A post-hoc analysis revealed the following:

first, with respect to the input-based type of grammar instruction, it was discovered that the group receiving processing instruction overall performed better in the interpretation task when compared to the other two groups.

However, what was also very interesting about the results of the interpretation task is that the group who received the output-based type of instruction, although being inferior to the processing instruction group, also improved in the first post-test and there was a significant difference between this group and the no-instruction group at interpreting sentences where the future is only expressed by verbal morphology. 
The first hypothesis of this study is supported as processing instruction seems to have a greater effect on the developing system of Italian learners than a different type of instruction output-based or a no-instruction treatment.

However, even the output-based group improved on the interpretation task and this finding differs from the finding obtained in Cadierno's study (1995) where the group who received a type of instruction based on explicit presentation of rules and output practice showed no improvement in the interpretation task.

\section{2)Research Question two (supported) :}

Would learners receiving processing instruction produce sentences to express future meaning in a written production task as well as learners receiving the output-based type of instruction?

On the basis of previous research it was hypothesized that the subjects receiving processing instruction would perform as well as those receiving the output-based instruction in the written completion task. This hypothesis was supported by the written data of this study.

The results of the written task revealed that both the instructional treatments performed equally.

The Anova (two-way) conducted on the raw scores of the production data yielded a significant effect for instruction $(p<.002)$, test $(p<.002)$ and interaction between instruction and test $(p<.002)$. The Tuckey post-hoc analysis showed that both the processing instruction group and the output-based group produced correct future tense forms to express future meaning better than the no-instruction group in the written completion task. The post-hoc analysis revealed no difference between the two instructional treatments.

The qualitative analysis on the number of ' 2 's for the written task on the two posttests also confirmed that there was no significant difference between the two instructional treatments. 


\section{3) Research Question three (supported):}

Would learners receiving processing instruction produce sentences to express future meaning in an oral limited response production task as well as learners receiving the output-based type of instruction?

It was hypothesized that the subjects receiving processing instruction should be able to perform as well as the subjects receiving the output-based type of instruction in an oral limited response production task.

The results of Anova (two-way) conducted on the raw scores of the oral production data yielded a significant effect for instruction $(p<.004)$, test $(p<.004)$ and interaction between instruction and test $(p<.004)$. The results of the post-hoc 1 analysis carried out on the oral data also revealed statistical differences within the three groups. The findings of the oral data are particularly important as they show that again as in the case of the written production task, the processing instruction group performed as well as the output-based instruction group in the oral task. Both instructional groups outperformed the no-instruction group.

The hypothesis that processing instruction would have an impact on how learners produce correct sentences in the future tense in an oral limited response task is also confirmed in this study.

\section{Research Question four (supported):}

Would the possible positive effects for instruction be retained over time by the two instructional group ?

Based on previous research it was hypothesized that the processing instruction group would retain the positive effects of instruction over a delayed post-test.

The results of Cadierno (1995)'s study on the acquisition of Spanish past tense showed that in the processing instruction group the effects of instruction held for one month for both the interpretation and the written task, while for the traditional group the instructional effects lasted only for the written task. 
The results of the present study are different as the statistical analysis has shown that for both for the processing instruction group and the output-based group the instructional effects lasted for the interpretation task and the two production tasks.

The positive effects of both types of instruction held over a second post-test administered three weeks later.

However, as previously stated, due to practical constraints, the second post-test was administered after three weeks (which corresponds to the end of the second semester of study). Therefore further research should be carried out to test the effects of processing instruction at a later time. 


\section{CHAPTER SEVEN: DISCUSSION-LIMITATIONS-IMPLICATIONS}

\section{Introduction}

The purpose of this chapter is to discuss the general findings in the light of previous research and to draw some conclusions about the results of this experimentation and the implications for research at the theoretical and the pedagogical level. This study investigated the effects of two types of explicit grammar instruction and their impact on the acquistion of the Italian future tense. The effects of instruction at sentence level were measured through an interpretation task, a written completion production task and finally an oral limited response production task.

Finally, limitations of this research will be addressed and suggestions for further research offered.

\subsection{Discussion of the findings}

The results of this study will be discussed separately for each set of data collected.

The results of the interpretation data confirmed the hypothesis formulated in this study according to which processing instruction would have a greater effect on the way L2 learners interpret sentences in which future tense morphology is only expressed by verb morphology, when compared to an output-type of instruction and no-instruction. Therefore, this study provides further evidence of the effectiveness of processing instruction at altering the way learners, in this case beginners in Italian, interpret an item of verbal morphology at sentence level.

The results of the interpretation data, although parallel to those obtained by Cadierno (1995) on the Spanish past tense, expand previous findings in relation to the effects of processing instruction on the acquisition of verbal morphology. This has been shown in two ways: 
1. firstly as previously suggested, the results of Cadierno's (1995) study were limited to one second language (Spanish) and one linguistic item (past tense) of the Spanish verbal system.

The present study provides empirical evidence on the positive effect of processing instruction on the acquisition of Italian future tense among beginner learners;

2. secondly, although the results of the interpretation task indicated that learners receiving the input processing instruction performed overall better than the learners receiving output-based instruction and no-instruction, the group receiving outputbased instruction was statistically different to the group receiving no-instruction, as the data show that the output-based group also improved in the interpretation task.

In Cadierno's study the non significant effect of a traditional approach to grammar instruction (this is what Van Patten and Cadierno called output-based instruction) on an interpretation task was explained on the basis that learners might have two separate types of linguistic knowledge.

In this respect Cadierno's study (1995) seemed to provide support for Krashen (1982) and lately Schwartz's (1993) claim of the existence of two types of linguistic knowledge systems.

Krashen argues that 'acquired knowledge' is achieved when learners are involved in natural communication, this is the case of activities where the focus is on meaning and where comprehensible input is provided in the language classroom. On the other hand, 'learned knowledge' occurs when learners' attention is focused on the general properties of a $\mathrm{L} 2$.

However the findings of the present study show that even learners in the output-based instruction treatment have acquired some new language to perform the task.

Therefore, although processing instruction had a greater effect on the developing system of beginner learners of Italian than the output-based type, the output group also improved in the interpretation task and this effect was maintained in a delayed post-test. A possible explanation of this finding is that learners in this group must have accessed some knowledge to perform the interpretation task. 
The output-based type of instruction consisted of explicit knowledge and various kind of output practice including meaning-oriented activities. When it comes to the interpretation task it is possible that the subjects in this group were accessing the information obtained in the output practice which led to their superior performance since the control group had no instruction.

Because some of the activities in the output-based group were meaning-oriented activities, it is possible to argue that subjects in this group have created some meaningful output and this has served as input to the others in the class. In other words, the output learners provided input for each other.

It is always very difficult to isolate completely input and output in real language classes.

Interestingly, in the traditional type of instruction used in Cadierno's study learners had very few opportunities to be involved in meaningful activities.

This is also one of the main methodological objections to Cadierno's study as the traditional type of instruction received by one of the group contained mostly mechanical form-oriented practice, compared with processing instruction received by the other group in which activities were only communicative and meaningful.

In contrast to Cadierno's study, the two treatments in the present study, differed only in terms of practice (input vs output) as both treatments contained meaningful and communicative activities.

Therefore, it can be claimed that the present study has not been biased towards one instructional treatment or the other in terms of a less or more meaningful type of activities included in the two different approaches to grammar instruction.

In the second research question of this study it was hypothesised that processing instruction and output-based instruction were both superior to no instruction on a written completion task at sentence level. The statistical analyses does not reveal any differences between the two instructional groups in the written task. The two instructional groups outperformed the control group in the written task and improved equally their performance. This is extremely important if we consider that the group receiving input processing instruction was never involved in activities in which they had to produce the target feature, in this case the future tense. 
Therefore, although the fact that the processing group was not familiar with the production task, it was able to perform at least as well as the output-based group.

This particular finding provides not only further evidence of the impact of processing instruction on learners' developing system (previous studies were carrried out by Van Patten \& Cadierno 1993 a on the object pronoun, Cadierno 1995 on the past tense and Cheng 1995 on the use 'ser' and 'estar') but also evidence of its impact on another romance language and on a different feature of verbal morphology. It can be explained in the light of a processing framework of SLA (Van Patten 1996 and Gass 1988) which has emphasised the crucial role of input processing in making data available to the developing system (conversion of input into intake).

In the third research question it was also hypothesised that processing instruction would show the same positive effects on a different production task : an oral limited response task.

The findings of the oral production data highlight again the role of processing instruction at helping the input processing phase which results in better intake. This specific finding builds on and reinforces previous findings (see Cadierno 1995 and Van Patten \& Cadierno 1993 a) which were limited to a written production task at sentence level, with the only exception of Sanz (Van Patten \& Sanz 1995) who provided some evidence of the effects of processing instruction in the acquisition of object pronoun on various communicative tasks.

The positive impact of processing instruction on the ability of Italian L2 learners at producing oral sentences containing future tense to express future meaning, provides new evidence for the positive effects of processing instruction on L2 learner's developing system and subsequently their output.

However, despite the fact that the present study offers further evidence of the effectiveness of processing instruction on a different mode of production (oral task), the two oral tasks were very short, contained no distractors, were restricted to sentence level and highly controlled tasks. In addition to that, it could be argued that learners might have used 'learned knowledge' rather than 'acquired knowledge' to perform the production tasks. 
In the final research question of the present study, it was hypothesised that the effects of instruction would hold over a period of three weeks.

The results of the analysis confirm the positive results obtained by Cadierno (1995) who studied the effects of processing instruction over a period of one month and Cheng (1995) in which the effects of processing instruction just as in the present study held over a three weeks period for the interpretation and the two written tasks. However, in contrast to Cadierno's results, the effect of instruction on the output group in the interpretation task held for the same period as it did for the production tasks.

Overall the general findings of this study indicate that processing instruction has a positive effect on the developing system of L2 learners. This, as has been said, confirm and expand the results obtained by the studies carried out in processing instruction which were limited to various linguistic features (past tense, object pronoun and 'ser' - 'estar') of the Spanish language.

The present investigation on the acquisition of the Italian future tense, provide evidence of the fact that a direct intervention on the subject input processing strategies has a significant effect on the subject's developing system.

Processing instruction would seem to have altered the way in which Italian beginner learners processed input which in turn had an effect on their developing system as the processing instruction group performed in the written and the oral production task as well as the output group.

Processing instruction produced a change in the way form-meaning connections are made, and this change appears to have generated new knowledge which was available for both interpreting and producing language in a written and oral task at sentence level. 


\subsection{Implications for theory}

The outcome of this study has repercussions at theoretical, and pedagogical level. As far as the theoretical level is concerned, the contributions of the present study are threefold:

1. it contributes to the discussion on the role of formal instruction by supporting a new avenue of research for the explanation of the effects of formal instruction.

In the first chapter of this study the main theoretical frameworks for the role of instruction were presented and some empirical studies which could account for those frameworks were reviewed. The results from the empirical research indicate a positive role for formal instruction. Formal instruction seems to promote more rapid SLA and contributes to higher levels of ultimate achievement. However, there might be some psycholinguistic constraints to limit its role and, in addition to that, it seems that formal instruction is effective in developing explicit knowledge measured through controlled tasks and less effective in spontaneous language use. The overall findings of the effects of formal instruction on SLA were mixed, and as suggested by Van Patten \& Cadierno (1993 a), one of the explanations of these conflicting results could be that instruction has been viewed as the explanation and practice of grammatical forms rather than explicit intervention in the processes and strategies used by L2 learners during input processing. In that sense, the present study supports this new avenue of research inaugurated by Van Patten which looks at how formal instruction might have an impact on the acquisition of a L2, rather than on whether or not instruction has a positive effect on SLA;

2. within this context the present study contributes directly to the discussion on the crucial role that input processing plays in SLA.

In respect of this, the results of the present study provide further support for current models of SLA (Van Patten 1996 and Gass 1988) which link input processing and the developing system, as it provides further evidence of the impact of processing instruction on two different production tasks (oral and written). Van Patten's model emphasises the role of input processing in the attempt to account for the derivation of intake data. 
As in previous studies (see table 4.3) the processing group was assisted (it was taught to attend to the input to notice the grammar) 'in building up an implicit knowledge of the language via intake facilitation' (Van Patten \& Cadierno 1993 b: 34). No attempts were made to make explicit knowledge implicit knowledge;

3. in this respect, a third contribution of the present study is that it provides some support to the 'facilitative position' which indicates that under certain conditions explicit grammar instruction can be of considerable help in the acquisition of implicit knowledge. However, it can be argued that the effects of explicit grammar instruction may vary according to certain factors. One of these factors has been identified by Hulstijn \& De Graaff (1994) who argued that explicit instruction is more effective in the case of complex (cognitively) rules than in the case of simple rules. In addition to this, it is likely that explicit grammar instruction would be more effective when a rule is large in scope (this applies to many cases) and highly reliable rather than viceversa (where a rule has small scope and low reliability).

The present study lends support to these hypotheses as the linguistic feature chosen in this study is highly reliable and complex as the Italian verbal morphology has complex inflectional rules (English has moderate flectional rules, therefore it is commonly accepted that English speakers have difficulty in comprehending and producing sentences containing verbal morphology).

In conclusion, processing instruction aims at pushing $\mathrm{L} 2$ learners to attend to elements in the input that might be otherwise missed. As was said in chapter four, processing instruction does not intend to 'pour knowledge' into learners' heads. Processing instruction intends to assist certain processes which can aid the growth of the developing system by enriching learners' intake.

Processing instruction accomplishes its goal of manipulating learners' strategy of giving precedence to temporal adverbs over morphological markers which results in the learner's ability to interpret and produce sentences. In the case of this study this latter finding has been proven in both written and oral production. 
As already pointed out, the overall results of the present study add further value to the effectiveness of processing instruction in the acquisition of Italian future tense verbal morphology by beginner learners. 


\subsection{Implications for pedagogy}

At the pedagogical level the findings from the present study seem to suggest the need to carry out more studies to compare the effects of different types of FFI on SLA in order to establish which type is more 'effective'. In chapter two, three main lines of research have been isolated to account for studies which have explored different ways of integrating instruction on grammatical forms within a communicative framework of language teaching. In this experimental study a comprehension-based approach using tasks requiring an interpretative comprehension of input has been investigated. The implications for pedagogy of the present study are threefold:

1. processing instruction seems to have a greater effect on learners' developing system than a type of instruction which involves grammar explanation and output practice. Therefore explicit instruction should involve a move from input to output which is compatable with Van Patten's model of language acquisition. In addition to this, the present empirical study emphasizes the need to follow a specific sequence in explicit grammar instruction such as: rule presentation by breaking down the rules in small pieces, explanation of the relationship between form and meaning, processing instruction activities by using different comprehension tasks (in this study two main types were used: binary options and matching). Production tasks should be delayed until later. In this context processing instruction has been proven an alternative way to present grammar instruction into the language classroom. A type of grammar instruction which is more congruent to the tenets of the communicative programme. Text-books should include materials which contain processing instruction activities (see paragraph 7.5);

2. it reasserts the important role of comprehensible meaning bearing input in language acquisition. This can be seen in the input-based type of instruction where meaning was always in focus and the subjects of the processing instruction group were involved in activities in which they had to respond to the informational content of the input. This has also been reinforced by the results of the interpretation data of the outputbased treatments. 
The output group improved on the interpretation task, although not as well as the processing instruction group. This latter finding has been interpreted as showing that in some of the output activities meaning played an important role;

3. it suggests that, because of the activities used in the processing instruction approach which focuses on both meaning and form, it is possible and desirable to have approaches that incorporate form and meaning-focused instruction.

This is also supported by Spada's (1987) findings which indicate that formal instruction might work best in promoting acquisition when it is linked to opportunities for natural communication. 


\subsection{Limitations of the present study}

1. Although the sample size of this experiment is relatively small (39 subjects), and would need to be duplicated before we can comment with more confidence on the generalizability of its findings, the results from the pilot studies support the wider validity of the results.

2. The conclusions drawn from this study are based on a sample of students from a single University; nevertheless, the similarities between the results of this study and previous empirical research on the impact of processing instruction do lend validity to the present study.

3. The findings from the present study have shown that processing instruction not only has an impact on learners' ability to process input better but also has an impact on their developing system so that they can access a linguistic feature in both oral and written production tasks under controlled situations. However, as in the case of Cadierno's (1995) empirical research, this study does not support the view that processing instruction results in better communicative performance.

4. Long-term effects of the variables under investigation should be reexamined as the long-lasting effects of instruction in this study was measured over a period of three weeks.

5. Finally, it could be argued that the fact that the instructor of the three groups was also the researcher meant that he could have been biased towards one approach or another.

On the other hand, the fact that the experimenter and the instructor were the same person for the three groups eliminated the complicating factor of having various instructors with different teaching abilities, styles and habits. 


\subsection{Suggestions for future research}

It is clear that further research should focus on measuring effects of processing instruction on different linguistic features, for example, in the case of gender morphology such as adjective agreement. In this study a meaning-bearing linguistic item was chosen as processing instruction has been proven effective in those items of the language. This is because input processing is largely concerned with creating form-meaning relationships. However, a possible limit of processing instruction could be whether or not it could be effective on a 'meaningless' linguistic feature. Would processing instruction be effective on those elements of language which are devoid of meaning?

Processing instruction should also be measured by altering different strategies used by L2 learners to process input (as indicated by Van Patten 1996) such as in the case of the preference given by L2 learners to 'more meaningful' morphology before less or 'nonmeaningful morphology'. Inflections of adjectives in Italian, for instance, tend to be low in communicative value because they are both redundant and lack semantic value (the ' $\mathrm{a}$ ' in bella does not carry any semantic meaning in the phrase la donna bella. Bella ends in 'a' because donna is of a grammatical class that requires this).

In addition to this, ' $a$ ' is spread across three words in the sentence, therefore it makes the phrase highly redundant. It would be interesting to compare inflections of adjectives low in communicative value with similar morphemes that are richer in communicative value due to the context, like sentences without explicit subjects where the only cue to identify the subject is gender (a practical example could be a sentence in which learners hear just ' $\mathrm{e}$ ' bella' and only from the adjective ending they have to identify who the sentence is refered to: Bill Clinton or Monica Lewinsky....).

The question whether the effects of instruction would hold over post-test sessions should also be addressed as empirical studies on the effects of processing instruction have failed to measure its long-lasting effects.

Another possible feature for further research, considering the increasing importance of input-based approaches and recent developments in L2 acquisition theory, might be to compare the effects of two input-based approaches to grammar instruction (e.g. a type 
of input enhancement or consciousness raising vs processing instruction), to investigate whether making a form salient in the input and bringing it to the attention of the learner is enough to get that form processed. The alternative, as suggested by research in processing instruction, is to establish whether the intake must constantly provide the developing system with examples of correct form-meaning connection in order for acquisition to happen.

Although there is some empirical evidence to support the view that a 'processing instruction' approach can work for some linguistic features, and some theoretical reasons to support this approach, more evidence is needed in different languages, including English and in different linguistic items.

In addition to that, it would be interesting to measure the effects of processing instruction in the acquisition of particular linguistic features in school children.

Although one of the studies reviewed in chapter four (Van Patten \& Oikkenon) was carried out with subjects from a local secondary school, it would be interesting to duplicate this study and test the effectiveness of processing instruction in subjects which are not adults. However, it has to be said that despite some differences in the way adults and children learn a L2, there is already considerable evidence (Long 1983, Weslander \& Stephany 1983) which indicates that grammar instruction is advantageous for children as well as for adults.

Finally, we need to pursue more practical questions about the role of processing instruction. Processing instruction is undoubtedly an effective way to incorporate FFI into a communicative framework, and while we need to carry out more empirical research in different contexts, in different languages and with different populations to find more support for this psycholinguistic type of grammar instruction, it is also vital to ask questions of a more practical nature: Can we use and deliver processing instruction in a more effective way? One of the possible answers to this question is that we can perhaps maximise the amount of time subjects spend practising through structure input activities by including processing instruction as part of subjects' homework or using the computer to deliver processing instruction. 


\section{REFERENCES}

Alanen R (1995) "Input enhancement and rule presentation in second language acquisition" in.Schmidt R (1995) Attention and awareness in foreign language teaching Second Langage Teaching and Curriculum Centre

Anderson J (1983) The Architecture of Cognition Harward University Press

Bardovi-Harlig K (1992) "The use of adverbials and natural order in the development of temporal expression" in International Review of Appled Linguistics 30 1992:299320

Bernini G \& Ramat G (ed.) (1990) La Temporalita' nell'acquisizione delle lingue straniere Franco Angeli

Berretta M (1990) "Il futuro in Italiano L2" in Quaderni del Dipartimento di Linguistica e Lettere Comparate 6 1990:147-188

Berretta M (1992) "Marcatezza in morfologia e apprendimento di lingue seconde" in Quaderni del Dipartimento di Linguistica e Lettere Comparate 8 1990:147-188

Bialystok E (1982) "On the relationship between knowing and using forms" in Applied Linguistics 3 1982:181-206

Bransdorfer R (1989) Communicative value and linguistic knowledge in second language oral input processing Unpublished doctoral thesis University of Illinois

Cadierno T (1995) "Formal instruction from a processing prospective: an investigation into the Spanish past tense" Modern Language Journal 79 1995:179-193 
Cadierno T \& Glass W R (1990) "Competing forms in the input: An investigation of hoe learners process past tense" Paper presented at The Annual Meeting of The American Association of Teachers of Spanish and Portuguese Miami.

Carroll J \& Swain M (1992) "The role of feedback in adult second language acquisition: error correction and morphological generalizations" in Applied Psycholingistics 13 1992:173-98

Chamot A, Kupper L, Impink-Hernandez M (1988) "A study of Learning Strategies in Foreign Language Instruction: Findings of the Longitudinal Study "Rosslyn Va: Interstate Research Associates" 1988

Cheng A (1995) Grammar instruction and input processing: The acquisition of spanish ser and estar Unpublished doctoral thesis University of Illinois

Day E \& Shapson S (1991) "Integrating formal and functional approaches in Language teaching in French immersion: An experimental study" in Language Learning 41 1991:25-58

De Mauro T (1993) Lessico di Frequenza dell'Italiano parlato Editori Riuniti Roma

Doughty C (1991) "Second Language Instruction does make a difference" Studies in Second Language Acquisition 13 1991:431-69

Doughty C \& Williams J (1998) Focus on Form in Classroom Second Language Acquisition Cambridge University Press

Eckman F, Bell L, Nelson D (1988) "On the generalization of relative clause instruction of English as a second language" in Applied Linguistics 9 1988:1-20 
Ellis N (1993) "Rules and instances in foreign language learning: Intereactions of explicit and implicit knowledge" in European Journal of Cognitive Psychology 5 1993:289-318

Ellis N (1994) Implicit and explicit learning of languages London Academic Press

Ellis R (1984) "Can Syntax be taught? A study on the effects of formal instruction on the acquisition of WH questions by children" in Applied Linguistics 9 1984:138-155

Ellis R (1989) “Are classroom and naturalistic acquisition the same? A study of the classroom acquisition of German word order rules" in Studies in Second Language Acquisition 11 1989:304-328

Ellis R (1990) Instructed Second Language Acquisition Basil Blackwell

Ellis R (1991) “Grammar teaching practice or consciousness raising?” in Ellis R (ed.) Second language acquisition and second language pedagogy 1991: 232-241 Multilingual Matters

Ellis R (1994) The Study of Second Language Acquisition Oxford University Press

Ellis R (1995) “Interpretation tasks for grammar instruction” in TESOL Quarterly 29 1995:87-106

Ellis R \& Rathbone M (1987) The acquisition of German in a classroom context Ealing College Of Higher Education

Eubank L (1987) "The acquisition of German negation by formal language learners" in Van Patten B. Dvorak T \& Lee J (eds.) Foreign Language Learning : A research perspective 1987:33-51 Newbury House 
Felix S (1981) "The effect of formal instruction on second language acquisition" in Language Learning 31 1981:87-112

Fotos S (1993) "Consciousness-raising and noticing through focus on form: grammar task performance versus formal instruction" in Applied Linguistics 14 1993:385-407

Fotos S \& Ellis R (1991) “Communicating about grammar: a task-based approach" in TESOL Quarterly 25 1991:605-28

Gass S (1988) "Integrating research areas: A framework for second language studies" in Applied Linguistics 9 1988:198-217

Hammerly H (1987) "The immersion approach . A litmus test of second language acquisition through classroom communication" in Modern Language Journal 71 $1987: 395-401$

Harley B (1986) Age in Second Language Acquisition Multilingual Matters

Harley B (1989) "Functional grammar in French immersion : A classroom experiment" in Applied Linguistics 10 1989:331-59

Higgs T V \& Clifford R (1982) "The push towards communication" in Higgs T V (ed.) Curriculum competence, and foreign language teacher IL National Textbook

Horwitz E, Horwitz M, Cope J (1986) "Foreign language classroom anxiety" in Modern Language Journal 70 1986:125-32

Hulstijn J (1989) "Implicit and incidental language learning: Experiments in the processing of natural and partly artificial input" in Dechert H \& Raupach M (eds.) Interlingual processing Gunter Narr 
Hulstijn J \& Schmidt R (1994) (eds) Consciousness in second language learning AILA Review 11

Hulstijn J \& Schmidt R (1994) "Under What Conditions Does Explicit Knowledge Of A Second Language Facilitate The Acquisition Of Implicit Knowledge? A Research Proposal" in Hulstijn J \& Schmidt R (1994) (eds.) Consciousness in second language learning AILA Review 11 1994: 97-112

Kadia K (1988) "The effect of formal instruction on monitored and spontaneous naturalistic interlanguage performance" in TESOL Quarterly 22 1988:509-515

Kaplan M (1987) "Developmental patterns of past tense acquisition among foreign language learners of French" in Van Patten B. Dvorak T \& Lee J (eds.) Foreign Language Learning : A research perspective 1987:52-60 Newbury House

Keenan E \& Comrie B (1977) "Noun phrase accessibility and universal grammar" in Applied Linguistics 8 1977:63-99

Klein W (1986) Second Language Acquisition Cambridge University Press

Krashen S (1982) Principles and Practice in Second Language Acquisition Pergamon

Krashen S (1985) The Input Hypothesis: Issues and Implications Longman

Krashen S (1993) "The Effects of Formal Grammar Teaching: Still Peripheral" in TESOL Quarterly 27 1993:22

Lee J, Cadierno T, Van Patten B, Glass W (1997) "The effects of lexical and grammatical cues on processing past temporal reference in second language input" in Applied Language Learning 8 1997:1-27 
Lennon P (1989) "Introspection and intentionality in advanced second-language acquisition' in Language Learning 39 1989:375-395

Lightbown P, Spada N \& Wallace R (1980) "Some effects of instruction in child and adolescent English learners" in Scarcella S \& Krashen S (eds.) Research in second language acquisition 1980:162-172 Newbury House

Lightbown P (1983) "Exploring relationship between developmental and instructional sequence in L2 acquisition" in Seliger H \& Long M (eds.) Classroom oriented research in second language acquisition 1983:217-245 Newbury House

Lightbown P (1985) "Great expectations: Second language acquisition research and classroom teaching" in Applied Linguistics 6 1985:173-189

Lightbown P (1987) "Classroom language as input to second language acquisition" in Pfaff C (eds.) First and second language acquisition processes 1987:169-187 Newbury House

Lightbown P \& Paris L (1986) "Pilot Investigation of Student Performance in Intensive ESL Classes in grade 5 \& 6: An Interim Report" Unpublished report.

Lightbown P \& Spada N (1990) "Focus on form and corrective feedback in communicative language teaching: effects on second language learning', Studies in Second Language Acquisition 12 1990:429-48

Lightbown P \& Spada N (1993) How Languages Are Learned Oxford University Press

Lightbown P M \& Spada N (1997) “ Learning English as a second language in a special school in Quebec" in Canadian Modern Language Review 53 1997:315-355 
Long M (1980) "Inside the "black box". Methodological issues in classroom research on language learning" in Language Learning 30 1980:1-42

Long M (1983) "Does second language instruction make a difference" in TESOL Quarterly 17 1983:359-82

Long M (1991) "Focus on form: a design feature in language teaching methodology" in De Bot K (eds.) (1991) Foreign Language Research in Cross-Cultural perspectives John Benjamins

Lyster R (1994) "The effect of functional analytic teaching on aspects of French immersion students' sociolinguistic competence" in Applied Linguistics 15 1994:26387

Mangubhai F (1991) "The processing behaviours of adult second language learners and their relationship to second language proficiency" in Applied Linguistics 12 1991: 268-297

Makino T (1980) "Acquisition order of English morphemes by Japanese secondary school students" in Journal Hokkaido University of Education 30 1980:101-148

McLaughlin B (1978) "The Monitor Model: some methodological considerations" in Language Learning 28 1978:309-332

McLaughlin B (1987) Theories of second language learning Edward Arnold

McLeod B, Rossman T \& McLaughlin B (1983) "Second language learning: An information-processing perspective" in Language Learning 33 1983:135-158

Montgomery C \& Eisenstein M (1985) "Real reality revisited: an experimental communicative course in ESL" in TESOL Quarterly 19 1985:317-333 
Musumeci D (1989) The ability of second language learners to assign tense at the sentence level: A cross-linguistic study Unpublished doctoral thesis at the University of Illinois at Urbana-Champaign

Paulston C (1972) "Structural patterns drills: A classification" in Allen H \& Campell R (eds.) Teaching English as a second language McGraw-Hill

Pavesi M (1986) "Markedness, discourse models and relative clause formation in a formal and informal context" in Studies in Second Language Acquisition 8 1986:3855

Peters A M (1985) "Language segmentation: Operating principles for the perception and analysis of language" in Slobin D 'ed' (1985) The Crosslinguistic Study of Language Acquisition: Theoretical Issues Lawrence Erlbaum Associates

Pica T (1983) “ Adult acquisition of English as a second language under different conditions of exposure" in Language Learning 33 1983:465-497

Pienemann M (1984) "Psychological constraints on the teachability of languages" in Second Language Acquisition 6 1984:186-214

Pienemann M (1987) "Determining the influence of instruction on L2 speech processing" in Australian Review of Applied Linguistics 10 1987:83-113

Pienemann M \& Johnston M (1987) "Processing constraints and learnability" Unpublished manuscript University of Sidney

Ramat G (ed) (1988) L'Italiano tra le altre lingue. Strategie di acquisizione Il Mulino Rutherford W \& Sharwood-Smith M (1988) Grammar and second language teaching Newbury House 
Savignon S (1972) Communicative Competence: an Experiment in Foreign Language Teaching Philadelphia Center for Curriculum Development

Schmidt R (1990) "The role of consciousness in second language learning" in Applied Linguistics 11 1990:129-158

Schmidt R (1994) "Deconstructing consciousness in search of useful definitions for applied linguistics" AILA Review II 1994:11-26

Schwartz B (1993) "On explicit and negative data effecting and affecting competence and linguistic behaviour" in Studies in Second Language Acquisition 15 1993:146-163

Seliger $\mathrm{H}$ (1979) "On the nature and function of language rules in language teaching" in TESOL Quarterly 13 1979:359-369

Selinker L (1972) "Interlanguage" in International Review of Applied Linguistics $10 \quad 1972: 209-31$

Sharwood-Smith M (1985) "From Input to Intake: an argumentation in second language acquisition" in Gass S \& Madden G (eds.) Input in second language acquisition 1985:394-403

Sharwood-Smith M (1986) "Comprehension versus acquisition: two ways of processsing input" in Applied Linguistics 7 1986:239-274

Sharwood-Smith M (1991) "Speaking to many minds: On the relevance of different types of of language information for the L2 learner" in Second Language Research 7 1991:118-132

Sharwood-Smith M (1993) "Input enhancement in instructed SLA: Theoretical bases" in Studies in Second Language Acquisition 15 1993:165-179 
Shiffrin R \& Scheider W (1977) "Controlled and automatic human information processing" in Psychological Review 84 1977:127-190

Singleton D (1989) Language Acquisition: the Age Factor Multilingual Matters

Skehan P (1989) Individual Differences in Second-Language Learning Edward Arnold

Slobin D (1985) The Crosslinguistic Study of Language Acquisition: Theoretical Issues Lawrence Erlbaum Associates

Sorace A (1985) "Metalinguistic knowledge and language use in acquisition-poor environments" in Applied Linguistics 6 1985:239-24

Spada N (1987) "Relationship between instructional differences and learning outcomes: a process-product study of communicative language teaching" in Applied Linguistics 8 1987:137-161

Spada N \& Lightbown P (1993) "Instruction and the development of questions in L2 classrooms" in Studies in Second Language Acquisition 15 1993:205-224

Spada N (1997) "Form-focused instruction and Seccond Language acquisition : A Review of Classroom and Laboratory research " in Language Teaching 30 1997:7387

Stevick E (1980) Teaching Languages: a way and ways Newbury House

Tarone E (1983) "On the variability of interlanguage systems" in Applied Linguistics 4 1983:143-163

Terrell T D (1986) "Acquisition in the Natural Approach: The Binding $\backslash A c c e s s$ Framework" in The Modern Language Journal 70 1986:213-228 
Terrell T D (1991) "The role of grammar instruction in a communicative approach" in The Modern Language Journal 75 1991:52-63

Tomasello M Herron C (1989) "Feedback for language transfer errors: the garden path techniques" in Studies in Second Language Acquisition 11 1989:385-95

Tomlin R \& Villa V (1994) "Attention in cognitive science and second language acquisition" in Studies in Second Language Acquisition 16 1994:183-204

Van Patten B (1990) "Attending to content and form in the input: An experiment in consciousness" in Studies in Second Language Acquisition 12 1990:287-301

Van Patten B (1994) "Evaluating the role of consciousness in second language acquisition: terms, linguistic features and research methodologies" in Hulstijn $\mathrm{J} \&$ Schmidt $\mathrm{R}$ (eds.) Consciousness in second language learning AILA Review 11 $1994: 27-36$

Van Patten B (1996) Input Processing and Grammar Instruction Ablex

Van Patten B \& Cadierno T (1993a) "Explicit instruction and Input processing" in Studies in Second Language Acquisition 15 1993:225-243

Van Patten B Cadierno T (1993b) "SLA as input processing. A role for instruction" in The Modern Language Journal 77 1993:45-57

Van Patten B \& Lee J F (1995) Making Communicative Teaching Happen McGrawHill

Van Patten B Sanz C (1995) "From Input to Output: Processing instruction and communicative tasks" in Eckman F (eds) (1995) Second Language Acquisition and Pedagogy Hillsdale 
Van Patten B \& Oikkenon S (1996) "The causative variables in processing instruction: Explanation vs, structured input activities" in Studies in Second Language Acquisition 18 1996:225-243

Weinert R (1987) "Processes in classroom second language development: the acquisition of negation in German" in Ellis $\mathrm{R}$ eds Second Language acquisition in context 1987:83-99 Prentice-Hall

Weslander D \& Stephany G (1983) “Evaluation of an English as a second language program for southeast Asian students" in TESOL Quarterly 17 1983:473-480

White L (1991) "Adverb placement in SLA: some effects of positive and negative evidence in the classroom" in Second Language Research 7 1991:133-61

White L, Spada N, Lightbown P, Ranta L (1991) "Input enhancement and L2 question formation" in Applied Linguistics 12 1991:416-432

White (1998) "Getting the learner attention: A typographical input enhancement study" in Doughty C \& Williams J (eds.) (1998) Focus on Form in Classroom Second Language Acquisition Cambridge University Press

Wode H (1981) "Language acquisitional universals: A unified view of language acquisition" in Vinitz $\mathrm{H}$ (eds.) Native Language and foreign language acquisition. Annals of the New York Academy of Sciences 379 1981:218-234

Zobl H (1983) "Markedness and the projection problem" in Language Learning 33 1983:293-313 
Zobl H (1985) "Grammar in search of input and intake" in Gass S \& Madden C (eds.) Input in second language acquisition 1985:329-344 Newbury House 


\section{APPENDIX A}

\section{The Instructional pack ${ }^{19}$ (future tense)}

\section{(input based treatment with pedagogical rules)}

This pack was constructed and created by the researcher to be used for a type of input-based instruction on the acquisition of a feature of the Italian verbal system: namely the future tense (regular forms).

\footnotetext{
${ }^{19}$ Pictures used to create the two instructional packs and the oral tests were taken from the following text-books for beginners in Italian: Benati A \& Peressini R (1998) Ritocchi Greenwich University Press; Van Patten B \& Lee J (1996) Sabias Que......Mc Graw Hill.
} 


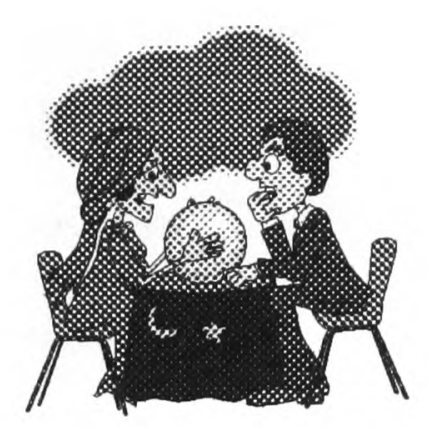

\section{Future Tense}

\section{Third person singular form}

The future is used to to talk about an action that has not yet taken place or making plan (in the picture above the future is used to make predictions... Cosa succederà nel futuro...?) Third person singular future forms are formed by adding the future ending à to the infinitive of the verb (however the are verbs change the a of the infinitive ending to an e). Here you are presented with the third person singular form for regular verbs:

FUTURE

\begin{tabular}{|c|c|c|c|}
\hline & arrivare & prendere & partire \\
\hline luillei & arriv-er-à̀ & prend-er-à & part-ir-à \\
\hline
\end{tabular}

Paolo arriverà la settimana prossima

(Paolo will arrive next week)

Laura partirà alle sette

(Laura will leave at seven o'clock)

There are two clues that will help you to recognize future tense forms:

1. the future tense (third person) of regular verbs is formed by adding the ending à to the infinitive minus the final $\mathrm{e}$. The future endings of verbs in are ere and ire are the same.

2. the spoken stress on 3rd persons singular is on the final accented vowel of the ending.

The second clue will be very useful in order to distinguish future forms from those forms of the present tense. An important difference is in the spoken stress of the final vowel of the future tense. 


\section{PRESENT}

\begin{tabular}{|l|l|l|l|}
\hline & arriv-are & prend-ere & part-ire \\
\hline luillei & arriv-a & prend-e & part-e \\
\hline
\end{tabular}

Future forms are usually accompanied by temporal adverbs that indicate that the action of the verboccured in the future. Here are some of these future temporal adverbs:-domani-la settimana prossima-il mese prossimo

However, although these adverbials are a good clue to know that an action has occured in the future they are not always present in the sentences you encounter. This is the reason why it will be important for you to recognize future tense forms. 


\section{Activity 1 (whole class)}

a)The fortune teller's message is rather confused . Can you help her to sort it out? She talks to you about the future of your brotherlsister.

a.

b

c. d.

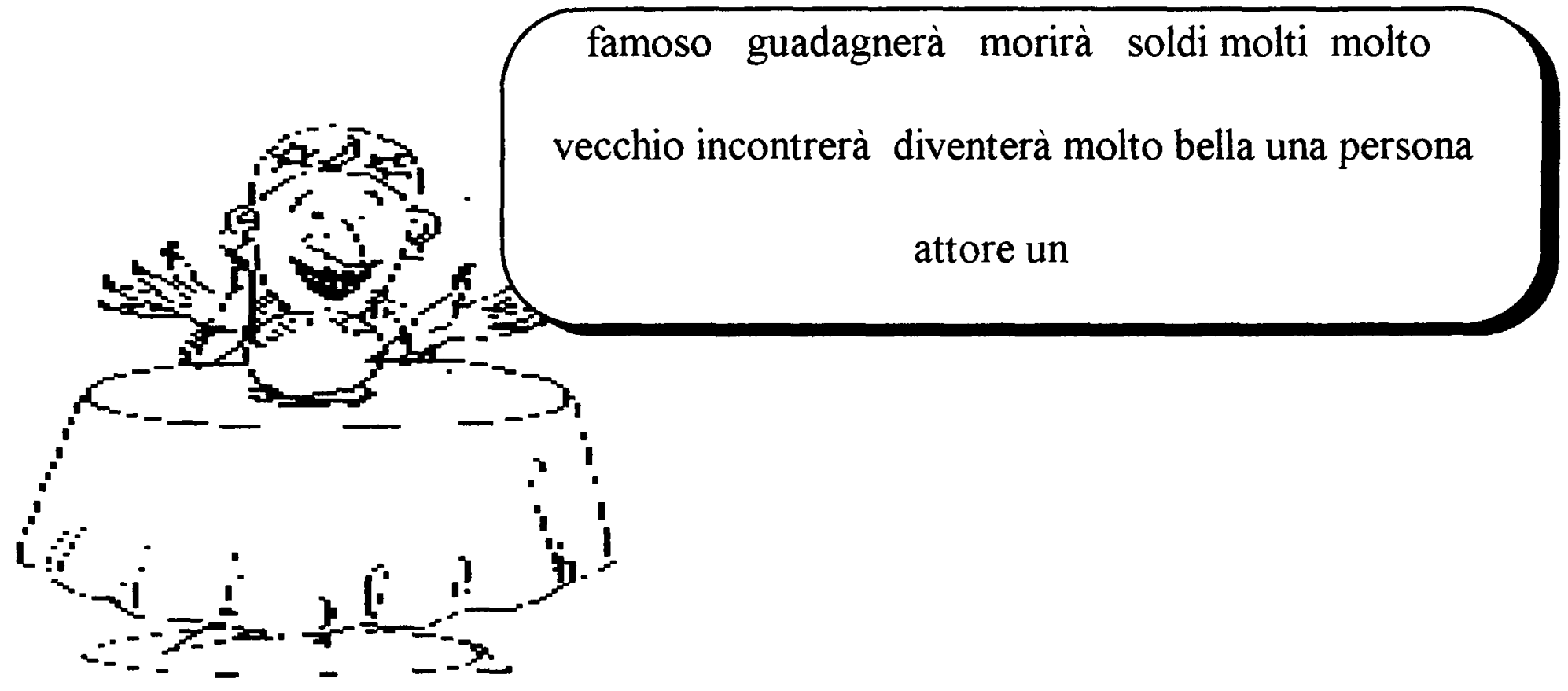

b) Can you now make a list, possibly in a chronological order of the fortune teller's predictions about your brotherlsister's future.

Notice that the verbs are all expressed in the future tense (3rd person).

1.

2 .

3.

4. 


\section{Activity 2 (whole class)}

Circle the verbs that you hear in each sentence
1. a) arriverà
b) arriva

2. a) studia

b) studierà

3. a) torna

b) tornerà

4. a) comprerà

b) compra

5. a) arriverà

b) arriva

b)You are going to hear some sentences in Italian. Select whether each sentence you hear occured in the present or the future. Keep in mind that future tense forms have the spoken stress in the vowel of the endings (3rd person)
1. a) present
b) future

2. a) present

b) future

3. a) present

b) future

4. a) present

b) future

5. a) present

b) future 
Attivita 2

1. Paolo arriva a casa tardi

2. La ragazza studierà per il suo esame

3. mio fratello tornerà a casa tardi

4. Mio padre comprerà una nuova macchina

5. La Signora Rossi arriva al lavoro in orario

1. Francesca compra un kilo di mele

2. Paolo lavorerà fino alla sera

3. Laura arriva a scuola in ritardo

4. mio padre smetterà di fumare

5. Forse, Carlo finirà tutti i suoi compiti in tempo 


\section{Activity 3 (whole class)}

a)You are going to hear about the activities that three people will do next weekend Write into the chart what each person will do.

Pay attention to the spoken stress of the verb.

\begin{tabular}{|l|l|l|l|}
\hline NOMI & $\begin{array}{l}\text { VENERDI } \\
\text { SERA }\end{array}$ & SABATO & DOMENICA \\
\hline \multirow{2}{*}{ MARCO } & 1. & 1. & 1. \\
& 2. & 2. & 2. \\
\hline PAOLA & 1. & 1. & 1. \\
& 2. & 2. & 2. \\
\hline $\begin{array}{l}\text { IL SIGNOR } \\
\text { ROSSI }\end{array}$ & 1. & 1. & 1. \\
\hline
\end{tabular}

b) Now listen to the questions. Can you tell who did what?

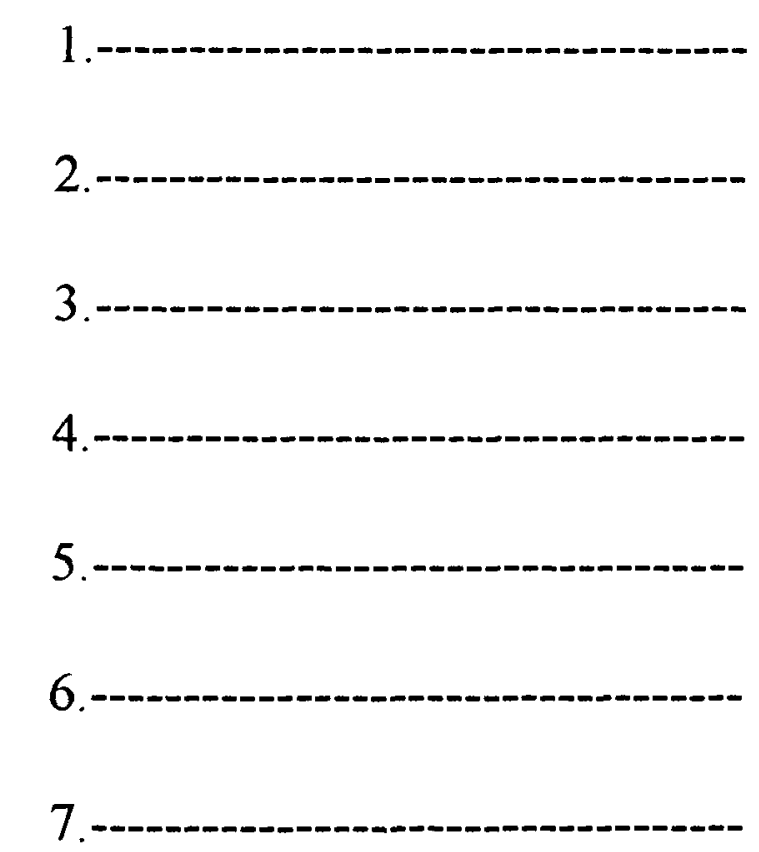


Attivita 3

2. Now listen to the questions. Can you tell who did what?

Chi visiterà suo padre, Venerdi?

Chi prenderà una birra al pub, Domenica?

Chi studierà , Sabato?

Chi pranzerà con un amico, Venerdi?

Chi lavorerà, Sabato sera?

Chi guarderà la televisione, Venerdi?

Chi scriverà una lettera, Venerdi?

Marco

Ven: pranzerà

con un amico

Sab: uscirà da casa e incontrerà la sua amica Francesca

Dom: resterà a casa guarderà la televisione
Paola

Sig. Rossi

Ven: telefonerà suo padre e poi

studierà per gli esami

$\mathrm{Sab}$ : studierà molto $\mathrm{e}$ lavorerà tutta la sera

Dom: resterà a casa ascolterà la musica

\section{Ven: scriverà una lettera e poi guarderà la tele}

Sab: resterà a casa tutto il giorno

Dom:

prenderà una birra al pub 


\section{Activity 4 (whole class)}

Listen to six future events and circle who will probably perform them or where they will take place.

$\begin{array}{ll}\text { Tony Blair } & \text { Brasile } \\ \text { Sydney } & \text { Manchester United } \\ \text { Greenwich } & \text { Prince Charles }\end{array}$

\section{Activity 5 (whole class)}

Listen to each sentences. First decide if the sentences are in the present or in the future. Then select the name of the person or country that answer the questions.

1. present

future

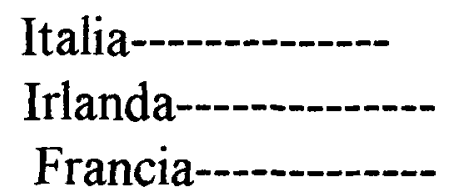

2. present

The Queen

future

Tony Blair.

Sean Connery...

3. present

France

future

Italy

England

4. present

future

Ravanelli-------

Zola-

Baggio

5. present

Il Papa

Bill Clinton

future

The Queen

6. present

Germany---.-...

Turkey---------

future

France 
Attivita 4

1 ospiterà le Olempiadi

2 resterà primo ministro per cinque anni

3 diventerà campione inglese di calcio

4 diventerà re d'Inghilterra

5 ospiterà il Millenium

6 diventerà campione del mondo di calcio

\section{Attivita 5}

1. diventerà un paese unito

2. abita a Buckingam Palace

3. ospiterà i campionati del mondo di calcio

4. lavora per il Chelsea

5. visiterà l'Irlanda del Nord

6. diventerà un membro della comunità europea 


\section{Activity 6 (pair work)}

Indicate whether or not you agree or disagree with each of the predictions listed below. Some of the will probably happen in the next ten years.

Compare your response with someone else.

\section{Sono d'accordo Non sono d'accordo}

1.una donna diventerà presidente degli USA

2. si troverà il vaccino per l'AIDS

3. L'Italiano diventerà la lingua più importante d' Europa.

4. L'uomo arriverà sul pianeta Marte.

5. Il Galles diventerà uno stato indipendente

6. L'Irlanda del Nord diventerà una repubblica.

Confront your answer with your partner. Sei|e' ' pessimista' or 'ottimista'. 


\section{Future Tense}

\section{First and Second persons singular form.}

First and second person singular future forms are formed by adding the future ending $\underline{\mathbf{g}}$ and $\underline{\text { ai }}$ to the infinitive of the verb_(however the are verbs change the a of the infinitive ending to an e). Here are the future forms that you will become familiar. The first and second persons singular form of regular verbs.

\begin{tabular}{|c|c|c|c|}
\hline & arrivare & prendere & partire \\
\hline $\begin{array}{l}\text { Io } \\
\text { tu }\end{array}$ & $\begin{array}{l}\text { arriv-er-ò } \\
\text { arriv-er-âi }\end{array}$ & 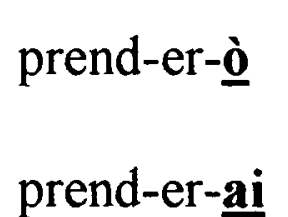 & $\begin{array}{l}\text { part-ir-文 } \\
\text { part-ir-ai }\end{array}$ \\
\hline
\end{tabular}

A che ora partir-ai domani?

(What time will you leave tomorrow?)

Partir-ò alle sette

(I will leave at seven o'clock)

There are two clues that will help you to recognize future tense forms:

1. the future tense of regular verbs (first and second person)are formed by adding endings(ò and ai $\left.{ }^{\prime}\right)$ to the infinitive minus the final $e$.The future endings of verbs in are ere and ire are the same.

2. the spoken stress of the first person singular is always on the final accented vowel of the ending ( $\grave{o}$ ) and the future ending( ai ) of the second person.

The second clue will be very useful in order to distinguish future forms from those forms of the present tense.

PRESENT

FUTURE

\begin{tabular}{|c|c|c|c|c|c|c|}
\hline & arriv-are & prend-ere & part-ire & arriv-are & prend-ere & part-ire \\
\hline Io & arriv-o & prend-o & part-o & arriv-er-文 & prend-er-文 & part-ir-ò \\
\hline tu & arriv-i & prend-i & partt-i & arriv-er-ai & prend-er-ai & part-ir-ai \\
\hline
\end{tabular}


Activity 7 (whole class)

a)Circle the verb that you hear in each sentence

1. a) guarderò $\quad$ b) guardo

2. a) tornerai b) torni

$\begin{array}{ll}\text { 3. a) parlerai } & \text { b) parli }\end{array}$

$\begin{array}{ll}\text { 4. a) passerò } & \text { b) passo }\end{array}$

$\begin{array}{ll}\text { 5. a) pranzerò } & \text { b) pranzo }\end{array}$

$\begin{array}{ll}\text { 6. a) scrivo } & \text { b) scriverò }\end{array}$

$\begin{array}{ll}\text { 7. a) parlo } & \text { b) parlerò }\end{array}$

$\begin{array}{ll}\text { 8. a) pranzerò } & \text { b) pranzo }\end{array}$

$\begin{array}{ll}\text { 9. a) telefonerai } & \text { b) telefoni }\end{array}$

10. a) incontro b) incontrerò

b) You are going to hear some sentences in Italian. Select whether each sentence you hear occured in the present or in the future. Keep in mind that future tense forms (especially the 1st person) has the spoken stress on the final vowel of the endings, and not on the stem vowel.

$\begin{array}{ll}\text { 1. a) present } & \text { b) future }\end{array}$

$\begin{array}{ll}\text { 2. a) present } & \text { b) future }\end{array}$

3. a) present $\quad$ b) future

4. $\begin{array}{ll}\text { a) present } & \text { b) future }\end{array}$

5. $\begin{array}{ll}\text { a) present } & \text { b) future }\end{array}$

$\begin{array}{lll}\text { 6. a) present } & \text { b) future }\end{array}$

$\begin{array}{ll}\text { 7. a) present } & \text { b) future }\end{array}$

$\begin{array}{lll}\text { 8. } & \text { a) present } & \text { b) future }\end{array}$

$\begin{array}{lll}\text { 9. a) present } & \text { b) future }\end{array}$

$\begin{array}{lll}\text { 10. a) present } & \text { b) future }\end{array}$ 


\section{Attività 7}

1. guardo il film in televisione

2. tornerai in treno con tuo fratello

3. resto a casa tutto il giorno

4. passerò le prossime vacanze con amici

5. pranzo a casa con i miei genitori

6. scriverò a Paola una bella lettera

7. parlo con Paolo del piu` e del meno

8. pranzero` con Lucia alle sette

9. telefonerai a tua mamma

10. incontrerò Giorgio alle otto

1.aspetterò l'autobus per il centro

2.comprerò un vestito per Francesca

3. studio spagnolo all'Universita' di Londra

4. guarderai in televisione la partita di calcio

5. scrivi a Maria una cartolina

6. ritornerò a Parigi per due settimane

7. chiamerò Paolo per il suo compleanno

8. lavoro in un bar del centro a Roma

9. parlerò con Maria

10. chiacchererai un po con Paolo 


\section{Activity 8 (pair work)}

Here is a cartoon called 'I buoni propositi'.

In which circunstances you would do 'I buoni propositi' ?
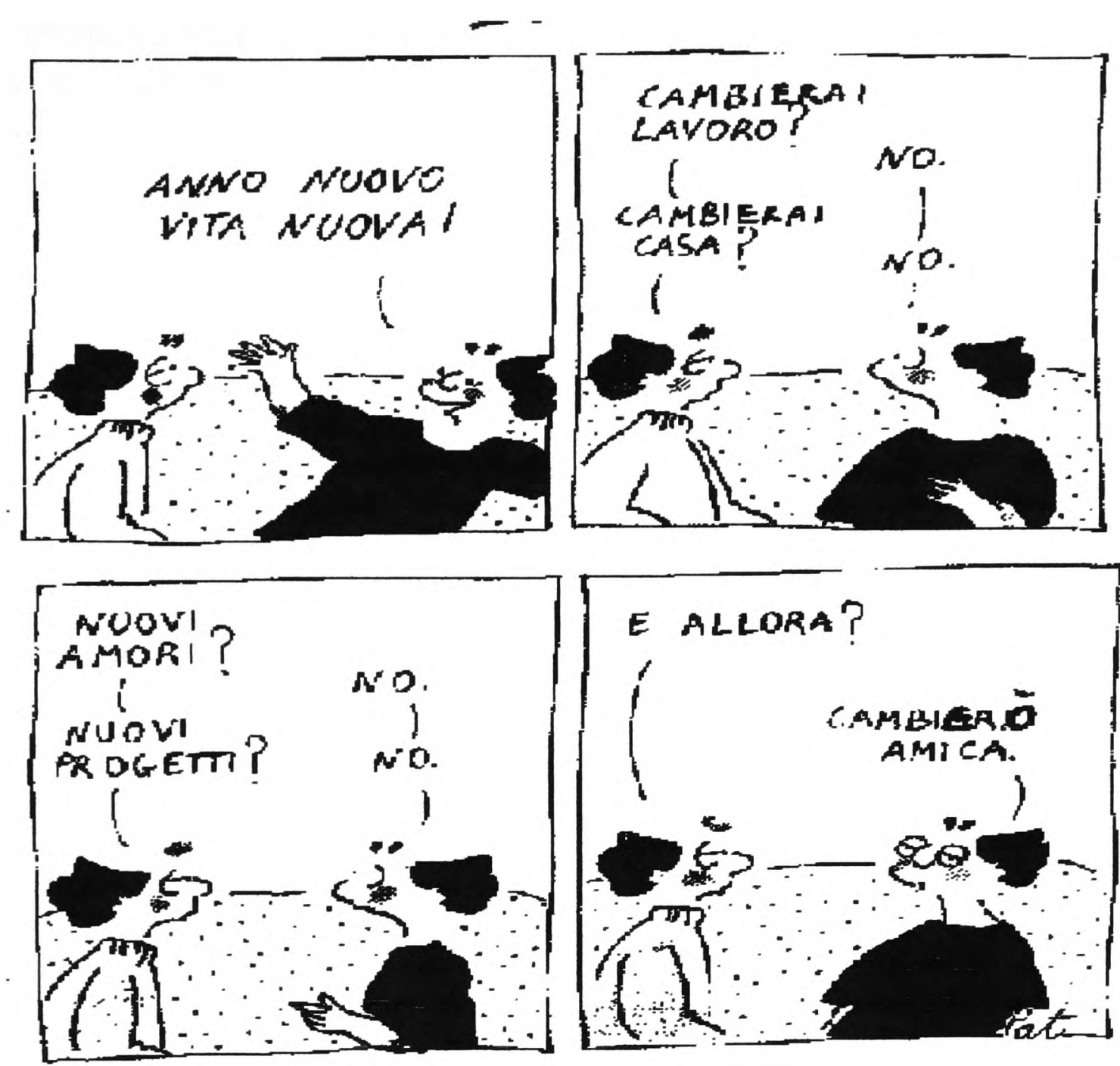

Do you understand the joke?

Have you noticed the future forms?

Are they first or second person forms?

How do you know? 


\section{Activity 9 (whole class)}

You are going to hear four sets of Italian sentences. First write down the sentences you hear in each set. Then order the activities that the sentences express in a chronological order.

Domani io...

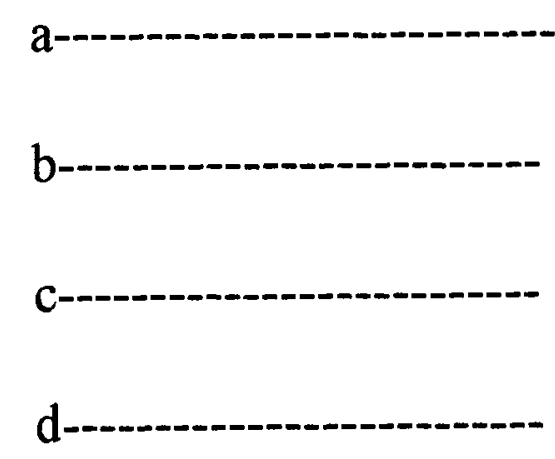

Now write the most appropriate chronological order:

First

Second-

Sabato prossimo tu.

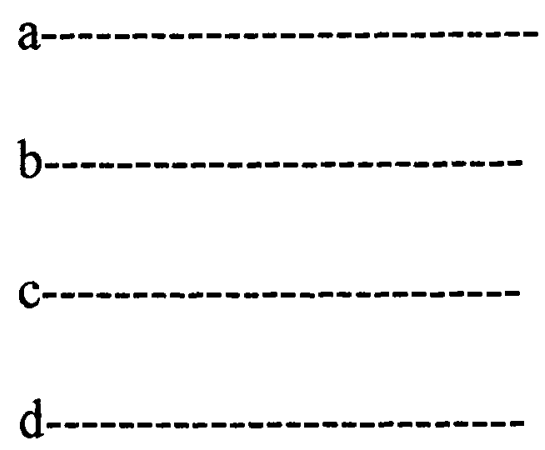

Now write the most appropriate chronological order:

First-

Third

Second-
Third-

Fourth- 
Attività 9

Domani io.......

arriverò in treno la mattina con un mio amico

partirò la sera per Milano

incontrerò Maria al caffe Greco

pranzerò con lei

Sabato prossimo tu.

pranzerai con Mario

metterai a posto la casa

inviterai Mario

cucinerai il pranzo 


\section{Activity 10 (pair work)}

Indicate whether or not each statement applies to you today. Compare your response with someone else.

$$
\mathrm{Si} \text {, vale anche per me No, non vale per me }
$$

1. Incontrerò i miei amici

2. Resterò a casa tutto il giorno

3. Pranzerò alla mensa dell'Universita'

4. Guarderò la partita in televisione

5. Prenderò una birra al bar con amici

6. Sentirò un po' di musica alla radio

7. Lavorerò tutto il giorno

8. Prenderò una pizza

9. Ascolterò il notiziario alla radio

10. Passerò la sera a casa

\section{Activity 11 (whole class)}

You are going to listen to a dialogue between two friends (Paolo e Francesca) who meet at school on the last day of semester two and talk about what they will do next summer, after the exams. After you will be asked to answer the following questions based on the reading:

a. Who will have the most exiting summer holyday of the two friends?

b. State at list two things that Farancesca and Paolo will do during summer holyday

Paolo

1. io

2. io
Francesca

1. io

2. io 
Attività 11

P. Ciao Francesca come stai?

F. Bene Paolo, e tu?

P. Molto bene. Senti Francesca, dove passerai le vacanze questa estate?

F. Oh, questa estate passerò una settimana in Francia. Restero' a Nizza con il mio amico Paul che abita in una bellissima villa. Poi, prenderò la nave e visiterò la Corsica. E tu Paolo?

P. Io resterò qui . Studierò per gli esami a settembre e lavorerò con mio padre

F. Che peccato! Il prossimo anno spero che passerai le vacanze con me! 
Activity 12 (pair work)

Alessandro is making New Years resolutions. Look at the six sentences and indicate whether or not each statement applies to you. Compare your response with someone else

Notice the spoken stress of the first person singular of the future tense.

L'anno prossimo:

Vale per me $\quad$ Non vale per me

1 studierò tutti i giorni

2 prometto che non arriverò all'Universita in ritardo

3 metterò in ordine la mia camera

4 tornerò a casa sempre presto

5 lavorerò per mantenermi

6 passerò i miei esami 


\section{Activity 13 (whole class)}

Look at the drawings which describe some events of Paul's plan for the summer holiday. Match each event with the sentences below and then put them in a cronological order.

Tutti i giorni dormirò e prenderò il sole al mare

partirò all'inizio e tornerò alla fine di agosto

viaggerò in nave e poi in macchina

resterò nella bellissima villa di un mio amico

passerò tutte le mie vacanze in Italia

visiterò Firenze per due giorni

a

- .
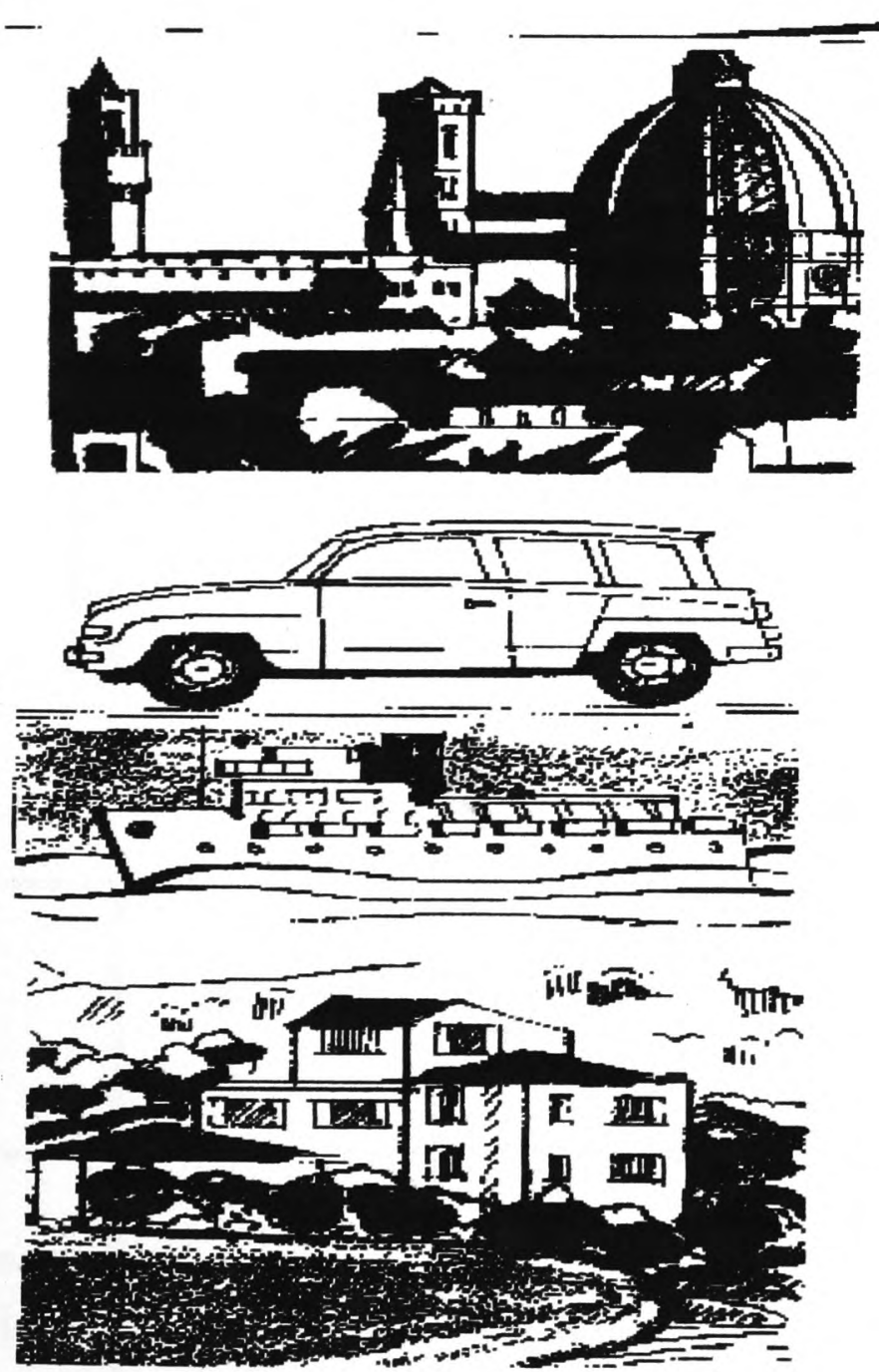

e b
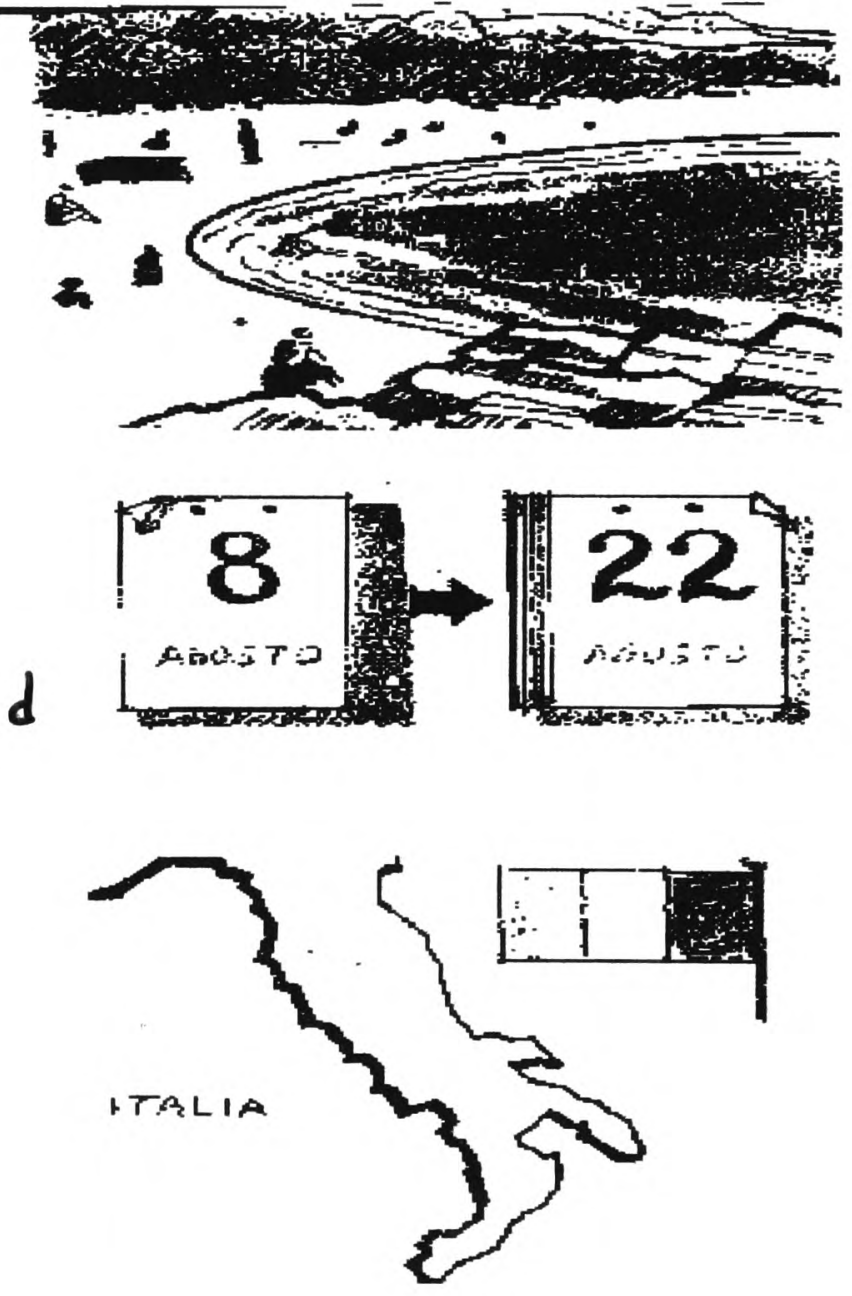

f 


\section{Future Tense}

\section{Third person plural form}

Like the other future forms, third person plural forms are formed by adding the future ending anno to the infinitive of the verb(however the are verbs change the a of the infinitive ending to an e). Here you are presented with third person plural form for regular verbs:

\begin{tabular}{|l|l|l|l|}
\hline & arrivare & prendere & partire \\
\hline \multirow{2}{*}{ loro } & arriv-er-anno & prend-er-anno & part-ir-anno \\
& & & \\
\hline
\end{tabular}

Paolo e Francesca arriver-anno la settimana prossima (Paolo and Francesca will arrive next week)

There are two clues that will help you to recognize future tense forms:

1. the future tense of regular verbs (third person plural) is formed by adding ending(anno) to the infinitive minus the final $e$. The future endings of verbs in are ere and ire are the same.

2. Notice one more that although there is a change in the way present and futureare formed, it will be still easy for you to recognise the third person plural by paying attention to the spoken stress failing on the future ending.

PRESENT

FUTURE

\begin{tabular}{|l|l|l|l|l|l|l|}
\hline & arrivare & prendere & partire & arrivare & prendere & partire \\
\hline loro & arriv-ano & prend-ono & part-ono & arriv-er-anno & prend-er-anno & part-ir-anno \\
\hline
\end{tabular}




\section{Activity 14 (whole class)}

a)Circle the verb that you hear in each sentence
1. a) prendono
b) prenderanno

2. a) parlano

b) parleranno

3. a) visitano

b) visiteranno

4. a) lavorano

b) lavoreranno

5. a) aspetteranno

b) aspettano

b)You are going to hear some sentences in Italian. Select whether each sentence you hear occured in the present or in the future. Keep in mind that future tense form ( 3rd person plural ) have the spoken stress on the first vowel of the endings. and not on the stem vowel.
1. a) present
b) future
2. a) present
b) future
3. a) present
b) future
4. a) present
b) future
5. a) present
b) future 


\section{Activity 15 (whole class)}

You are going to hear several activities that some people will do

Circle the letter of the activities that are not logical and say why there are not

1. In Europa i miei genitori

a

b

c

d

2. Paolo e Francesca passeranno le vacanze di Natale e

a

b

c

d

3 I miei amici visiteranno Londra e

a

b

c

d

4. se e' bel tempo Paolo e Giulia usciranno e

a

b

c

d 
Attività 14

1. Francesco e Paola, prenderanno l'aereo

2. Maria e Giulio parlano con il dottore

3. visiteranno Firenze e poi Venezia

4. Paolo e Francesca parlano sempre

5. I turisti aspettano l'autobus per l'albergo

1. I signori Rossi compreranno un nuovo appartamento

2. Maria e Roberto lavorano a Londra

3. Paola e Francesca scriveranno a Luigi

4. I miei amici entrano in collegio

5. I miei genitori passeranno il Natale in Italia 
Activity 16 (pair work )

You are going to hear 6 sentences about what your family will do for summer

Write them down first and then indicate whether or not each statement will apply to them or not.

$$
\mathrm{Si} \text {, vale anche per loro } \quad \mathrm{No} \text {, non vale per loro }
$$

1

2

3

4

5

6.

Compare with your partner.. 
Attivita 16

1. Resteranno a casa

2. Visiteranno I loro amici al mare

3. Passeranno l'estate in montagna

4. Prenderanno un mese di ferie

5. Viaggeranno in treno

6. Lavoreranno 
Activity 17 (whole class)

You are going to listen to some predictions about the 'horrorscope' of some 'signs'.

Identify the predictions with the 8 pictures and write the name of the signs. At the end compare with your partner.
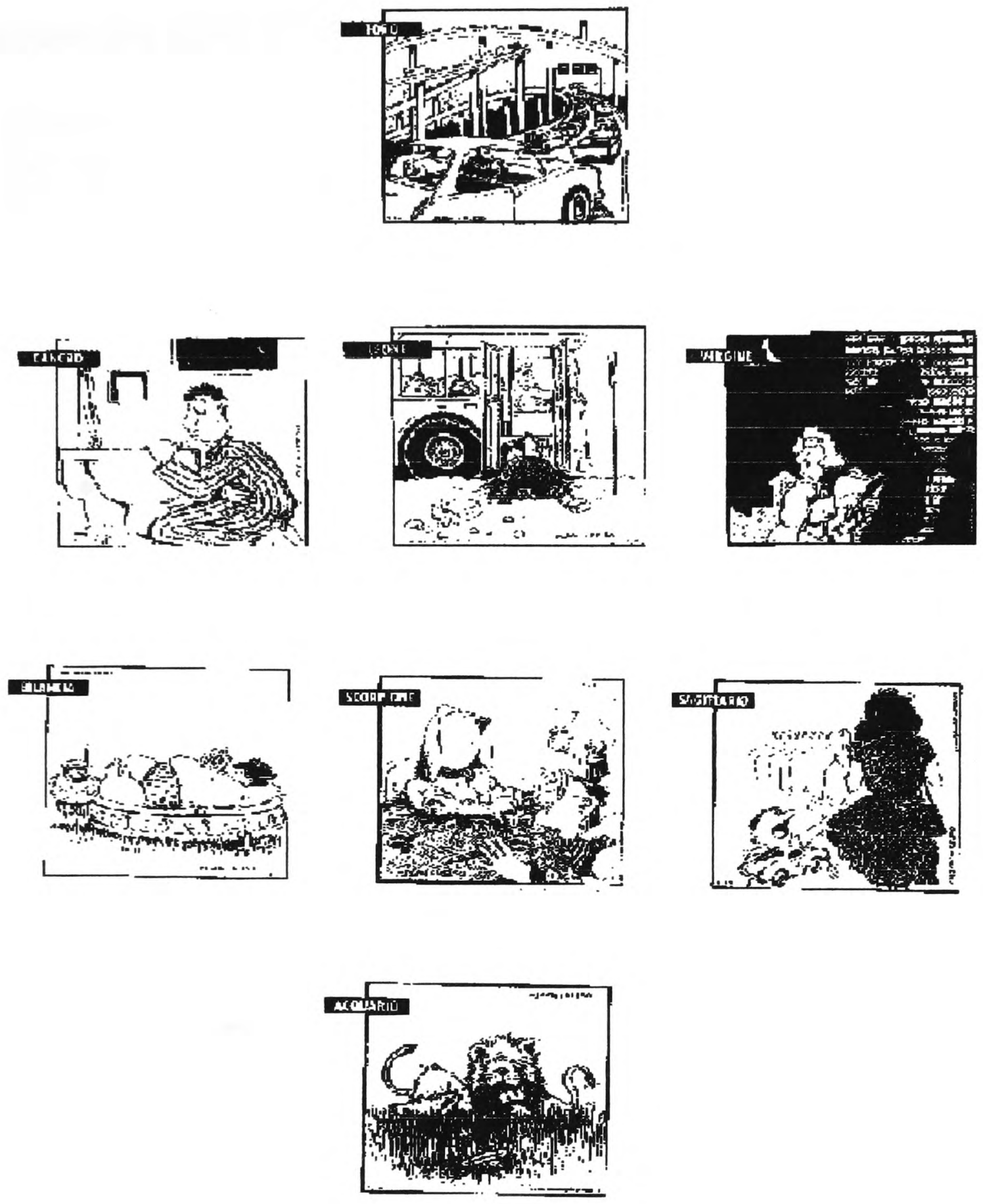

1

3.

4

5 .

6.

7.

8. 


\section{Attività 15}

1. a) visiteranno il Museo del Louvre

b) pranzeranno in un buon ristorante francese

c) visiteranno le piramidi di Il Cairo

d) passeranno due giorni a Roma

2. a) resteranno a casa con I loro parenti

b) lavoreranno

c) mangieranno molto

d) chiacchereranno

3. a) visiteranno Harrowds

b) prenderanno una birra

c) prenderanno il sole al mare

d) incontreranno la Regina

4. a) usciranno

b) resteranno in casa

c) incontreranno amici

d) prenderanno la bicicletta

\section{Reading}

Attivita 17

1. incontrerà uno straniero alto e scuro

2. passerà una bella giornata in macchina

3. farà una festa per celebrare il suo compleanno

4. passerà il pomeriggio in piscina

5. scenderà dall'autobus

6. parlerà con un leone

7. comprera' una automobile a buon prezzo

8. visitera’ il bagno 
Activity 18 (whole class)

Identify the subject of the following sentences that you are going to hear.
1. a) io
b) tu
c) lui
d) loro

2. a) lei

b) tu

c) lo studente

d) gli studenti

3. a) io

b) tu

c) lui

d) loro

4. a) io

b) tu

c) Paolo

d) loro

5. a) La famiglia Rossi

b) lei

c) Francesco

d) tu

6. a) io

b) Maria

c) tu

d) i miei amici

7. a) Paolo

b) tu

c) io

d) lei

8. a) lui

b) loro

c) lei

d) io 
Attività 18

1. dormirò con un mio amico di lavoro

2. arriverà a scuola in ritardo

3. telefonerà a Paolo

4. prenderanno la nave per andare in Francia

5. inviterai tuti gli amici alla festa

6. pranzerà con Paolo e Francesca

7. passerò le vacanze con mia madre

8. chiamerò Giulia 
1. Third person plural of the future, like the first and second singular forms, are formed by adding endings (same for all verbs) to the infinitive minus the final $-e-$.

2. The most important clue to recognize future tense forms is that , in contrast to present tense forms, the spoken stress on 3rd persons plural singular(like the first and third singular) falls on the vowel of the ending rather than the stem vowel. For third person plural forms this means that it falls on the next to the last syllabe of the word (parler-anno).

3. Notice the parallelism in spoken stress between first and third person singular forms at one hand and second person singular and third person plural forms on the other.

1 per. sing. parl-er- $\underline{\text { ò }}$.

2 per. sing. parl-er-ại

3 per. sing. parl-er-à

3 per. plur. parl-er-anno 


\section{APPENDIX B}

Instructional pack for the output-based treatment.

This pack was constructed to be used in a type of output-based instruction on the acquisition of a feature of the Italian verbal system: namely the future tense (regular forms). 


\section{Future Tense.}

Just like verbs in the present tense, verbs in the future tense in italian change their endings depending on the subject of the verb (lo, tu , lui lei, noi, voi, loro).

The endings are the same for Verbs in are-and ere and ire (see chart). Note the accent on 1st and 3rd person singular. The stress always falls on the endings. There are two main points to remember when forming the future tense:

1) Take the infinitive and cross off the final $e$ and add the future endings. However the are verbs change the a of the infinitive ending to an $e$.

2) Verbs in -are- and -ere have the same endings .

Unlike the english future the italian future is not a compound tense.

it translates the future simple in english: eg. I will arrive, I will take, I will leave.

\begin{tabular}{|c|c|c|}
\hline ARRIVARE & PRENDERE & PARTI \\
\hline Io arriv-er-ò & Io prend-er-ồ & Io part-ir-ò \\
\hline I will arrive & I will take & I will leave \\
\hline tu arriv-er-äi & tu prend-er-a $\underline{\mathbf{i}}$ & tu part-ir-ai \\
\hline you will arrive & you will take & you will leave \\
\hline luillei arriv-er- & luillei prend-er-à & 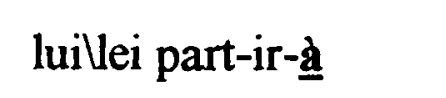 \\
\hline helshe will arrive & helshe will take & belshe sleeps leave \\
\hline noi arriv-er-emo & noi prend-er-emo & noi part-ir-emo \\
\hline we will arrive & we will take & we will arrive \\
\hline voi arriv-er-ete & voi prend-er-ete & voi part-ir-ete \\
\hline you will arrive & you will take & you will leave \\
\hline loro arriv-er-anno & loro prend-er-anno & loro part-ir-anno \\
\hline they will arrive & they will take & they will leave \\
\hline
\end{tabular}

The use of the future tense in Italian corresponds to its use in english. For example:

Domani lavorerò tutto il giorno $=$ Tomorrow I will work all day

The future expresses an action the has not yet taken place. You can use the future tense to talk about things you plan to do in the future:

- things you definitely intend to do- make arrangements, predictions and resolutions- used to express possibility 
Activity $N 1 \& 2$ (carried out as a whole class activity and subsequentelly as pair work activity where the students have to report to the rest of the class).

1. At the beginning of every year we make a new year's resolution.

These are Francesco e IO 's resolutions. Complete the sentences by using the infinitive of the verbs in brankets in the future tense.

Francesco: (smettere) di fumare $\backslash$ (studiare) ogni sera $\backslash$ (tornare) a casa presto la sera $\backslash$ (non arrivare) a scuola in ritardo $\backslash$.

Io: (arrivare) a scuola in orario $\backslash$ (finire) tutti i miei compiti $\backslash$ (lavorare) di piu $\backslash$ (studiare) un po di piu' $\backslash$.

what IO and Francesco will have in common?

Write the three things they will do next year

1.

2.

2. Now you have to say what you and your partner will do and report to the rest of the class. (Che decisioni prenderai per il prossimo anno?)

1. 
Activity 3 will be carried out as a whole class activity

3. Describe the following holiday plan using future tense forms.

I progetti per le vacanze di Alessandro

\begin{abstract}
Alessandro
- (passare) le mie vacanze in Francia

- (partire) in agosto e (restare) due settimane a Parigi

- a Parigi (studiare) il francese e (imparare) molto della cultura francese

- (visitare) il sud della Francia con la sua amica Francesca

- Alessandro e Francesca (passare) un periodo tranquillo e rilassante
\end{abstract}


Activity 4 will be carried out as a pair work activity

Activity 5 will be carried out as a pair work activity + students have to report to the rest of the class.

4. Student A-B

You want to know what your partner will do next summer.

You need to use these verbs, prepare the questions first and then write the answer beside

domande

risposte

1.Come passare le prossime vacanze?

2.Come viaggiare?

3.Quanto restare a ......?

4.Dove abitare?

5.Cosa visitare a ......?

6.Quando ritornare a casa?

Now is your turn to answer your partner's questions about your holiday. 


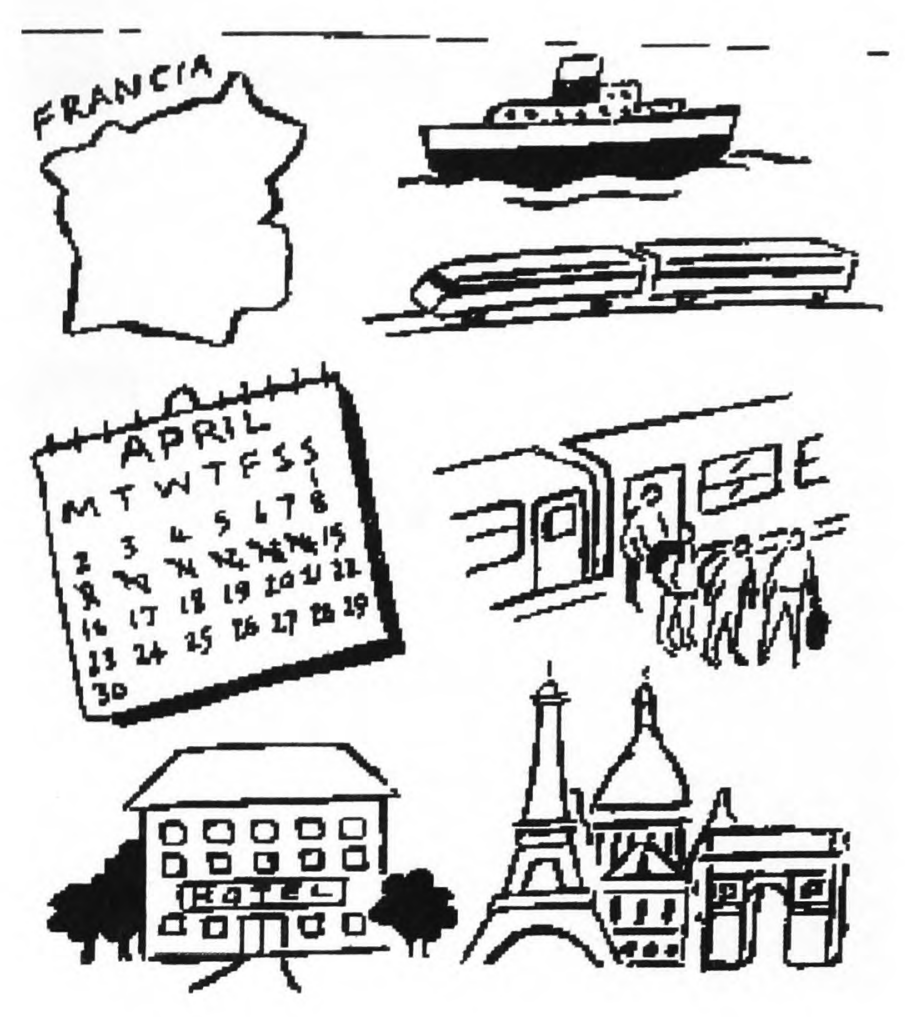

You have to answer your partner's questions with the help of the pictures.

5. Now, what will you really do next summer? Ask your partner and answer the same questions.

IO

IL TUO COMPAGNO

1.

2.

3 .

4.

5 .

6. 
4. Student A-B

You want to know what your partner will do next summer.

You need to use these verbs, prepare the questions first and then write the answer beside.

domande

1.Come passare le prossime vacanze? risposte

2.Come viaggiare?

3. Quanto restare a ......?

4.Dove abitare?

5.Cosa visitare a ......?

6.Quando ritornare a casa?

Now is your turn to answer your partner's questions about your holiday.

You have to answer your partner questions with the help of the pictures.

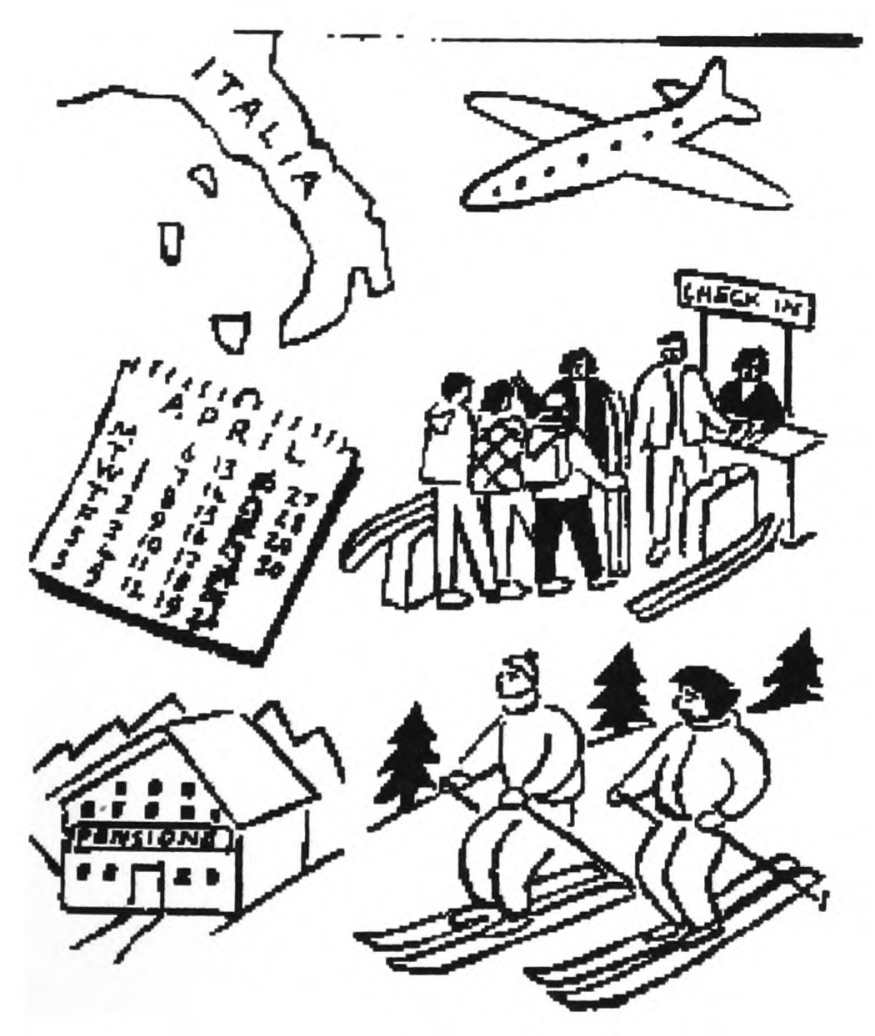


5. Now, what will you really do next summer? Ask your partner and answer the same questions.

IO

1.

2.

3.

4.

5.

6.

.

.

4.

5.

(

\section{IL TUO COMPAGNO}




\section{Activity 6 as a whole class activity}

6. Tre giornate differenti .

Form a sentence using the future tense.

\section{1) Cosa farai dopo la scuola?}

(aspettare) l'autobus, e (tornare) a casa nel primo pomeriggio

A casa (pranzare) con i miei genitori e poi (studiare) un po

Dopo cena, (uscire) con i miei amici e (prendere) una birra insieme a loro.

\section{2) Cosa faranno dopo la scuola?}

tornare)

a casa $\mathrm{e}$ (mangiare) qualcosa poi

(guardare) la televisione e (chiaccherare) un po.

$\mathrm{Nel}$ pomeriggio (mettere) a posto la casa e poi (prendere) un te.

\section{3) Cosa fara` Lucia?}

(restare) a casa (chiamare) la sua amica Giulia

Poi nel pomeriggio (dormire) un po e poi la sera

(cucinare) qualcosa per il suo amico Paolo. Paolo. (tornare) a casa alle otto e (mangiare-loro) insieme. 
Activity 7 is to be carried out as a whole class activity

7. Change the verbs in the future tense

1. Compro una macchina nuova

2. Lavoro alle otto di sera

3. Guarda la partita di calcio

4. Ascoltano il notiziario alla radio

5. Aspettiamo il tram delle due

6. Telefoni a Paolo

7. Parlate tutti il francese bene

8. Visiti il Museo d'arte moderna

9. Torno a casa alle tre

10 Cambio casa 


\section{Activity $8 \& 9$ is to be carried out as a whole class activity}

8. Complete the story (Enrico's future plans) using the future tense of the verbs.

La prossima estate (io) (passare) le mie vacanze in Italia con mio fartello. (restare) li per due settimane, (studiare) italiano.

Mio fratello (restare) solo per una settimana e (lavorare) in un bar per guadagnare un po di soldi.

Mio fratello (tornare) a casa, mentre io (visitare)

Roma, e .(tornare) a Londra alla fine del mese.

9.During the summer holyday you work for an Italian travel agency which organises trips to London. Tomorrow a trip to London by bus is scheduled.

Answer the following questions by using the programme.

1. A che ora partiranno domani mattina?

2. Che cosa visiteranno?

3. Dove pranzeranno?

4. Quanto resteranno St. Paul?

5. A che ora ritorneranno in albergo?

LONDRA-VISITA GUIDATA

VENERDI 15 LUGLIO

\section{Programma}

7.30-8.30 Colazione

9.00 Partenza in pulmann dall'albergo

10.00 Westminster Abbey(1 ora di sosta)

11.00 Buckingham Palace-cambio della guardia

12.00 Trafalgar Square

12.30 Pranzo-Covent Garden

2.00 La Cattedrale di St.Paul(30 minuti di sosta)

2.30 La Torre di Londra

4.00 Ritorno in albergo 


\section{RIFLETTIAMO}

The future tense in Italian as in English indicate an action which has not yet taken place. It is formed from the verb stem and by adding different endings for each person .

Activity 10 is to be carried out as a pair work activity .The students work in pairs and then they will report to the rest of the class what they have learned about their partner student

10. Conversazione in coppia..

Dove e Come passerai il prossimo fine settimana?

If you are not sure you can say 'forse' (maybe).

\section{Sample questions?}

a) Dove passerai il prossimo fine settimana?

b) Con chi lo passerai ?

c) Come lo passerai ?

a)

b)

c) a)

b)

c) 


\section{Activity 11 is to be carried out as whole class activity}

11. Write a sentence in the future describinge what $\operatorname{Paolo}(\mathrm{A})$ and his friends(B) will do today

A.

1. un $\backslash$ gelato $\backslash$ mangiare $\backslash$ limone $\backslash$ al

2. coca $\backslash$ prendereluna

3. comprarelcartolinalunalspedireldalla|Carla

B.

1. aperitivolprenderelbarlal

2. unlspaghettilal|ristorantelpiattolmangiare

3. unalcartolinalcomprare

4. Iscriverelela \Paololletteraluna 


\section{Activity 12 is to be carried out as a whole class activity}

12. You have to form some sentences by using one single word in each of the three groups. Use the future forms of the verbs

$\begin{array}{ll}\text { Gruppo 1 } & \text { Gruppo 2 } \\ \text { Io } & \text { morire } \\ \text { Io } & \text { incontrare } \\ \text { Elena } & \text { uscire } \\ \text { i miei amici } & \text { visitare } \\ \text { Tony Blair } & \text { studiare } \\ \text { i turisti } & \text { prendere } \\ \text { Mario e Francesca } & \text { partire } \\ \text { noi } & \text { cucinare } \\ \text { voi } & \text { aspettare } \\ \text { lui } & \text { guadagnare } \\ \text { lei } & \text { trovare }\end{array}$

Gruppo 3

il museo d'arte moderna

Bill Clinton

una pizza

un caffe

fra un ora

molto

alle 8

tutta la sera

molto vecchio

molti soldi

Francesca 


\section{Activity 13 is to be carried out as a whole class activity}

13. Complete with the forms of the verbs:

\section{1. passare}

Io l'estate a Londra e tu dove la ?

Mio padre il Natale in Italia.

Mia sorella e mio fratello, forse le ferie a Firenze.

e voi dove le ?

\section{2. prendere}

Cosa ................ Luigi per andare al lavoro? Se la metropolitana io. la macchina.

Paolo e Francesca l'autobus e noi la bicicletta.

\section{3. dormire}

Carlo e Franca tutta la mattina. Carlo, forse fino all' una.

Io fino alle dieci e tu fino a che ora $?$

Noi fino alle dieci.

\section{tornare}

4. L'anno prossimo che programma ha per le vacanze? Penso che in Inghilterra.

con me anche Paola. I miei genitori. in Egitto, mentre mio fratello a Parigi. E voi da Luisa? 


\section{Activity $14 \& 15$ is to be carried out as a pair activity}

\section{OROSCOPO}

14 Find the approppriate verb (one verb can be used more than one time) in the list to complete the 'horoscopes'. The verbs are provided in the infinitive form and you are asked to use the future when you complete the sentences
a) Acquario (tu)
b) Leone (lei)

Finalmente

una

Purtroppo molti soldi

persona interessante. Nel lavoro ma la persona giusta

molti soldi

c) Ariete (voi)

Cambiamenti su tutta la linea una nuova persona e molto amici d) Vergine (tu)

Che fortuna! un vecchio amico e. la

lotteria

\section{f) Scorpione (voi)}

Finalmente un viaggio!

soldi e tanti molto scontrosi gente nuova

e ................. la pace

\section{Lists of verbs}

incontrare-guadagnare-conoscere-perdere-diventare-ritrovare-vincere

Pretend you are a fortune teller. Work with your partner, found out his ther horoscope and predict ( 2 predictions) his her future

\section{Come sara`il mio oroscopo questa settimana?}

1.

2. 
15. Change the verbs into the future forms

Alessandro ha gia` organizzato la sua serata:

Stasera dopo il lavoro Alessandro (entrare) (1) in un bar,,(prendere) (2) una birra e un panino. (tornare)(3) a casa alle dieci e (guardare)(4) un po di televisione e (sentire)(5) un po di musica, poi (studiare)(6) per i suoi esami.

1.

2.

3 .

4

5

6.

Activity 16 is to be carried out as a pair work activity

\section{Conversation}

What will you do next weekend if .....?

Talk to your partners and ask what you will do in these two circunstances.

In each case you have to say at least two things you will do.

Cosa farai se il tempo sara' bello?

Forse....

e se il tempo sara' brutto?

Forse... 
Activity 17 is to be carried out as a whole class activity

17. Based yor description on the pictures and write what Paola will do next weekend (two sentences for each picture)

1.

3

5

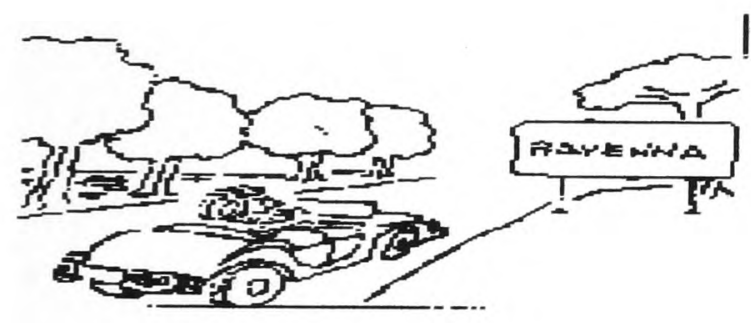

2

4.

6.

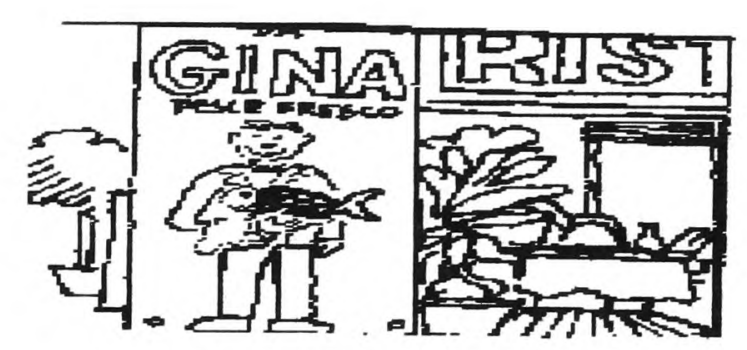

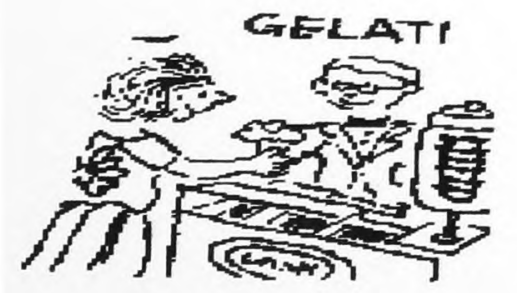
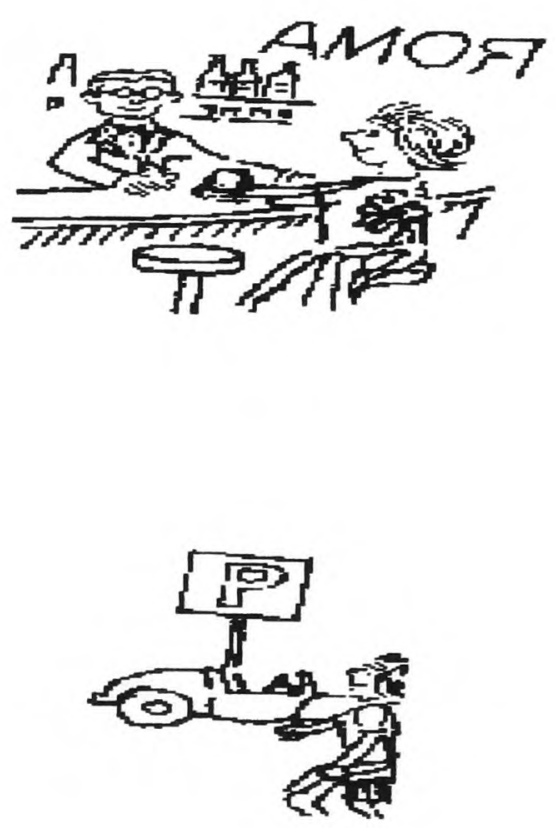
Activity 18 is to be carried out as a whole class activity

18. Complete the dialogue with the appropriate form of the following verbs

passare-restare-lavorare-tornare-festeggiare-pranzare-finire-telefonare-prendere

Giulio: Come .................il fine settimana?

Marco: a casa, e tu?

Giulio: $\quad \ldots \ldots \ldots \ldots \ldots \ldots$ a Londra dai miei genitori,....................... il mio compleanno in un ristorante italiano.

Marco: e Maria?

Giulio: Maria , tutto il giorno, ma se presto mi e una birra insieme. 
Activity 19 is to be carried out as a whole class activity

19. Change the future forms according to the subjects of the new sentence you have to produce.

Modello: Domani lavorerò tutto il giorno

(lui) (the new sentence will be: lavorera' tutto il giorno)

1.Domani Mario resterà a casa

(io)

2.La prossima settimana Tu e Mario lavorerete insieme (loro|Paolo)

3. Stasera guerderò la partita in televisione (Paolo)

4. Quando tornerai da Barcellona Parlerai bene lo spagnolo (loroltu)

5. Domani dormirò fino a mezzogiorno (voilnoi)

6. Sabato prenderà il treno per venire qui da noi (ioli miei genitori) 


\section{APPENDIX C}

\section{FORM FOR THE EXPERIMENT}

I agree to participate in this experiment and I understand that any results will not effect my final mark in Italian. All the information collected in this experiment will be kept confidential.

Name:

Signed:

Date: 


\section{APPENDIX D}

\section{PROFILE QUESTIONNAIRE}

1) Name:

3) Mother Tongue:

5) Sex:
2) Nationality:

4) Age:

6) Degree course:

7) Previous study or knowledge of Italian: yes no

if yes what kind?

Other foreign languages you know or you are studying:

French

German

Spanish

Greek

others(specify)

Do you have any qualification in a foreign language? If yes what mark di you get?

$\mathrm{O}$ level $\square \quad$ specify the mark you obtained

A level $\square \quad$ specify the mark you obtained

8) a)Do you use Italian in any way with someone outside yes no the classroom?

b) do you have any contact with native speakers outside the classroom

c) have you ever visited Italy

if yes for how long? 


\section{APPENDIX E}

PRE-TEST

NAME

List of nouns to familiarise with.

$$
\begin{aligned}
& \text { consultare }=\text { to look at } \\
& \text { mandare }=\text { to send } \\
& \text { salutare }=\text { to say hello } \\
& \text { regalo }=\text { present } \\
& \text { biblioteca }=\text { library } \\
& \text { ricevere }=\text { to receive }
\end{aligned}
$$




\section{Interpretation Task}

Indicate whether the speaker is relating information about the present of the future.

\begin{tabular}{|c|c|c|c|}
\hline 1. & present & could not tell & future \\
\hline 2. & present & could not tell & future \\
\hline 3. & present & could not tell & future \\
\hline 4. & present & could not tell & future \\
\hline 5. & present & could not tell & future \\
\hline 6. & present & could not tell & future \\
\hline 7. & present & could not tell & future \\
\hline 8. & present & could not tell & future \\
\hline 9. & present & could not tell & future \\
\hline 10. & present & could not tell & futur \\
\hline 11. & present & could not tell & future \\
\hline 12. & present & could not tell & future \\
\hline 13. & present & could not tell & future \\
\hline 14. & present & could not tell & future \\
\hline 15. & present & could not tell & future \\
\hline 16. & present & could not tell & future \\
\hline 17. & present & could not tell & future \\
\hline 18. & present & could not tell & future \\
\hline 19. & present & could not tell & future \\
\hline 20. & present & could not tell & future \\
\hline
\end{tabular}




\section{Written Production Task}

Complete the text with the future tense form of the verbs in brackets.

Finalmente, l'anno prossimo io (studiare) Italiano all'Università di

Roma durante le vacanze d'estate.

A Roma (apprendere) molte cose della cultura e

storia Italiana. I miei genitori (arrivare) due settimane

dopo per passare un pò di tempo con me.

La mia ragazza, invece, (restare) in Irlanda. Sono

sicuro che io (passare) delle vacanze di studio

bellissime. 
Oral production task

Vocabulary to familiarise with for the oral task

lavare

prendere

ballare

passeggiare

pulire

la macchina

un video

in disco

al parco

con Maria 


\section{Oral production task}

You have five minutes to look at the pictures in the five frames and produce one sentence containing the future for each of the pictures. Notice that the pictures are in chronological order and show Paolo's plan for next sunday.

\section{Tell what Paolo will do next sunday?}

\section{La mattina}

1

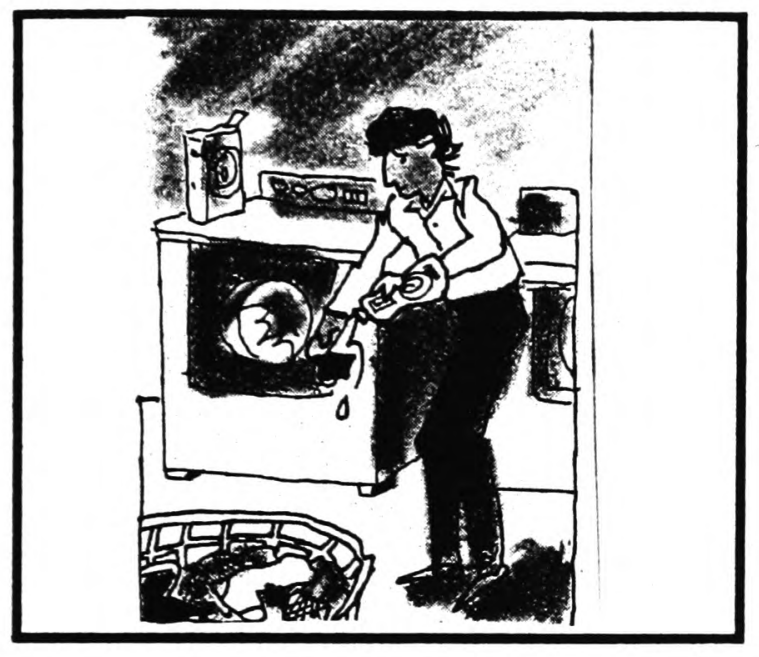

Il pomeriggio

3

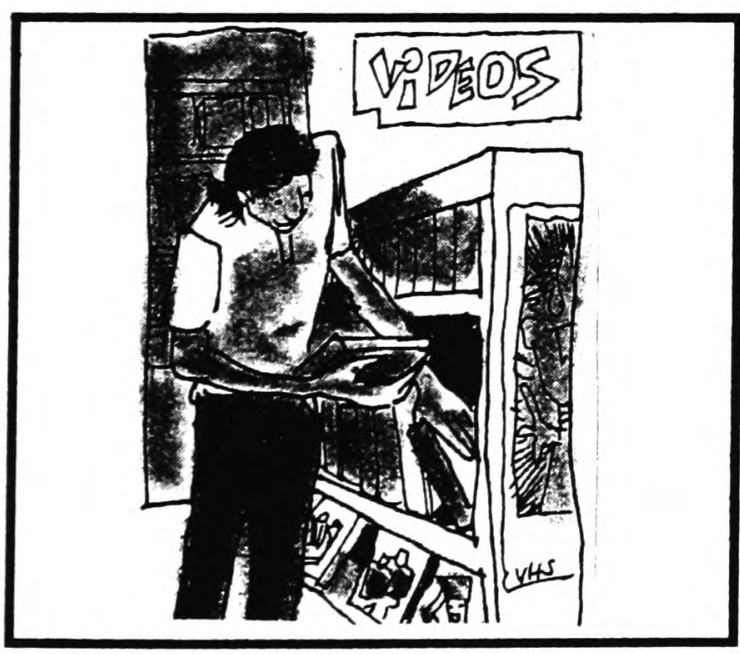

2

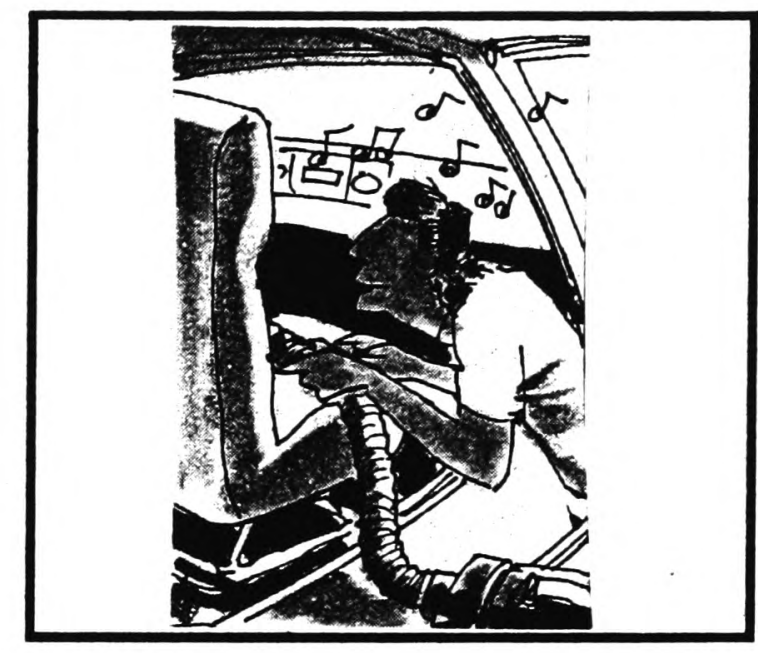

4

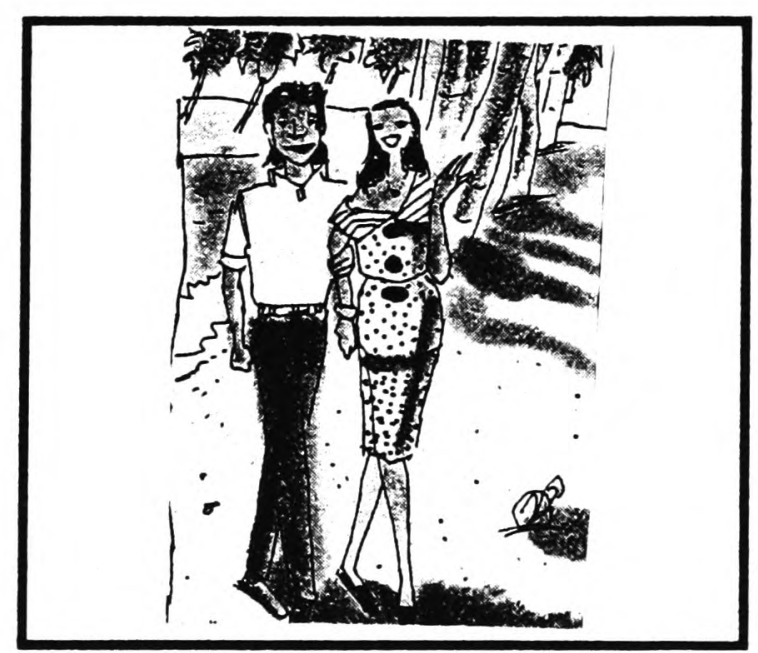

La sera

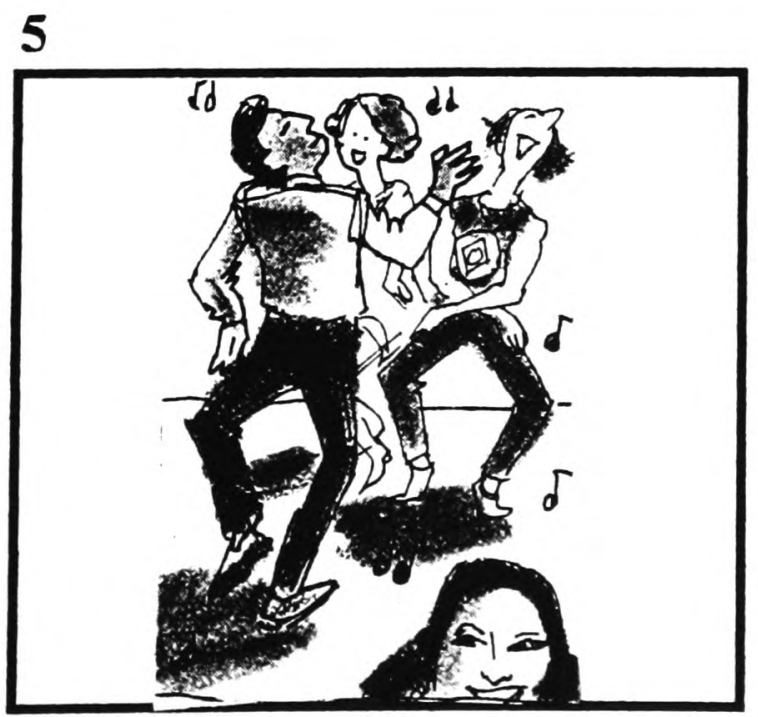




\section{PRE - TEST 1}

\section{INTERPRETATION TASK SENTENCES}

1. A casa torneranno insieme agli amici

2. Ad una amica comprano un regalo molto bello

3. A casa di un amico caro ascolti la radio

4. Prima di partire saluterò tutti gli amici

5. Ad una compagna di scuola presto i libri di Italiano

6. In una scuola privata di Roma studia italiano

7. Alla biblioteca dell'Università consulterai i libri

8. Al caffè dell'Universita`aspetta l'amico per andare al cinema

9 Con vari amici di scuola lavorerò in un bar.

10. A tutti gli amici dell'Università manderai una cartolina

11. Le vacanze d'estate costano molti soldi

12. A scuola studio la storia

13. Nel parco troverà una sua vecchia amica

14. In un ristorante cinese inviti una amica a cenare

15. Dalla famiglia riceveranno molti regali per il compleanno

16. In una festa cucinerò dei buonissimi spaghetti al pomodoro

17 In casa di un amico prenderà un caffè prima di tornare a casa.

18. Nel campo da tennis gioca con un amico

19. In vari paesi d' europa compro un souvenir da portare a casa

20. In compagnia di altri amici pranzerà in un ristorante francese 


\section{APPENDIX F \\ POST-TEST 1}

NAME

List of nouns to familiarise with.

$$
\begin{aligned}
& \text { centro storico }=\text { city centre } \\
& \text { amici del cuore }=\text { bosom friend } \\
& \text { anfiteatro }=\text { amphitheatre } \\
& \text { spiegazioni }=\text { explanations } \\
& \text { percorrere }=\text { to walk } \\
& \text { invitare }=\text { to invite } \\
& \text { prestare }=\text { to lend }
\end{aligned}
$$




\section{Interpretation Task}

Indicate whether the speaker is relating information about the present of the future

\begin{tabular}{|c|c|c|c|}
\hline 1. & present & could not tell & future \\
\hline 2. & present & could not tell & future \\
\hline 3. & present & could not tell & future \\
\hline 4. & present & could not tell & future \\
\hline 5. & present & could not tell & future \\
\hline 6. & present & could not tell & future \\
\hline 7. & present & could not tell & future \\
\hline 8. & present & could not tell & future \\
\hline 9. & present & could not tell & future \\
\hline 10. & present & could not tell & future \\
\hline 11. & present & could not tell & future \\
\hline 12. & present & could not tell & future \\
\hline 13. & present & could not tell & future \\
\hline 14. & present & could not tell & future \\
\hline 15. & present & could not tell & future \\
\hline 16. & present & could not tell & future \\
\hline 17. & present & could not tell & future \\
\hline 18. & present & could not tell & future \\
\hline 19. & present & could not tell & future \\
\hline 20 . & present & could not tell & future \\
\hline
\end{tabular}




\section{Written Production task}

Complete the text with the future tense form of the verbs in brackets.

L'anno prossimo (io) ( studiare) in una Universita americana

molto famosa. Anche Paola (partire) per l'America per fare un

Master a New York. Francesco e Giovanna, invece (restare)

in Italia per finire gli studi. La mia ragazza mi (raggiungere)

in America per passare le vacanze insieme. Io (passare)

un anno meraviglioso. 
Oral production task

Vocabulary to familiarise with for the oral task

correre

pulire

incontrare

pranzare

guardare

nel parco

la casa

Paolo

con Maria

sola 
Oral production task

You have five minutes to look at the pictures in the five frames and produce one sentence containing the future for each of the pictures. Notice that the pictures are in chronological order and show Francesca's plan for next sunday.

\section{Tell what Francesca will do next sunday?}

\section{La Mattina}

1

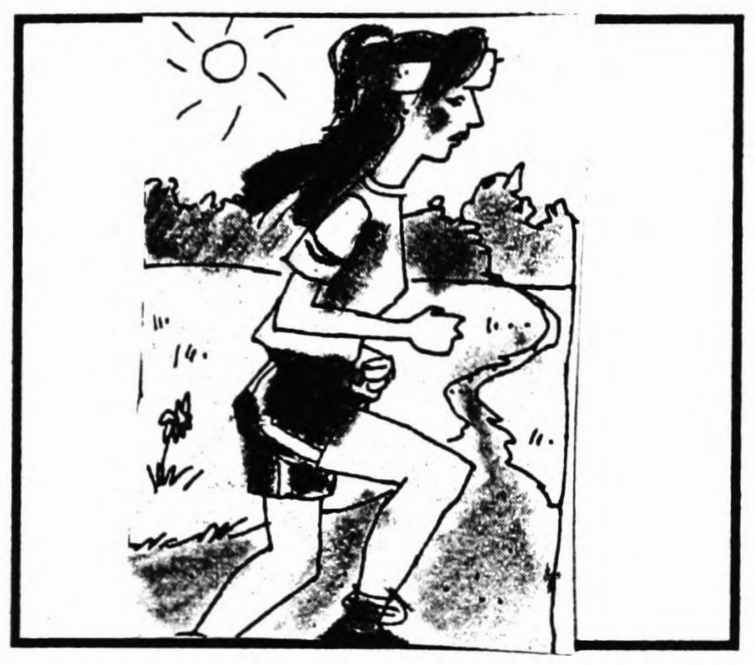

Il pomeriggio

3

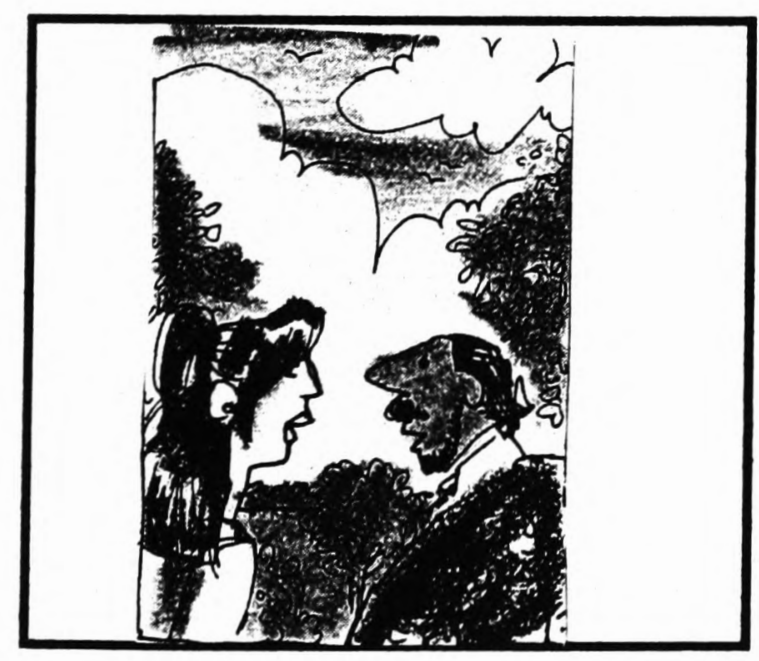

2

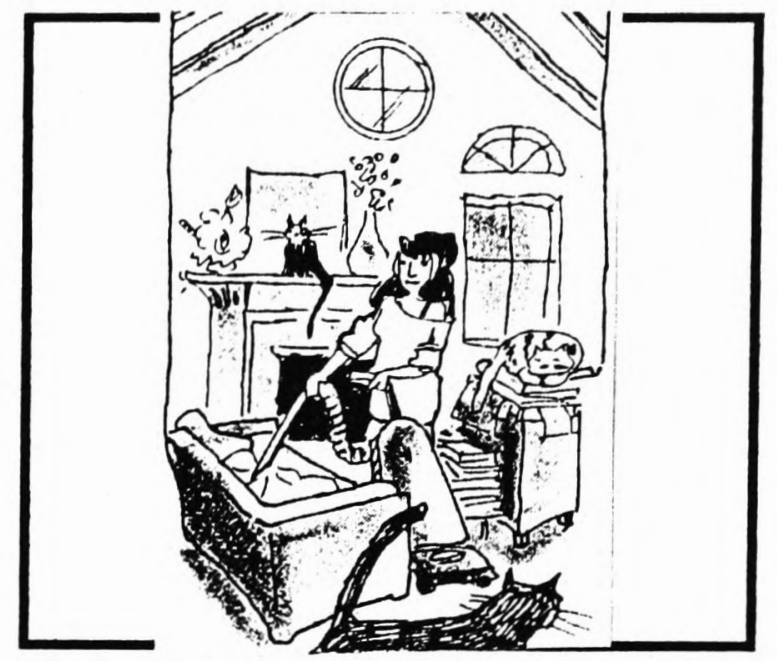

4

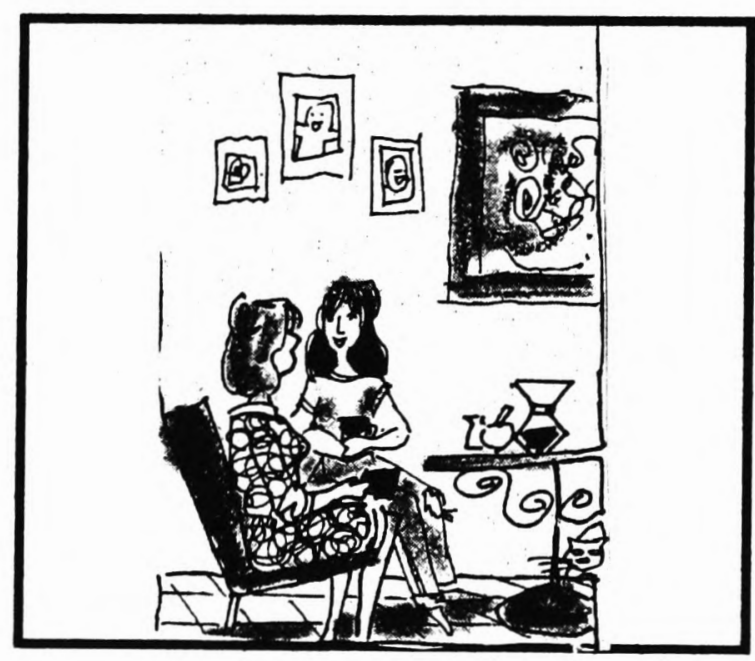

La sera

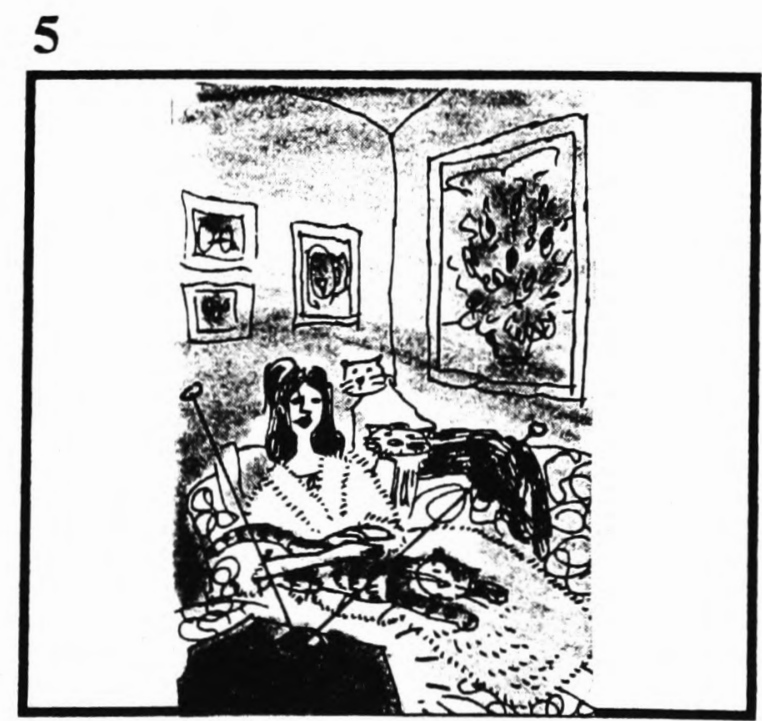




\section{POST-TEST 1 \\ INTERPRETATION TASK SENTENCES}

1. Alla festa di compleanno inviteranno molti amici

2. Per la cena di un amico cucinano della pasta

3. Ad una compagna presta tutti i libri di Italiano

4. In una scuola privata imparerai a parlare l'inglese molto bene.

5. Con alcuni compagni di scuola prenderò una birra al bar

6. A Roma trovo moltissime cose da fare

7. Nella classe di linguistica insegni molta teoria e poca pratica

8. Con un compagno di scuola visita l'anfiteatro romano

9. Per poter pagare gli studi lavoro come un pazzo

10. In un ristorante elegante inviteranno molte persone

11. Prima di andare in vacanza telefonerò a Gianni

12. A tutti gli amici del cuore manderà una cartolina

13. Con due amici di scuola segui un corso di Italiano all'Universita'

14. All' esame di Italiano risponderà a tutte le domande

15. Prima di andare a scuola salutano i loro genitori

16. Ad una cara amica scriverò una lettera

17. Con una compagna di classe percorro da scuola a casa

18. Nel periodo di vacanza da scuola continua a studiare

19. Alla insegnante di latino domanderà delle spiegazioni

20. Dopo gli esami preparerai tutta la roba per partire 


\section{APPENDIX G}

POST-TEST 2

NAME

List of nouns to familiarise with.

arte moderna $=$ modern art

insegnare $=$ to teach

intervallo $=$ break

partita di calcio $=$ football match

spedire $=$ to send

accompagnare $=$ to go and see somebody off 


\section{Interpretation Task}

Indicate whether the speaker is relating information about the present of the future.

present

could not tell

future

2.

present

could not tell

future

3.

present

could not tell

future

present

could not tell

future

6

8.

present

could not tell

future

6. present

could not tell

future

7. present

could not tell

future

9.

present

future

10.

present

could not tell

future

present

could not tell

future

12.

present

could not tell

future

13. present

could not tell

future

14. presen

could not tell

future

15. present

could not tell

future

16. present

could not tell

future

17. present

could not tell

future

18. present

could not tell

future

19. present

could not tell

future

20. present

could not tell

future 


\section{Written Production task}

Complete the text in the future tense form of the verb in parenthesis.

Il prossimo fine settimana Paolo (passare) un po di tempo con la sua famiglia in campagna.

La sua ragazza Francesca (visitare) i suoi genitori in montagna.

Invece, I suoi amici Franco e Giulia (restare) a casa tutto il giorno per guardare la partita.

Al contrario io (incontrare) la mia amica Giovanna e (prendere) una birra con lei al bar. 
Oral production task

Vocabulary to familiarise with for the oral task

prendere

ascoltare

guardare

dormire

pranzare

film

video

musica

con Paola 
Oral production task

You have five minutes to look at the pictures in the five frames and produce one sentence containing the future for each of the pictures. Notice that the pictures are in chronological order and show Francesco's plan for next sunday.

Tell what Francesco will do next sunday?

La mattina

1

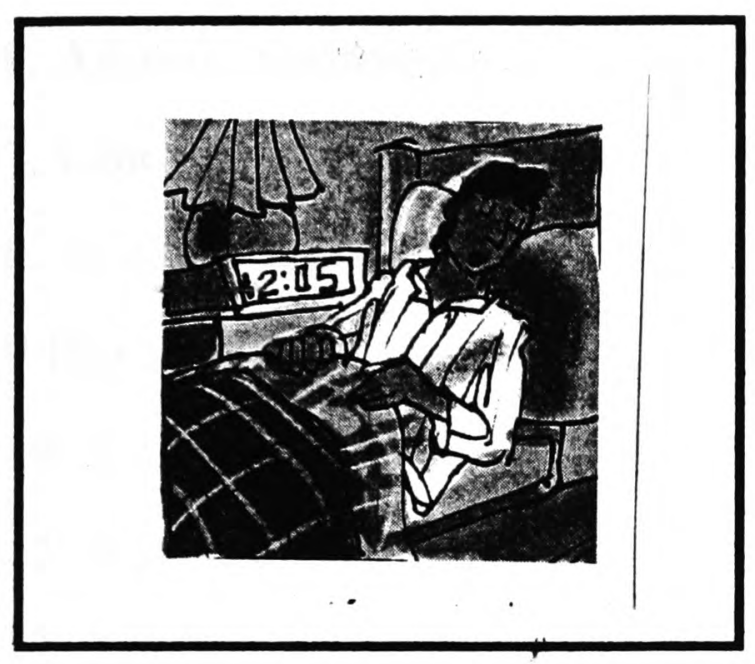

Il pomeriggio

3

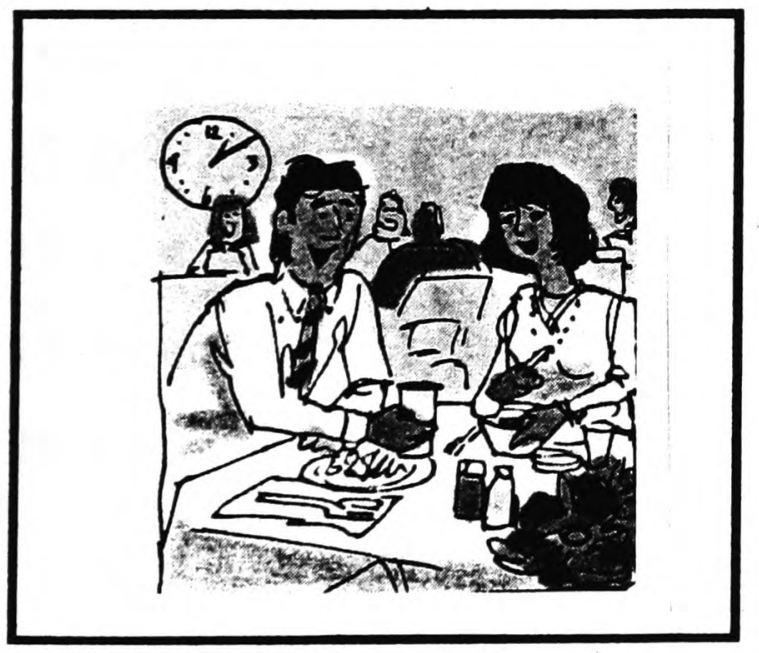

2

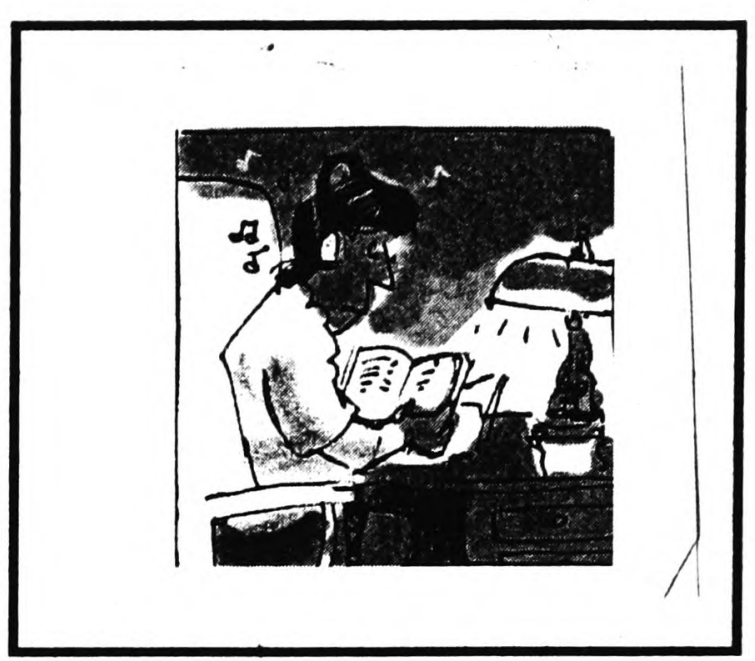

4

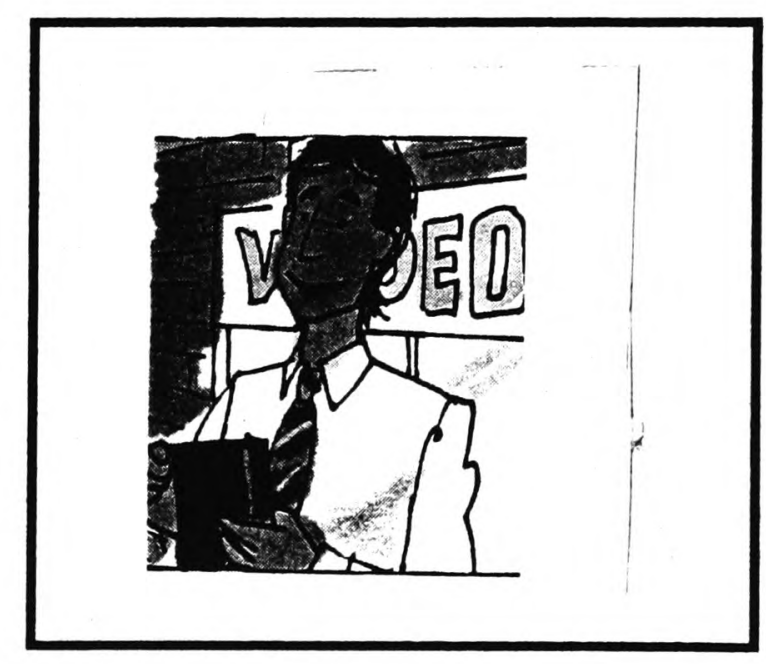

La sera

5

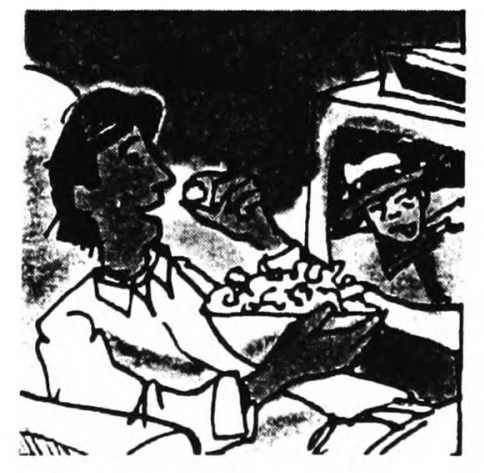




\section{POST-TEST 2}

\section{INTERPRETATION TASK SENTENCES}

1. Ad un amico inglese scriveranno una lettera

2. Come insegnante di Italiano lavoro in una scuola

3. In una libreria guarda un libro di storia

4. A Parigi visito il museo d'arte moderna

5. Nella classe di inglese insegni il futuro agli studenti.

6. Ad una compagna di classe presterai il libro di Italiano

7. Con molte amiche di scuola lavorano in un bar.

8. Al caffe dell'Università aspetteranno l' amica per andare a teatro

9 Durante l' intervallo ascolti la partita di calcio alla radio

10. A tutti gli amici di scuola spedirà una cartolina dalla Francia

11. A casa guardano tutto il giorno la televisione

12. Nel bar vicino a casa pranzerai con i compagni di lavoro

13. Davanti alla porta di casa saluta gli amici

14. Per il compleanno regalerò una biclicletta a Paola

15. In un ristorante francese invito una amica a cenare

16. Prima di partire comprerò un regalo a Paola

17 All 'Università studia l'Italiano per andare in Italia

18. Con un amico accompagnerà Paola a scuola

19. In una festa cucino della pasta molto buona

20. Con altri amici cena in un ristorante cinese di Londra 


\section{APPENDIX H}

\begin{tabular}{|l|l|l|}
\hline passare & finire & viaggiare \\
\hline abitare & cambiare & dormire \\
\hline partire & pranzare & chiaccherare \\
\hline visitare & prendere & guardare \\
\hline entrare & entrare & aspettare \\
\hline restare & cucinare & uscire \\
\hline studiare & vincere & chiamare \\
\hline lavorare & comprare & guadagnare \\
\hline aiutare & incontrare & morire \\
\hline smettere & scendere & diventare \\
\hline trovare & sentire & pranzare \\
\hline tornare & telefonare & \\
\hline arrivare & ospitare & \\
\hline scrivere & mettere & \\
\hline
\end{tabular}




\section{APPENDIX I \\ INDIVIDUAL RAW SCORES FOR TESTS}

int.pre wp.pre int.post wp.post int.post 2 wp.post 2 wp.q or.pre or.post or.post2

or.q

$\begin{array}{llllllllllll}\text { input } & 2 & 2 & 8 & 9 & 7 & 8 & 13 & 0 & 7 & 6 & 10 \\ \text { input } & 2 & 2 & 8 & 9 & 8 & 8 & 13 & 3 & 8 & 7 & 12 \\ \text { input } & 5 & 2 & 8 & 7 & 7 & 5 & 10 & 4 & 7 & 7 & 10 \\ \text { input } & 3 & 3 & 8 & 6 & 7 & 5 & 8 & 2 & 8 & 7 & 11 \\ \text { input } & 5 & 2 & 9 & 7 & 9 & 7 & 10 & 3 & 6 & 6 & 8 \\ \text { input } & 5 & 3 & 9 & 10 & 9 & 8 & 15 & 3 & 8 & 7 & 12 \\ \text { input } & 5 & 3 & 10 & 8 & 10 & 7 & 11 & 2 & 7 & 7 & 10 \\ \text { input } & 5 & 2 & 7 & 7 & 7 & 7 & 10 & 2 & 8 & 7 & 11 \\ \text { input } & 2 & 2 & 8 & 7 & 8 & 5 & 10 & 2 & 7 & 6 & 10 \\ \text { input } & 5 & 2 & 8 & 5 & 8 & 5 & 6 & 1 & 7 & 7 & 10 \\ \text { input } & 5 & 5 & 10 & 10 & 10 & 10 & 15 & 4 & 6 & 6 & 8 \\ \text { input } & 2 & 2 & 7 & 6 & 8 & 7 & 7 & 3 & 7 & 7 & 9 \\ \text { input } & 4 & 3 & 9 & 6 & 8 & 6 & 7 & 4 & 7 & 7 & 9 \\ \text { output } & 5 & 4 & 5 & 6 & 5 & 5 & 9 & 3 & 8 & 8 & 12 \\ \text { output } & 5 & 2 & 7 & 6 & 7 & 8 & 9 & 2 & 8 & 7 & 9 \\ \text { output } & 4 & 2 & 6 & 6 & 6 & 6 & 9 & 1 & 8 & 7 & 10 \\ \text { output } & 5 & 2 & 6 & 7 & 5 & 6 & 10 & 1 & 7 & 6 & 9 \\ \text { output } & 3 & 2 & 5 & 9 & 6 & 9 & 13 & 2 & 8 & 8 & 12 \\ \text { output } & 2 & 2 & 7 & 9 & 7 & 9 & 13 & 2 & 7 & 7 & 10 \\ \text { output } & 5 & 2 & 6 & 8 & 6 & 9 & 12 & 3 & 8 & 7 & 10 \\ \text { output } & 5 & 2 & 6 & 9 & 5 & 8 & 13 & 3 & 8 & 7 & 10 \\ \text { output } & 5 & 2 & 5 & 5 & 6 & 6 & 7 & 4 & 7 & 7 & 10 \\ \text { output } & 3 & 2 & 7 & 10 & 5 & 10 & 15 & 4 & 7 & 7 & 10 \\ \text { output } & 3 & 2 & 4 & 10 & 4 & 8 & 15 & 4 & 7 & 7 & 10 \\ \text { output } & 5 & 4 & 7 & 7 & 7 & 7 & 10 & 3 & 8 & 8 & 12 \\ \text { output } & 3 & 3 & 5 & 8 & 5 & 7 & 11 & 2 & 8 & 8 & 12 \\ \text { control } & 3 & 2 & 3 & 2 & 3 & 2 & 4 & 2 & 2 & 2 & 6 \\ \text { control } & 3 & 3 & 4 & 4 & 3 & 3 & 5 & 2 & 2 & 2 & 6 \\ \text { control } & 3 & 2 & 3 & 3 & 3 & 3 & 3 & 3 & 3 & 2 & 6 \\ \text { control } & 4 & 3 & 4 & 3 & 2 & 2 & 4 & 3 & 3 & 2 & 6 \\ \text { control } & 4 & 2 & 4 & 4 & 3 & 3 & 6 & 3 & 2 & 2 & 2 \\ \text { control } & 5 & 2 & 5 & 4 & 4 & 3 & 4 & 2 & 2 & 2 & 2 \\ \text { control } & 3 & 2 & 4 & 3 & 4 & 3 & 4 & 2 & 3 & 2 & 6 \\ \text { control } & 4 & 3 & 4 & 3 & 3 & 3 & 4 & 2 & 3 & 2 & 6 \\ \text { control } & 5 & 3 & 5 & 3 & 4 & 3 & 4 & 1 & 2 & 2 & 2 \\ \text { control } & 2 & 2 & 3 & 3 & 2 & 3 & 3 & 2 & 3 & 3 & 4 \\ \text { control } & 5 & 2 & 5 & 3 & 5 & 2 & 3 & 2 & 4 & 3 & 4 \\ \text { control } & 5 & 2 & 5 & 3 & 5 & 2 & 4 & 2 & 3 & 3 & 3 \\ \text { control } & 3 & 4 & 3 & 4 & 3 & 4 & 6 & 2 & 4 & 3 & 3\end{array}$



Abbreviations for the individual raw scores
int.pre $=$ interpretation task. pre-test
wp.pre $=$ written task. pre-test
int.post $=$ interpretation task. post-test
wp.post $=$ written task. post-test
int.post $2=$ interpretation task. post-test 2
wp.post $2=$ written task. post-test 2
wp.q $=$ written task. qualitative analysis
or.pre $=$ oral task. pre-test
or.post $=$ oral task. post-test
or.post $2=$ oral task. post-test 2
or.q $=$ oral task. qualitative analysis 